\title{
Impact of Diabetes Complications on Breast Cancer Screening, Diagnosis, and Prognosis among Elderly Women with Pre-existing Diabetes Using the SEER-Medicare Dataset
}

\author{
Ebtihag 0. Alenzi
}

Follow this and additional works at: https://researchrepository.wvu.edu/etd

\footnotetext{
Recommended Citation

Alenzi, Ebtihag O., "Impact of Diabetes Complications on Breast Cancer Screening, Diagnosis, and Prognosis among Elderly Women with Pre-existing Diabetes Using the SEER-Medicare Dataset" (2017). Graduate Theses, Dissertations, and Problem Reports. 5057.

https://researchrepository.wvu.edu/etd/5057

This Dissertation is protected by copyright and/or related rights. It has been brought to you by the The Research Repository @ WVU with permission from the rights-holder(s). You are free to use this Dissertation in any way that is permitted by the copyright and related rights legislation that applies to your use. For other uses you must obtain permission from the rights-holder(s) directly, unless additional rights are indicated by a Creative Commons license in the record and/ or on the work itself. This Dissertation has been accepted for inclusion in WVU Graduate Theses, Dissertations, and Problem Reports collection by an authorized administrator of The Research Repository @ WVU. For more information, please contact researchrepository@mail.wvu.edu.
} 


\title{
Impact of Diabetes Complications on Breast Cancer Screening, Diagnosis, and Prognosis among Elderly Women with Pre-existing Diabetes Using the SEER-Medicare Dataset
}

\author{
Ebtihag O. Alenzi \\ Dissertation submitted to the School of Pharmacy \\ at West Virginia University \\ in partial fulfillment of the requirements for the degree of \\ Doctor of Philosophy in \\ Health Services and Outcomes Research
}

\author{
S. Suresh Madhavan, MBA, PhD, FAPhA., Chair \\ Xi Tan, Pharm.D, Ph.D., Co- Chair \\ Usha Sambamoorthi, M.A., Ph.D. \\ Charles D. Ponte, BS, PharmD, FAADE, FAPhA, FASHP, FCCP, FNAP \\ Traci J. LeMasters, M.A., M.S., Ph.D.
}

Department of Pharmaceutical Systems and Policy

Morgantown, West Virginia

2017

Keywords: Breast Cancer; Diabetes; Elderly; Screening, Stage Mortality

Copyright 2017 Ebtihag O. Alenzi 


\title{
ABSTRACT \\ Impact of Diabetes Complications on Breast Cancer Screening, Diagnosis, and Prognosis among Elderly Women with Pre-existing Diabetes Using the SEER- Medicare Dataset
}

\author{
Ebtihag O. Alenzi
}

Diabetes has been linked to lower rates of breast cancer (BC) screening, late stage of BC at diagnosis, and high mortality of incident BC. Up to date, no study has investigated the influence of diabetes complications and their severity on this linkage. The aims of the study were to explore the association between severity of diabetes-related complications and persistence with screening mammography in elderly women with diabetes; to check the association of diabetes complications severity with stage of BC at diagnosis in elderly women with incident $\mathrm{BC}$ and preexisting diabetes; and to assess the effect of diabetes-related complications severity on all-cause mortality within 3 years of a BC diagnosis in elderly women with pre-existing diabetes. Aim 1 was conducted using the 5\% random sample of linked Surveillance, Epidemiology, and End Results (SEER)-Medicare data among 16,526 elderly women with diabetes who were free of cancer during the years 2002 to 2008. Aim 2 was conducted using SEER-Medicare data among 7,729 elderly women with incident BC and pre-existing diabetes during the years 2004-2011. Aim 3 was conducted among a cohort of women age $\geq 67$ years diagnosed with BC in 2007 to 2011 and pre-existing diabetes $(\mathrm{N}=4,307)$. Chi-square tests were used to examine the significant differences in characteristics of the study cohorts by persistence with screening mammogram, stage of BC at diagnosis, and three-year mortality, respectively. Multinomial logistic regressions were used to check the association of diabetes complications severity with persistence with screening mammography and stage of $\mathrm{BC}$ at diagnosis. Hazards ratios (HR) of all-cause mortality within 3 years of $\mathrm{BC}$ diagnosis was estimated using unadjusted and adjusted Cox proportional hazards models to compare time to death based on diabetes complications severity index (DCSI). Overall, having high severity of diabetes complications was significantly associated with a decrease in the likelihood of receiving breast cancer screening as compared to those without diabetes complications. Among elderly women with diabetes, those with a DCSI $\geq$ 5 were significantly less likely to use screening mammogram (either persistent use (odds ratio $(\mathrm{OR})=0.08 ; 95 \%$ confidence intervals $(\mathrm{CI})=0.07-0.10)$ or non- persistent use $(\mathrm{OR}=0.32 ; 95 \%$ $\mathrm{CI}=0.28-0.37)$ ), as compared to those without diabetes complications. Also, the severity of diabetes complications was no longer an independent predictor of BC stage II or advanced stage (III/IV) at diagnosis. However, women with DCSI $=2$ were significantly $26 \%$ more likely to be diagnosed at stage I (versus stage 0 ) of $\mathrm{BC}$ at diagnosis as compared to those without diabetes complications $(\mathrm{OR}=1.26 ; 95 \% \mathrm{CI}=1.03-1.53)$. In addition, severity of diabetes complication was significantly associated with all-cause mortality within three years of BC diagnosis. Women with a DCSI $=1$, DCSI $=2$, and DCSI $\geq 3$ had $34 \%$ (hazard $\operatorname{ratios}(\mathrm{HR})=1.34 ; 95 \% \mathrm{CI}=1.02$ $1.75), 69 \%(\mathrm{HR}=1.69 ; 95 \% \mathrm{CI}=1.39-2.05)$, and $124 \%(\mathrm{HR}=2.24 ; 95 \% \mathrm{CI}=1.86-2.70)$ increased risk of death within 3 years after $\mathrm{BC}$ diagnosis as compared to those without diabetes complications. The association between diabetes and worse $\mathrm{BC}$ outcomes could be predicted by severity of diabetes complications since this severity has negative consequences on screening mammography, diagnosis, and prognosis. 


\section{ACKNOWLEDGEMENTS}

I would like to start by thanking Allah for giving me the strength, and the patience to complete my dissertation finally, after all the challenges.

A special thanks to my beloved husband, Abdulkarim Alharbi, for the sacrifices and the immense support in every step of the way to strive towards my goal. I also would like to thank my two little angels, my daughter Rifan and my son Rayan for their unconditional love and for happiness they add to my life.

Second, I would like to express my sincere gratitude to my advisor, Dr. Suresh Madhavan for the continuous support of my Ph.D. study and related research, and for his insightful discussions about the research. His guidance helped me in all the time of research and writing of this thesis.

Besides my advisor, I would like to thank my co-advisor, Dr. Xi Tan for her valuable feedback, encouraging, guiding, and supporting my research ideas and me.

I am deeply appreciative to each of them for all their hard work with me and their important contributions.

My thanks also go to my other committee members: Dr. Usha Sambamoorthi, Dr. Charles D. Ponte, and Dr. Traci J. LeMasters for their critical inputs, brilliant comments and suggestions which incented me to widen my research from various perspectives

I would like to thank my family in Saudi Arabia: my mother, my brothers, and sisters for supporting me spiritually during my study abroad.

Finally, thanks to my scholarship sponsor, Ministry of Higher Education of Saudi Arabia, and people in Saudi Arabian Cultural Mission (SACM), who have given me the necessary financial support to pursue my PhD degree at West Virginia University.

Without all this support, it would not be possible to conduct this research. 


\section{CONTENTS}

\section{Page}

\section{CHAPTER ONE}

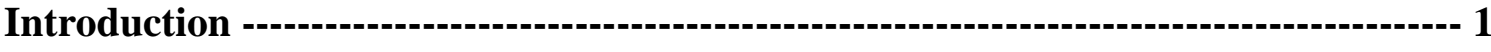

\section{CHAPTER TWO}

The Association between the Severity of Diabetes Complications and Persistence with Screening Mammography among Elderly Women with Pre-existing Diabetes Mellitus

\section{CHAPTER THREE}

Association between the Severity of Diabetes-related Complications and Stage of Breast Cancer at diagnosis among Elderly women with Pre-existing Diabetes Mellitus

\section{CHAPTER FOUR}

The Severity of Diabetes Complications in Relation to All-cause Mortality in Elderly Women with pre-exiting Diabetes and Incident Breast Cancer

\section{CHAPTER FIVE}

Discussion 
CHAPTER ONE

INTRODUCTION 


\section{INTRODUCTION}

Diabetes mellitus (DM) is a major public health issue that has grown worldwide in conjunction with aging of populations, urbanization, and unhealthy behaviors (Shikata, Ninomiya, \& Kiyohara, 2013). According to the American Diabetes Association (ADA), the annual incidence of diabetes in the US was 1.7 million in 2012 (Diabetes.org, 2015). It is associated with many complications and comorbidities that are responsible for impairing quality of life and increasing mortality in affected individuals (Zimmet, Alberti, \& Shaw, 2001). About one third of individuals with DM are elderly with ages $\geq 65$ year who are disproportionately at the highest risk of developing complications due to the potentially longer duration of disease and aging process (Corriere, Rooparinesingh, \& Kalyani, 2013).

A large body of literature suggests that individual with diabetes have a significantly higher risk of cancer than those without diabetes (Barone et al., 2008; Giovannucci et al., 2010; Lam et al., 2011; Liao et al., 2011; Lipscombe et al., 2008; Tudzarova \& Osman, 2015; Vigneri et al., 2009). One of the most common types of cancer is breast cancer (BC) with about 1.7 million new cases worldwide in 2012 and more than $50 \%$ of cases occurring in women aged $\geq 65$ years ( wcrf.org, 2015; Muss, 2010).

Many epidemiological studies have showed that women with DM have a significantly higher risk of incident breast cancer than women without diabetes (Boyle et al., 2012; Larsson, Mantzoros, \& Wolk, 2007; Liao et al., 2011). A meta-analysis by Boyle et al., showed that the risk of $\mathrm{BC}$ in women with type 2 diabetes has increased by $27 \%$, even after controlling for body mass index (BMI) (Boyle et al., 2012). Other studies demonstrated that the prevalence of preexisting DM among incident BC was from $16 \%$ to $20 \%$ (Bao et al., 2015; Tammemagi et al., 
2005), especially among postmenopausal women (Cleveland et al., 2012). A study by Cleveland et al., showed that postmenopausal women with DM are at higher risk of developing incident breast cancer than those without DM (Cleveland et al., 2012). Taken together, these studies reveal that DM is a well-established independent risk factor for breast cancer.

\section{Diabetes and BC Screening}

Since diabetes is associated with increased risk of BC, regular BC screenings for women with DM is essential. The American College of Obstetricians and Gynecologists (ACOG) guideline strongly recommends starting regular annual mammography screening for women at age 40 years (ACOG, 2016). The American Cancer Society (ACS) recommends starting annual mammogram screening at age 45 years, and women can switch to biennial mammogram screening at age 55 years (Oeffinger et al., 2015). However, the US Preventive Services Task Force (USPSTF) recommends biennial screening mammography for women aged 50-74 years (Table 1) ( USPSTF, 2016).

Studies have been shown that having regular BC screening decrease the likelihood of late stage diagnosis and mortality from incident BC (McCarthy et al., 2000; Vyas, Madhavan, \& Sambamoorthi, 2014). A previous study by McCarthy et al., found that elderly women who had regular screening mammography were diagnosed with an earlier stage of disease and had lower mortality rates as compared to non-users of screening mammography (McCarthy et al., 2000). Also, a recent study by Vyas et al. showed that women with persistent mammography screening were more likely to be diagnosed at earlier stages of $\mathrm{BC}$ as compared to non-persistent women or non-users (Vyas et al., 2014). 
Although regular screening mammography has been shown to reduce morbidity and mortality due to breast cancer, studies have shown lower rates of BC screening use among elderly women with DM as compared to those without DM (Beckman et al., 2001; Fleming, Love, \& Bennett, 2011; Lipscombe, Hux, \& Booth, 2005; Luo et al., 2015; McBean \& Yu, 2007). A study by Lipscombe et al. found that despite frequent primary health care visits, women with DM were significantly less likely to have a biennial mammogram than women without diabetes (Lipscombe et al., 2005). Another study among women with DM in Kentucky found that women with diabetes were half as likely to have regular screening mammography as compared to those without diabetes (Fleming et al., 2011). Lipscombe et al. indicated that the complexity of diabetes care could compete with the provision of women's preventive care services (Lipscombe et al., 2005). Further, a recent study showed that women who had diabetes for more than two years have lower rates of $\mathrm{BC}$ screening as compared to those without $\mathrm{DM}$ (Sanderson et al., 2014). This could explain the impact of diabetes duration on persistence with BC screening among women with DM. However, persistence with BC screening among women with DM could be affected by other diabetes-related factors, including diabetes severity and diabetes-related complications.

\section{Diabetes and BC Diagnosis}

In addition to lower rates of screening mammography use, the literature also indicated that women with pre-existing DM were more likely to be diagnosed with advanced stages of BC as compared to those without DM ( Lipscombe et al., 2015; Luo et al., 2015; van de Poll-Franse et al., 2007). One study by Luo et al., showed that women with DM were more likely to be diagnosed with advanced stage of BC as compared to those without DM (Luo et al., 2015). A study conducted among Canadian women with BC showed that women with diabetes were $21 \%$ 
and $16 \%$ more likely to be diagnosed with Stage III and Stage IV of BC, respectively, than Stage I. (Lipscombe et al., 2015). This associated was significant even after controlling for mammogram use ( Lipscombe et al., 2015).

\section{DM and BC Prognosis}

The above findings may suggest that women with diabetes are predisposed to developing more aggressive $\mathrm{BC}$, which may contribute to higher cancer mortality. Many studies have found that among women with BC, DM was associated with $40 \%$ higher mortality rate then women without DM (Lipscombe et al., 2008; Luo et al., 2015; Verlato et al., 2003). One study conducted among a cohort of women in United Kingdom found that women with BC and diabetes had a higher risk of all-cause mortality as compared to those without diabetes (Redaniel et al., 2012). Among Asian patients with early stage BC, DM was an independent predictor of lower BC survival and overall survival rates (Chen et al., 2012). Another prospective cohort study provided additional evidence that that pre-existing DM increases the risk of all-cause total mortality among women with $\mathrm{BC}$, but it was not associated with increased risk of breast cancer-specific mortality (Luo et al., 2014). Thus, a careful attention should be paid to pre-existing DM and its related factors that contribute to this risk among incident $\mathrm{BC}$.

\section{Shared Risk Factors in Diabetes \& BC}

In general, there are common factors that could lead to diabetes and BC. Women with DM are more likely to have factors related to delayed diagnosis and high mortality rates from incident BC (Luo et al., 2015). In fact, women with DM are more likely to be obese, older, and have more chronic comorbidities, compared to those without DM (Garg et al., 2014; Giovannucci et al., 2010; Vona-Davis \& Rose, 2012; Zanders et al., 2013). Other studies showed 
older women with diabetes had a greater risk of developing BC than younger women with DM (VanderWalde \& Hurria, 2012; Verhaeghe, 2009). However, there are other potential factors closely related to DM that may explain the late stage diagnosis and worse prognosis of incident BC among women with pre-existing DM.

\section{Potential Factors Contributing to the Association between Diabetes \& BC}

One main factor that may contribute to the association between DM and $\mathrm{BC}$ is dysregulation in insulin and steroid hormones. Hyperinsulinemia and steroid hormonal changes commonly occur in women with DM as part of its pathophysiological process and are considered to be potentially carcinogenic conditions for the breast (Salpeter et al., 2006). Insulin resistance, hyperinsulinemia, and chronic inflammatory factors in DM are strongly associated with BC (Handelsman et al., 2013; Sun \& Kashyap, 2011). These changes in DM could become worse during menopause, and thereby make a woman with $\mathrm{DM}$ at a higher risk of having $\mathrm{BC}$ after menopause (Ding et al., 2007; Golden et al., 2007; Key et al., 2002; Verhaeghe, 2009). During menopause, women with DM are exposed to a sudden hypersecretion of androgen and estrogen hormones, and the boost of these hormones secretion in women with DM promotes cancer cells growth (Ding et al., 2006; Ding et al., 2007; Golden et al., 2007). One study revealed that DM was associated with a 20-25\% increase in BC risk, mainly hormone-receptor-positive cancers (Larsson et al., 2007). In this type of hormone-receptor-positive cancer, cancer cells have receptors for estrogen or progesterone, so they are called either estrogen-receptor-positive (ER+) or progesterone-receptor-positive ( $\mathrm{PR}+)$. These hormones send signals to cancer cells to enhance their proliferation ( Breastcancer.org, 2015). Thus, these cancer-related mechanisms among elderly women with DM could synergistically act to promote BC development in advanced stages and to worsen the prognosis of incident BC (van de Poll-Franse et al., 2007). 
In addition to insulin resistance and dysregulation of steroid hormones, DM could worsen the outcomes of BC treatment. Therefore, physicians may need to modify $\mathrm{BC}$ treatment for women with DM. In a systematic review by Peairs et al., three studies demonstrated that patients with $\mathrm{BC}$ and diabetes received modified breast cancer treatment as compared to those without diabetes (Peairs et al., 2011; Srokowski et al., 2009; van de Poll-Franse et al., 2007; Yancik et al., 2001). Van de Poll-Franse et al, showed that patients with diabetes and breast cancer were more likely to receive surgery and/or hormonal therapy, but less likely to receive chemotherapy and/or radiotherapy as compared to women without diabetes (van de Poll-Franse et al., 2007). The study conducted by Srokowski et al found that women with BC and DM were less likely to receive anthracyclines and taxanes as compared to women without DM (Srokowski et al., 2009). This data begs the question "why". What were the author explanations for the differential treatment of women with DM and BC? This discrepancy needs to be further expanded for the reader.

Pre-existing diabetes is also contraindicated with some medications and therapies of BC, thus presenting certain challenges that make cancer treatment decisions difficult and complicated. Previous studies showed that pre-existing DM predisposes women with BC to a higher risk of a chemotherapy-related toxicity as compared to those without pre-existing DM (Peairs et al., 2011; Psarakis, 2006; Srokowski et al., 2009). Thus, women with BC and preexisting DM are usually less likely to receive chemotherapy as compared to those without DM. Two studies have shown that women with DM were less likely to receive chemotherapy during the six months that follow a $\mathrm{BC}$ diagnosis and had higher all-cause mortality than those without DM (Srokowski et al., 2009; van de Poll-Franse et al., 2007). Furthermore, women with diabetes 
who underwent cancer surgery were more likely to die in the month following their operations than those who have cancer but without diabetes ( hopkinsmedicine.org, 2016).

Therefore, all the above-mentioned factors could predict a worse prognosis of incident BC among women with pre-existing diabetes.

\section{The Role of Diabetes-related Complications Severity}

As was discussed above, there are many factors related to the association between diabetes and BC. However, studies have not adjusted for diabetes severity. We do not know whether the presence of diabetes (controlled) or the severity of diabetes (uncontrolled) and its complications contribute to lower screening, advanced stage at diagnosis, and poorer prognosis for breast cancer. Therefore, we need to examine the independent role of diabetes severity on BC screening, diagnosis and prognosis.

The main significant indicators of diabetes severity are diabetes-related complications (Hogan, Dall, \& Nikolov, 2003; Selby et al., 1997; Simon et al., 2005; Tomlin et al., 2006). The most frequent diabetes-related complications are cardiovascular diseases and atherosclerosis, and the main troublesome complications in the elderly are heart and kidney insufficiencies (Chentli et al., 2015). These complications could exacerbate chemotherapy-induced toxicity and worsen cancer symptoms (Psarakis, 2006; Malik et al., 2016; Morsy \& Heeba, 2016; Volkova \& Russell, 2011).

Further, research has indicated that diabetes complications are independent predictors of hospitalization and mortality among individuals with DM (Hogan et al., 2003; Selby et al., 1997; Simon et al., 2005; Tomlin, Dovey, \& Tilyard, 2008; Tomlin et al., 2006). Diabetes complications account for more than $35 \%$ of the health care utilizations for individuals with 
diabetes (Hogan et al., 2003). Thus, an indicator, the diabetes complications severity index (DCSI), was developed to capture the severity of illness and care requirements (Young et al., 2008; Rosenzweig et al., 2002). This indicator was first developed by Young and colleagues to include 7 categories of diabetes complications: cardiovascular disease, nephropathy, retinopathy, peripheral vascular disease, cerebrovascular, neuropathy, and metabolic complications (Young et al, 2008), and theses complications were identified using laboratory data and International Classification of Diseases, Ninth Edition, Clinical Modification (ICD-9-CM) diagnosis code to represent gradations of the diabetes complications severity (Young et al., 2008). The index for each complication was categorized into 2 or 3 levels (no abnormality $=0$, some abnormality $=1$, and severe abnormality $=2$ ), based on the presence and severity of the complication. The indices of all complications were added together to get the DCSI which is a 13-point scale with a range of 0-13. Using this scale, Wu et al found that compared to patients without complications (DCSI $=0$ ), those with more complications (higher DCSI score) had an increased risk of higher healthcare utilization (Wu et al., 2012).

\section{Need for the Study}

Since DM has a complex relationship with BC, many researchers have emphasized the need for well-designed studies to include a comprehensive list of potential factors that may contribute to this relationship (Bakhru, Buckanovich, \& Griggs, 2011; Vigneri et al., 2009).

Recent studies have confirmed the association between DM and BC (Boyle et al., 2012; Cleveland et al., 2012; Giovannucci et al., 2010; Lam et al., 2011; Larsson et al., 2007; Liao et al., 2011; Redaniel et al., 2012; Shikata et al., 2013; Sun \& Kashyap, 2011; Tudzarova \& Osman, 2015; Vigneri et al., 2009). Others studies have demonstrated the impact of DM on lower rates of 
screening mammography use (Beckman et al., 2001; Fleming et al., 2011; Lipscombe et al., 2005; McBean \& Yu, 2007; Sanderson et al., 2014), later stage diagnosis of BC ( Lipscombe et al., 2015), and BC mortality ( Bao et al., 2015; Barone et al., 2008; Chen et al., 2012; Cleveland et al., 2012; Lipscombe et al., 2008; Luo et al., 2015; Luo et al., 2014; Peairs et al., 2011; Redaniel et al., 2012; Srokowski et al., 2009; van de Poll-Franse et al., 2007; Verlato et al., 2003). While most of the previously conducted studies have confirmed the significant influence of DM on BC spectrum of care (prevention, diagnosis, and prognosis), no study yet has examined the independent role of diabetes-related complications on this association, controlling for other possible factors (e.g. other comorbidities, diabetes medications, access to care...etc.) that could confound this association.

Therefore, considering the prevalence of pre-existing DM with incident $\mathrm{BC}$ and the high burden of diabetes-related complications among elderly women, it is prudent to consider how the severity of diabetes complications impacts the BC screening, diagnosis and prognosis using DCSI. Using the linked Surveillance, Epidemiology and End-Results (SEER)-Medicare data which represents a large population of elderly in the US, we will determine the independent impact of diabetes-related complication(s) on BC spectrum of care among elderly women with DM in US.

Bearing these thoughts in mind, this study has three specific aims:

Aim 1: To investigate the association between the severity of diabetes complications and persistence with BC screening (mammogram) among elderly women with pre-existing DM.

Aim 2: To determine the association of the severity of diabetes complications with stage of BC at diagnosis among elderly women with pre-existing DM. 
Aim 3: To explore the impact of the severity of diabetes complications on all-cause mortality among elderly women with incident BC and pre-existing DM. 


\section{REFERENCES}

ACOG Statement on Breast Cancer Screening Guidelines - ACOG. (2016). Retrieved from http://www.acog.org/About-ACOG/News-Room/Statements/2016/ACOG-Statement-onBreast-Cancer-Screening-Guidelines

Bakhru, A., Buckanovich, R. J., \& Griggs, J. J. (2011). The impact of diabetes on survival in women with ovarian cancer. Gynecol Oncol, 121(1), 106-111.

doi:10.1016/j.ygyno.2010.12.329

Bao, P. P., Zhao, Z. G., Gao, Y. T., Zheng, Y., Zhang, B., Cai, H., . . Lu, W. (2015). Association of type 2 diabetes genetic variants with breast cancer survival among Chinese women. PLoS One, 10(2), e0117419. doi:10.1371/journal.pone.0117419

Barone, B. B., Yeh, H. C., Snyder, C. F., Peairs, K. S., Stein, K. B., Derr, R. L., . . Brancati, F. L. (2008). Long-term all-cause mortality in cancer patients with preexisting diabetes mellitus: a systematic review and meta-analysis. Jama, 300(23), 2754-2764. doi:10.1001/jama.2008.824

Beckman, T. J., Cuddihy, R. M., Scheitel, S. M., Naessens, J. M., Killian, J. M., \& Pankratz, V. S. (2001). Screening mammogram utilization in women with diabetes. Diabetes Care, 24(12), 2049-2053.

Boyle, P., Boniol, M., Koechlin, A., Robertson, C., Valentini, F., Coppens, K., . . Autier, P. (2012). Diabetes and breast cancer risk: a meta-analysis. Br J Cancer, 107(9), 1608-1617. doi:10.1038/bjc.2012.414

Calle, E. E., \& Kaaks, R. (2004). Overweight, obesity and cancer: epidemiological evidence and proposed mechanisms. Nat Rev Cancer, 4(8), 579-591. doi:10.1038/nrc1408

Chen, W. W., Shao, Y. Y., Shau, W. Y., Lin, Z. Z., Lu, Y. S., Chen, H. M., . . Lai, M. S. (2012). The impact of diabetes mellitus on prognosis of early breast cancer in Asia. Oncologist, 17(4), 485-491. doi:10.1634/theoncologist.2011-0412

Chentli, F., Azzoug, S., \& Mahgoun, S. (2015). Diabetes mellitus in elderly. Indian J Endocrinol Metab, 19(6), 744-752. doi:10.4103/2230-8210.167553

Cleveland, R. J., North, K. E., Stevens, J., Teitelbaum, S. L., Neugut, A. I., \& Gammon, M. D. (2012). The association of diabetes with breast cancer incidence and mortality in the Long Island Breast Cancer Study Project. Cancer Causes Control, 23(7), 1193-1203. doi:10.1007/s10552-012-9989-7

Corriere, M., Rooparinesingh, N., \& Kalyani, R. R. (2013). Epidemiology of diabetes and diabetes complications in the elderly: an emerging public health burden. Curr Diab Rep, 13(6), 805-813. doi:10.1007/s11892-013-0425-5 
Diabetes Raises Risk of Death In Cancer Surgery Patients - 03/29/2010. (2016). Retrieved from http://www.hopkinsmedicine.org/news/media/releases/diabetes_raises_risk_of_death_in cancer_surgery_patients

Ding, E. L., Song, Y., Malik, V. S., \& Liu, S. (2006). Sex differences of endogenous sex hormones and risk of type 2 diabetes: a systematic review and meta-analysis. Jama, 295(11), 1288-1299. doi:10.1001/jama.295.11.1288

Ding, E. L., Song, Y., Manson, J. E., Rifai, N., Buring, J. E., \& Liu, S. (2007). Plasma sex steroid hormones and risk of developing type 2 diabetes in women: a prospective study. Diabetologia, 50(10), 2076-2084. doi:10.1007/s00125-007-0785-y

Final Update Summary: Breast Cancer: Screening - US Preventive Services Task Force. (2016). Retrieved from http://www.uspreventiveservicestaskforce.org/Page/Document/UpdateSummaryFinal/bre ast-cancer-screening

Fleming, S. T., Love, M. M., \& Bennett, K. (2011). Diabetes and cancer screening rates among Appalachian and non-Appalachian residents of Kentucky. J Am Board Fam Med, 24(6), 682-692. doi:10.3122/jabfm.2011.06.110094

Folsom, A. R., Kaye, S. A., Prineas, R. J., Potter, J. D., Gapstur, S. M., \& Wallace, R. B. (1990). Increased incidence of carcinoma of the breast associated with abdominal adiposity in postmenopausal women. Am J Epidemiol, 131(5), 794-803.

Garg, S. K., Maurer, H., Reed, K., \& Selagamsetty, R. (2014). Diabetes and cancer: two diseases with obesity as a common risk factor. Diabetes Obes Metab, 16(2), 97-110. doi:10.1111/dom.12124

Giovannucci, E., Harlan, D. M., Archer, M. C., Bergenstal, R. M., Gapstur, S. M., Habel, L. A., . .. Yee, D. (2010). Diabetes and cancer: a consensus report. Diabetes Care, 33(7), 16741685. doi:10.2337/dc10-0666

Golden, S. H., Dobs, A. S., Vaidya, D., Szklo, M., Gapstur, S., Kopp, P., . . Ouyang, P. (2007). Endogenous sex hormones and glucose tolerance status in postmenopausal women. J Clin Endocrinol Metab, 92(4), 1289-1295. doi:10.1210/jc.2006-1895

Handelsman, Y., Leroith, D., Bloomgarden, Z. T., Dagogo-Jack, S., Einhorn, D., Garber, A. J., . . Hennekens, C. H. (2013). Diabetes and cancer--an AACE/ACE consensus statement. Endocr Pract, 19(4), 675-693. doi:10.4158/ep13248.cs

Hogan, P., Dall, T., \& Nikolov, P. (2003). Economic costs of diabetes in the US in 2002. Diabetes Care, 26(3), 917-932.

Hormone Receptor Status | Breastcancer.org. (2015). Retrieved from http://www.breastcancer.org/symptoms/diagnosis/hormone_status 
Key, T., Appleby, P., Barnes, I., \& Reeves, G. (2002). Endogenous sex hormones and breast cancer in postmenopausal women: reanalysis of nine prospective studies. $J$ Natl Cancer Inst, 94(8), 606-616.

Lam, E. K., Batty, G. D., Huxley, R. R., Martiniuk, A. L., Barzi, F., Lam, T. H., . . Woodward, M. (2011). Associations of diabetes mellitus with site-specific cancer mortality in the Asia-Pacific region. Ann Oncol, 22(3), 730-738. doi:10.1093/annonc/mdq405

Larsson, S. C., Mantzoros, C. S., \& Wolk, A. (2007). Diabetes mellitus and risk of breast cancer: a meta-analysis. Int J Cancer, 121(4), 856-862. doi:10.1002/ijc.22717

Liao, S., Li, J., Wei, W., Wang, L., Zhang, Y., Wang, C., \& Sun, S. (2011). Association between diabetes mellitus and breast cancer risk: a meta-analysis of the literature. Asian Pac J Cancer Prev, 12(4), 1061-1065.

Lipscombe, L., Fischer, H., Austin, P., Jaakkimainen, L., Ginsburg, O., Rochon, P., \& Narod, S. A. P., Lawrence. (2015). Women with diabetes more likely to be diagnosed with advanced stage breast cancer. Retrieved from http://www.eurekalert.org/pub_releases/2015-03/wch-wwd032415.php

Lipscombe, L. L., Fischer, H. D., Austin, P. C., Fu, L., Jaakkimainen, R. L., Ginsburg, O., . . Paszat, L. (2015). The association between diabetes and breast cancer stage at diagnosis: a population-based study. Breast Cancer Res Treat, 150(3), 613-620. doi:10.1007/s10549-015-3323-5

Lipscombe, L. L., Goodwin, P. J., Zinman, B., McLaughlin, J. R., \& Hux, J. E. (2008). The impact of diabetes on survival following breast cancer. Breast Cancer Res Treat, 109(2), 389-395. doi:10.1007/s10549-007-9654-0

Lipscombe, L. L., Hux, J. E., \& Booth, G. L. (2005). Reduced screening mammography among women with diabetes. Arch Intern Med, 165(18), 2090-2095.

doi:10.1001/archinte.165.18.2090

Luo, J., Hendryx, M., Virnig, B., Wen, S., Chlebowski, R., Chen, C., . . Margolis, K. L. (2015). Pre-existing diabetes and breast cancer prognosis among elderly women. $\mathrm{Br} J$ Cancer, 113(5), 827-832. doi:10.1038/bjc.2015.249

Luo, J., Virnig, B., Hendryx, M., Wen, S., Chelebowski, R., Chen, C., . . Margolis, K. (2014). Diabetes, diabetes treatment and breast cancer prognosis. Breast Cancer Res Treat, 148(1), 153-162. doi:10.1007/s10549-014-3146-9

Malik, S., Suchal, K., Bhatia, J., Gamad, N., Dinda, A. K., Gupta, Y. K., \& Arya, D. S. (2016). Molecular mechanisms underlying attenuation of cisplatin-induced acute kidney injury by epicatechin gallate. Lab Invest. doi:10.1038/labinvest.2016.60 
McBean, A. M., \& Yu, X. (2007). The underuse of screening services among elderly women with diabetes. Diabetes Care, 30(6), 1466-1472. doi:10.2337/dc06-2233

McCarthy, E. P., Burns, R. B., Freund, K. M., Ash, A. S., Shwartz, M., Marwill, S. L., \& Moskowitz, M. A. (2000). Mammography use, breast cancer stage at diagnosis, and survival among older women. J Am Geriatr Soc, 48(10), 1226-1233.

Morsy, M. A., \& Heeba, G. H. (2016). Nebivolol Ameliorates Cisplatin-Induced Nephrotoxicity in Rats. Basic Clin Pharmacol Toxicol, 118(6), 449-455. doi:10.1111/bcpt.12538

Muss, H. B. (2010). Coming of Age: Breast Cancer in Seniors. doi:10.1634/theoncologist.2010S5-57

Oeffinger, K. C., Memorial Sloan Kettering Cancer Center, N. Y., New York, Fontham, E. T. H., Louisiana State University School of Public Health, N. O., Etzioni, R., University of Washington and the Fred Hutchinson Cancer Research Center, S., . . American Cancer Society, A., Georgia. (2015). Breast Cancer Screening for Women at Average Risk: 2015 Guideline Update From the American Cancer Society. JAMA, 314(15), 1599-1614. doi:10.1001/jama.2015.12783

Peairs, K. S., Barone, B. B., Snyder, C. F., Yeh, H. C., Stein, K. B., Derr, R. L., . . Wolff, A. C. (2011). Diabetes mellitus and breast cancer outcomes: a systematic review and metaanalysis. J Clin Oncol, 29(1), 40-46. doi:10.1200/jco.2009.27.3011

Psarakis, H. M. (2006). Clinical Challenges in Caring for Patients With Diabetes and Cancer. doi:10.2337/diaspect.19.3.157

Redaniel, M. T., Jeffreys, M., May, M. T., Ben-Shlomo, Y., \& Martin, R. M. (2012). Associations of type 2 diabetes and diabetes treatment with breast cancer risk and mortality: a population-based cohort study among British women. Cancer Causes Control, 23(11), 1785-1795. doi:10.1007/s10552-012-0057-0

Rosenzweig, J. L., Weinger, K., Poirier-Solomon, L., \& Rushton, M. (2002). Use of a disease severity index for evaluation of healthcare costs and management of comorbidities of patients with diabetes mellitus. Am J Manag Care, 8(11), 950-958.

Salpeter, S. R., Walsh, J. M., Ormiston, T. M., Greyber, E., Buckley, N. S., \& Salpeter, E. E. (2006). Meta-analysis: effect of hormone-replacement therapy on components of the metabolic syndrome in postmenopausal women. Diabetes Obes Metab, 8(5), 538-554. doi:10.1111/j.1463-1326.2005.00545.x

Sanderson, M., Lipworth, L., Han, X., Beeghly-Fadiel, A., Shen-Miller, D., Patel, K., . . . Hargreaves, M. K. (2014). Mammography use among women with and without diabetes: results from the Southern Community Cohort Study. J Epidemiol Glob Health, 4(3), 223230. doi:10.1016/j.jegh.2014.03.001 
Selby, J. V., Karter, A. J., Ackerson, L. M., Ferrara, A., \& Liu, J. (2001). Developing a prediction rule from automated clinical databases to identify high-risk patients in a large population with diabetes. Diabetes Care, 24(9), 1547-1555.

Selby, J. V., Ray, G. T., Zhang, D., \& Colby, C. J. (1997). Excess costs of medical care for patients with diabetes in a managed care population. Diabetes Care, 20(9), 1396-1402.

Shikata, K., Ninomiya, T., \& Kiyohara, Y. (2013). Diabetes mellitus and cancer risk: review of the epidemiological evidence. Cancer Sci, 104(1), 9-14. doi:10.1111/cas.12043

Simon, G. E., Katon, W. J., Lin, E. H., Ludman, E., VonKorff, M., Ciechanowski, P., \& Young, B. A. (2005). Diabetes complications and depression as predictors of health service costs. Gen Hosp Psychiatry, 27(5), 344-351. doi:10.1016/j.genhosppsych.2005.04.008

Siu, A. L. (2016). Screening for Breast Cancer: U.S. Preventive Services Task Force Recommendation Statement. Annals of Internal Medicine doi:10.7326/M15-2886

Srokowski, T. P., Fang, S., Hortobagyi, G. N., \& Giordano, S. H. (2009). Impact of Diabetes Mellitus on Complications and Outcomes of Adjuvant Chemotherapy in Older Patients With Breast Cancer. J Clin Oncol, 27(13), 2170-2176. doi:10.1200/jco.2008.17.5935

Srokowski, T. P., Fang, S., Hortobagyi, G. N., \& Giordano, S. H. (2009). Impact of Diabetes Mellitus on Complications and Outcomes of Adjuvant Chemotherapy in Older Patients With Breast Cancer. doi:10.1200/JCO.2008.17.5935

Statistics About Diabetes. (2015). Retrieved from http://www.diabetes.org/diabetesbasics/statistics/

Sun, G., \& Kashyap, S. R. (2011). Cancer risk in type 2 diabetes mellitus: metabolic links and therapeutic considerations. J Nutr Metab, 2011, 708183. doi:10.1155/2011/708183

Tammemagi, C. M., Nerenz, D., Neslund-Dudas, C., Feldkamp, C., \& Nathanson, D. (2005). Comorbidity and survival disparities among black and white patients with breast cancer. Jama, 294(14), 1765-1772. doi:10.1001/jama.294.14.1765

Tomlin, A. M., Dovey, S. M., \& Tilyard, M. W. (2008). Risk factors for hospitalization due to diabetes complications. Diabetes Res Clin Pract, 80(2), 244-252. doi:10.1016/j.diabres.2007.12.017

Tomlin, A. M., Tilyard, M. W., Dovey, S. M., \& Dawson, A. G. (2006). Hospital admissions in diabetic and non-diabetic patients: a case-control study. Diabetes Res Clin Pract, 73(3), 260-267. doi:10.1016/j.diabres.2006.01.008

Tudzarova, S., \& Osman, M. A. (2015). The double trouble of metabolic diseases: the diabetescancer link. Mol Biol Cell, 26(18), 3129-3139. doi:10.1091/mbc.E14-11-1550 
van de Poll-Franse, L. V., Houterman, S., Janssen-Heijnen, M. L., Dercksen, M. W., Coebergh, J. W., \& Haak, H. R. (2007). Less aggressive treatment and worse overall survival in cancer patients with diabetes: a large population based analysis. Int J Cancer, 120(9), 1986-1992. doi:10.1002/ijc.22532

VanderWalde, A., \& Hurria, A. (2012). Early breast cancer in the older woman. Clin Geriatr Med, 28(1), 73-91. doi:10.1016/j.cger.2011.10.002

Verhaeghe, J. (2009). Menopause care for obese and diabetic women. Facts Views Vis Obgyn, $1(2), 142-152$.

Verlato, G., Zoppini, G., Bonora, E., \& Muggeo, M. (2003). Mortality from site-specific malignancies in type 2 diabetic patients from Verona. Diabetes Care, 26(4), 1047-1051.

Vigneri, P., Frasca, F., Sciacca, L., Pandini, G., \& Vigneri, R. (2009). Diabetes and cancer. doi:10.1677/ERC-09-0087

Vigneri, P., Frasca, F., Sciacca, L., Pandini, G., \& Vigneri, R. (2009). Diabetes and cancer. Endocr Relat Cancer, 16(4), 1103-1123. doi:10.1677/erc-09-0087

Volkova, M., \& Russell, R., 3rd. (2011). Anthracycline cardiotoxicity: prevalence, pathogenesis and treatment. Curr Cardiol Rev, 7(4), 214-220.

Vona-Davis, L., \& Rose, D. P. (2012). Type 2 diabetes and obesity metabolic interactions: common factors for breast cancer risk and novel approaches to prevention and therapy. Curr Diabetes Rev, 8(2), 116-130.

Vyas, A., Madhavan, S., \& Sambamoorthi, U. (2014). Association between persistence with mammography screening and stage at diagnosis among elderly women diagnosed with breast cancer. Breast Cancer Res Treat, 148(3), 645-654. doi:10.1007/s10549-014-32043

World Cancer Rsearch Fund International. (2015). Worldwide data. Retrieved from http://www.wcrf.org/int/cancer-facts-figures/worldwide-data

Wu, C. X., Tan, W. S., Toh, M. P., \& Heng, B. H. (2012). Stratifying healthcare costs using the Diabetes Complication Severity Index. J Diabetes Complications, 26(2), 107-112. doi:10.1016/j.jdiacomp.2012.02.004

Yancik, R., Wesley, M. N., Ries, L. A., Havlik, R. J., Edwards, B. K., \& Yates, J. W. (2001). Effect of age and comorbidity in postmenopausal breast cancer patients aged 55 years and older. Jama, 285(7), 885-892.

Young, B. A., Lin, E., Von Korff, M., Simon, G., Ciechanowski, P., Ludman, E. J., .. . Katon, W. J. (2008). Diabetes complications severity index and risk of mortality, hospitalization, and healthcare utilization. Am J Manag Care, 14(1), 15-23. 
Zanders, M. M., Boll, D., van Steenbergen, L. N., van de Poll-Franse, L. V., \& Haak, H. R. (2013). Effect of diabetes on endometrial cancer recurrence and survival. Maturitas, 74(1), 37-43. doi:10.1016/j.maturitas.2012.10.007

Zimmet, P., Alberti, K. G., \& Shaw, J. (2001). Global and societal implications of the diabetes epidemic. Nature, 414(6865), 782-787. doi:10.1038/414782a 
Table 1

The American Guidelines Recommendations for Breast Cancer Screening

\begin{tabular}{|lllll|}
\hline & Guideline & Age group & Frequency & References \\
\hline Mammogram & & & & \\
& ACS & $45-54$ & Annual & (Oeffinger et al., 2015) \\
& & 55 and older & Biennial & (Oeffinger et al., 2015) \\
& USPSTF & $50-74$ & Biennial & (Siu, 2016) \\
& ACOG & 40 and older & Annual & (ACOG, 2016) \\
& & & & \\
\hline
\end{tabular}

GYNE: gynecological. ACS: American Cancer Society. USPSTF: US Preventive Services Task Force. ACOG: American College of Obstetricians and Gynecologist 


\section{CHAPTER TWO}

The Association between the Severity of Diabetes Complications and

Persistence with Screening Mammography among Elderly Women with

Diabetes Mellitus 


\begin{abstract}
Objective: To determine whether there is an association between the severity of diabetes complications using the diabetes complications severity index (DCSI) and persistence with screening mammography among elderly women with diabetes Mellitus (DM) after controlling for all covariates that may mediate this association.
\end{abstract}

Methods: This was a retrospective study using a 5\% random sample of linked Surveillance, Epidemiology, and End Results (SEER)-Medicare data of 16,526 elderly women with DM who were free of cancer during the years 2002 to 2008. Chi-square tests were used to test for significant differences in characteristics among the three groups based on persistence with screening mammography. The expanded Andersen behavioral model was used to guide the selection of variables that could influence persistence with screening mammography. Multinomial logistic regressions were used to examine unadjusted and adjusted association between the severity of diabetes complications and persistence with screening mammography controlling for predisposing factors (race and age), enabling factors (annual visits to primary care providers), need factors (comorbid conditions), and external environmental factors (regions and metropolitan status).

Results: Overall, presence and severity of diabetes complications was significantly associated with screening mammography use (either persistent or non-persistent use). Among elderly women with DM, those with DCSI $=1$, DCSI=2, DCSI=3, DCSI $=4$, and DCSI $\geq 5$ were significantly $23 \%$ (odds ratio $(\mathrm{OR})=0.77 ; 95 \%$ confidence intervals $(\mathrm{CI})=0.68-0.89), 46 \%(\mathrm{OR}$ $=0.54 ; 95 \% \mathrm{CI}=0.48-0.61), 66 \%(\mathrm{OR}=0.34 ; 95 \% \mathrm{CI}=0.29-0.41), 79 \%(\mathrm{OR}=0.21 ; 95 \% \mathrm{CI}=$ $0.17-0.25)$, and $92 \%(\mathrm{OR}=0.08 ; 95 \% \mathrm{CI}=0.07-0.10)$ less likely to be persistent with screening 
mammography, respectively, as compared to those without diabetes complications after controlling for predisposing factors, enabling factors, need factors, health behaviors, and external environmental factors.

Conclusions: Using a nationally representative linked data of elderly women with DM, this study found that as the severity of diabetes complications increases, persistence with screening mammography decreases among elderly women with DM. Tailored diabetes educations programs and new strategies that target primary care physicians, caregivers, and patients are essential to raise awareness about the importance of breast cancer screening for elderly women with diabetes complications who are high-risk patients in term of poor persistence with BC screening.

Keywords: Diabetes complications; breast cancer screening; mammography; persistence; comorbidity 


\section{INTRODUCTION}

A growing body of literature suggests that diabetes mellitus (DM) is a well-established independent risk factor for breast cancer (BC) (Boyle et al., 2012; Cleveland et al., 2012;

Giovannucci et al., 2010; Lam et al., 2011; Larsson, Mantzoros, \& Wolk, 2007; Liao et al., 2011; Redaniel et al., 2012; Shikata, Ninomiya, \& Kiyohara, 2013; Sun \& Kashyap, 2011; Tabassum, Mahmood, \& Faheem, 2016; Tudzarova \& Osman, 2015; Vigneri et al., 2009). A meta-analysis by Boyle et al., showed that DM increased the risk of BC by $27 \%$ as compared to women without DM (Boyle et al., 2012). Another study by Cleveland et al., showed that women with $\mathrm{DM}$ are at a significantly higher risk (35\%) of developing incident $\mathrm{BC}$ as compared to those without DM (Cleveland et al., 2012). A recent study conducted in Pakistan showed that women with diabetes had about five times more odds of developing $\mathrm{BC}$ than those without diabetes (Tabassum et al., 2016).

Since diabetes is strongly associated with the risk of developing BC among women, persistence with BC screenings for women with DM is essential. The American College of Obstetricians and Gynecologists (ACOG) guideline strongly recommends starting regular annual mammography screening for women at age 40 years (ACOG, 2016). The American Cancer Society (ACS) recommends starting annual mammogram screening at age 45 years, and women can switch to biennial mammogram screening at age 55 years (Oeffinger et al., 2015). Thus, elderly women who aged $\geq 65$ years must have either annual or biennial mammogram screening to decrease the likelihood of having BC diagnosis and mortality from incident BC (McCarthy et al., 2000; Vyas, Madhavan, \& Sambamoorthi, 2014). A recent cohort study by Vyas et al. showed that elderly women with persistent screening mammography were more likely to be diagnosed at earlier stages of BC as compared to non-persistent women (Vyas et al., 2014). 
Although regular screening mammography is very important with many benefits, studies have shown a lower rates of screening mammography use among elderly women with DM as compared to those without DM (Beckman et al., 2001; Fleming, Love, \& Bennett, 2011; Lipscombe et al., 2015; Lipscombe, Hux, \& Booth, 2005; Luo et al., 2015; McBean \& Yu, 2007). Studies found that women with DM were significantly less likely to have screening mammography than women without diabetes although women with diabetes had more frequent primary health care visits as compared to those without diabetes (Lipscombe et al., 2005; Lipscombe et al., 2015 ). One study in Kentucky found that women with diabetes had a significantly 50\% lower odds of having regular mammography screening as compared to those without DM (Fleming et al., 2011).

These findings highlight the need for a better understanding of how diabetes reduces persistence with screening mammography among elderly women with diabetes who are at higher risk of developing BC. These studies have not adjusted for diabetes severity and diabetes-related complications as a confounder; however, this factor may have a significant influence on this association.

Few studies have examined the impact of diabetes-related complications on provision of preventive care (Conwell \& Boult, 2008; Timar et al., 2016), but the influence of diabetes-related complications on having preventive services is only partly understood and focusing only on specific type of complications (Conwell \& Boult, 2008; Timar et al., 2016).

To date, no study has addressed the impact of diabetes severity and diabetes-related complications on persistence with screening mammography among women with diabetes. Therefore, the primary aim of this study is to examine the association between the severity of 
diabetes complications and persistence with screening mammography among elderly women with diabetes by comparing them to women who have diabetes with no complications.

\section{Conceptual Framework}

The association between the severity of diabetes complications and persistence with screening mammography is the focus of this study. However, there are other covariates that could affect this association. Thus, we used the expanded Andersen behavioral model to guide the selection of other independent variables that may affect persistence with BC screening (Andersen, 1995). This model suggests that healthcare services utilization, such as breast cancer screening use depends upon predisposing factors, enabling factors, need factors, and the external environment factors (Figure 1). Predisposing factors include individual factors such as demographic characteristics (e.g. age) biological imperative (e.g. sex), or social factors (ethnicity) (Andersen, 2001). Enabling factors are conditions enabling services utilization or factors entail whether an individual has a regular source of care. Need factors include assessment and measurement of patients' health status and need for medical care (e.g. comorbid conditions). External environmental factors include metropolitan status and regions.

\section{RESEARCH DESIGN AND METHODS}

\section{Study Design}

This study was a retrospective cohort study among elderly women with DM. The baseline years in which the individuals were first identified with DM were 2002-2008. In each year, there was 12-months enrollment period, and then each case was followed up to 60 months to assess the impact of diabetes complications severity on persistence with screening mammography (Figure 2). 


\section{Data Source}

We used a 5\% random sample data of Surveillance Epidemiology and End Results (SEER)-non-cancer linked with Medicare files and generated in a file called the Summarized Denominator (SUMDENOM) file (SEER-Medicare, 2016). This database consists of Medicare beneficiaries who are free of cancer living in SEER areas (Atlanta, Connecticut, Detroit, Hawaii, Iowa, New Mexico, San Francisco-Oakland, Seattle-Puget Sound, Utah, Los Angeles and San Jose-Monterey, Rural Georgia, Alaska Native, Greater California, Kentucky, Louisiana, New Jersey, and Greater Georgia)( SEER, 2016; Hellman, 1997). The linked Medicare file provides claims of hospitalizations recorded for part A enrollees in Medicare Provider Analysis and Review (MEDPAR) file, and claims of care delivered in hospital outpatient departments and physician's offices for part B enrollees in an outpatient (OUTPT) file and National Claims History (NCH) file. Also, Medicare files contain the Home Health Agency (HHA) file of all claims for home health services (SEER-Medicare, 2016).

This database has been used to study factors and behaviors related to multiple types of cancer screening among Medicare population who are free of cancer (Kagay, Quale, \& SmithBindman, 2006; McBean \& Yu, 2007; White, Vernon et al., 2011). Variables are created based on enrollment records in SUMDENOM file and medical claims using International Classification of Diseases, Ninth Edition, Clinical Modification (ICD-9-CM) diagnosis and procedure codes, Current Procedural Terminology (CPT) codes, and Healthcare Common Procedure Coding System (HCPCS) codes.

\section{Study Cohorts}


Our cohort consisted of elderly women aged 65 years or older with DM in the 5\% random sample of non-cancer cases in the SEER-Medicare during the years 2002 to 2008. Other inclusion criteria were at least 6-years continuous enrollment in Medicare part A and B, no enrollment in a health maintenance organization (HMO) at any time during the study period, without any type of cancer, without end stage renal disease (ESRD), and alive during the study period. Diabetes was determined on the basis of either a single inpatient claim or at least two outpatient claim diagnoses with ICD-9-CM diagnosis code of 250.xx (Luo et al., 2014) during the 12-month period of continuous enrollment of the baseline period.

\section{Measures}

\section{Outcome variable}

The key outcome variable was persistence with screening mammography during the follow-up five years. We identified the screening mammography using HCPCS codes (76085, 76092, 77052, 77057, 77063, G0202, and G0203), and ICD-9-CM diagnosis code V7612 which are assigned for only screening mammography (McBean \& Yu, 2007). For each year during the follow-up period, each woman who had $\geq 1$ mammogram screening were considered to have a one screening mammogram during that year. Thereafter, the total number of annual screening mammograms was calculated for each case during the follow-up period (5 years) with a maxim number equals to 5 and minimum number equals to 0 . Based on the number of annual screening mammograms a woman had during the follow-up five years, the study cohort was categorized into non-users (no screening mammograms), non-persistent users (with 1-2 screening mammograms), and persistent users (with three or more screening mammograms) (Vyas et al., 2014).

\section{Key independent variable}


The main independent variable was diabetes complications severity that was identified before the first observed mammogram screening. For those who do not have any mammogram screening during the 60 -months follow-up period, we picked a random year to capture the diabetes severity. Diabetes complications severity was measured by end-organ damage and diabetes-related complications using the diabetic comorbidity severity index (DCSI). The DCSI was first developed by Young and colleagues to include 7 categories of diabetes complications: cardiovascular disease, nephropathy, retinopathy, peripheral vascular disease, cerebrovascular, neuropathy, and metabolic complications (Young et al., 2008). Theses complications were identified using International Classification of Diseases, Ninth Edition, Clinical Modification (ICD-9-CM) diagnosis code to represent gradations of the diabetes complications severity (Young et al., 2008). The index for each complication was categorized into 2 or 3 levels (no abnormality $=0$, some abnormality $=1$, and severe abnormality $=2$ ), based on the presence and severity of the complication, and then the indices of all complications were added together to get the DCSI which is a 13-point scale with a range of 0-13 (Chang et al., 2012a; Young et al., 2008). The study cohort was divided into 6 subgroups consisting of DCSI=0 (no complications), $\mathrm{DCSI}=1, \mathrm{DCSI}=2, \mathrm{DCSI}=3, \mathrm{DCSI}=4$, and DCSI $\geq 5$ indication increasing number of diabetes complications and/or severity.

\section{Covariates}

The covariates were selected based on the expanded Andersen behavioral model (Andersen, 1995). Predisposing factors were identified in the baseline year, and these factors include race and age. Race was categorized into white, African-American, and others. Age was categorized into $65-70,71-74,75-79$, and 80 years or older. Number of annual visits to primary care providers (PCPs) during the study period (6years) including the baseline year were classified 
as an enabling factor. These visits were identified from Medicare claims using physician claims in $\mathrm{NCH}$ files for the services representing routine office visits. Like previous research (Baldwin et al., 2002; Fisher et al., 2013; Yu, McBean, \& Virnig, 2007), we defined PCPs as providers who had the following specialties: general practice, family medicine, primary care internal medicine, geriatric medicine, and obstetrics and gynecology. For each case, there must be at least one visit to PCPs during a year to be counted as one annual visit toward the whole number of annual visits to PCPs during the study period. Based the on the above definition, the variable was categorized into 3 groups: 0 to 3 visits, 4 to 5 visits, and 6 visits. Need factor was defined as the presence or absence of the following chronic conditions: arthritis, asthma, chronic obstructive pulmonary disease (COPD), dementia, hyperlipidemia, hypertension, thyroid syndrome, osteoporosis, anxiety, and depression. All the chronic conditions were identified in the year that preceded the first observed mammogram screening. For those who did not have any mammogram screening during the 60-months follow-up period, we picked a random year to capture the chronic conditions. External environment factors consisted of SEER regions (Northeast, South, North Central, and West), and metropolitan status (metro, urban, and rural) of the individuals.

\section{Statistical Analyses}

Descriptive statistics were reported using frequencies and percentages since all the variables were categorical. Chi-square tests were used to test for significant differences in characteristics among the three groups based on use of screening mammography: non-users, nonpersistent, and the persistent. Statistical significance was defined as a p-value $\leq 0.05$. The adjusted associations between persistence with screening mammogram and diabetes complications severity were examined in a series of three multinomial logistic regressions models. 
Model 1 included only the severity of diabetes complications measured by DCSI; model 2 additionally included enabling factor (the number of annual visits to PCPs); and model 3 included predisposing factors (race and age), enabling factor (the number of annual visits to PCPs), need factors (comorbid conditions), and the external environment characteristics (SEER regions and metropolitan status). In all models, "non-users", who had no screening mammography during the follow-up period, were used as the reference group for the outcome. The parameter estimates were transformed to odds ratios and their corresponding $95 \%$ confidence intervals (CI). All analyses were conducted using statistical analysis systems software SAS 9.4 (SAS® version 9.4, SAS Institute Inc., Cary, NC, USA).

\section{RESULTS}

\section{Cohort Characteristics}

Of 60,756 women who were identified with DM in our 5\% non-cancer random sample of Medicare data, 16,526 were eligible for our study based on the study inclusion and exclusion criteria (Figure 3). Table 1 presents the characteristics of the study cohort. The majority of women were white $(73.5 \%)$, living in metro areas $(79.7 \%)$, and had at least one PCP visit per year during the study period (6 years). The most common comorbid conditions among women with DM in our study cohort were hypertension (84.6\%), hyperlipidemia (65.8\%), arthritis (36.6\%), thyroid syndrome (29.9\%), osteoporosis (17.1\%), COPD (14.4\%), dementia (11.6\%), and asthma (11.5\%). About $42.5 \%$ of the women with DM did not receive any mammography screening during the follow-up five years, $28.1 \%$ were non-persistent and only had one or two mammography screenings, and $29.5 \%$ were persistent with 3 or more mammography screening during the follow-up period. About $42.5 \%$ of the women in our study had no diabetes complications and $12.7 \%$ had DCSI $\geq 5$. The minimum DCSI was 0 while the maximum DCSI 
was 11 . The most frequent diabetes-related complications were cardiovascular complications (48.9\%), cerebrovascular complications (18.5\%), neuropathy (17.6\%), nephropathy (17.5\%), peripheral vascular disease $(12.6 \%)$, while metabolic complications $(0.6 \%)$ and retinopathy (7.4\%) were less frequent among elderly women with DM (non-tabulated).

\section{Group Differences by Persistence with BC Screening}

Table 2 shows the bivariate associations between persistence with screening mammogram and other characteristics of the study cohort. The variables that were significantly associated with persistence with screening mammogram include DCSI, age groups, race, number of annual visits to PCPs, SEER regions, and metropolitan status. The comorbid conditions that were significantly associated with persistence with BC were arthritis, asthma, COPD, dementia, hyperlipidemia, hypertension, thyroid syndrome, osteoporosis, and depression.

Among those who did not have any BC screening during the 60 months, the percentage of women with a high severity of diabetes complications (DCSI $\geq 5)$ was higher (21.8\%) as compared to non-persistent (9.5\%) and persistent (2.8\%) groups. Also, those who were non-users of BC screening were more likely to have older ages as compared to non-persistent and persistent groups. Women who did not have any screening mammogram during the follow-up 60 months were less likely to have annual PCP visits during the study period (75.7\%) as compared to persistent group (85.5\%). Also, they were more likely to have arthritis, asthma, dementia, and COPD, and they were less likely to have hyperlipidemia and hypertension.

\section{Associations with Persistence with BC Screening}

Table 3 depicts the unadjusted and adjusted associations between persistence with screening mammography and the severity of diabetes complications. Generally, the severity of 
diabetes complications was significantly associated with less likelihood of BC screening use (either persistent or non-persistent use). In the unadjusted association, women with DCSI =1, $\mathrm{DCSI}=2, \mathrm{DCSI}=3, \mathrm{DCSI}=4$, and DCSI $\geq 5$ were $14 \%(\mathrm{OR}=0.86 ; 95 \% \mathrm{CI}=0.76-0.97), 45 \%$ $(\mathrm{OR}=0.55 ; 95 \% \mathrm{CI}=0.50-0.62), 66 \%(\mathrm{OR}=0.34 ; 95 \% \mathrm{CI}=0.29-0.40), 81 \%(\mathrm{OR}=19 ; 95 \%$ $\mathrm{CI}=0.16-0.22)$, and $93 \%(\mathrm{OR}=0.07 ; 95 \% \mathrm{CI}=0.06-0.09)$ less likely to be persistent with screening mammogram as compared to those without diabetes complications.

This strong association remained significant in model 2 even after controlling for annual visits to PCPs during the 60 months. In model 3, after controlling for predisposing factors, enabling factors, need factors, health behaviors, and external environmental factors, women with $\mathrm{DCSI}=1, \mathrm{DCSI}=2, \mathrm{DCSI}=3, \mathrm{DCSI}=4$, and DCSI $\geq 5$ were $23 \%(\mathrm{OR}=0.77 ; 95 \% \mathrm{CI}=0.68$ $0.89), 46 \%(\mathrm{OR}=0.54 ; 95 \% \mathrm{CI}=0.48-0.61), 66 \%(\mathrm{OR}=0.34 ; 95 \% \mathrm{CI}=0.29-0.41), 79 \%(\mathrm{OR}$ $=21 ; 95 \% \mathrm{CI}=0.17-0.25)$, and $92 \%(\mathrm{OR}=0.08 ; 95 \% \mathrm{CI}=0.07-0.10)$ less likely to be persistence with screening mammography, as compared to those without diabetes complications.

\section{DISCUSSION}

This cohort study is the first to examine the association between the severity of diabetes complications and persistence with BC screening in a large nationally representative sample of elderly women who are Medicare beneficiaries, living in SEER areas and were free of cancer. It makes an important contribution to the current literature, as it moves beyond identifying the general association between diabetes and lower BC screening towards exploring the impact of severity of diabetes complications and other covariates on having BC screening.

Our study showed that $42.5 \%$ of elderly women with DM had no screening mammography during 60 months of follow-up period. This is higher than what was found in the 
general population of elderly women since a previous study reported that $21 \%$ of elderly women are non-users with no screening mammography during a 24-month follow-up period (McCarthy et al., 2000). Another study by Vyas et al, reported that $27.9 \%$ of elderly women who are Medicare beneficiaries in SEER areas were non users with no screening mammography over the 60-months follow-up period (Vyas et al., 2014). Overall, this is consistent with previous literature regarding the underuse of $\mathrm{BC}$ screening among elderly women with $\mathrm{DM}$ as compared to those without diabetes (Beckman et al., 2001; Chan et al., 2014; Fleming et al., 2011; Lipscombe et al., 2005; Martinez-Huedo et al., 2012; McBean \& Yu, 2007). The findings highlight the need for better understanding of the role diabetes in lower rates of BC screening.

Our findings revealed that the severity of diabetes complications is significantly associated with lower persistence with screening mammography after controlling for predisposing factors, enabling factors, need factors, health behaviors, and external environment factors. As the DCSI increases, the likelihood of being persistent with screening mammography decreases. Women with DCSI $=1$, DCSI $=2$, DCSI $=3$, DCSI $=4$, and DCSI $\geq 5$ were $26 \%, 48 \%$, $67 \%, 80 \%$, and $92 \%$ less likely to be persistence with screening mammogram, respectively, as compared to those without diabetes complications. This association of presence and severity of diabetes complications with low persistence with screening mammogram was confirmed even in the presence of more frequent PCP visits as compared to those without complications. This draws attention to the role of primary care providers to increase the awareness of elderly women and their caregivers about the importance of BC screening, especially since these women are at a high risk of developing breast cancer. Theories was proposed to explain why some patients, who have frequent visits to primary care physicians, do not get preventive services. Time constraints could be a factor that may explain why the primary care providers do not give preventive care a 
priority during the visits, especially among elderly women with diabetes complications. A previous study by Yarnall et al, showed the ability of physicians to comply with preventive services recommendations are limited with time (Yarnall et al., 2003). In our study cohort, the presence and severity of diabetes complications may take precedence over $\mathrm{BC}$ screening during annual visits to PCPs. Another reason could be related to a shorter life expectancy of women with more sever diabetes complications. Guidelines including ACS, American College of Radiology (ACR) guidelines, and American Geriatrics Society (AGS) recommend that decisions about BC screening in elderly women should be considered based on the woman's current health conditions and predicted life expectancy. Young et al found that as the DCSI increased, the mortality risk increased (Young et al., 2008). However, still having BC screening decreases the burden of comorbidity between the diabetes complications and cancer among elderly women with diabetes. Since elderly women with diabetes are at high risk of breast cancer diagnosis, new approaches and guidelines of preventive care are required to address the complexity and heterogeneity of diabetes, and to detect $\mathrm{BC}$ early, and thereby this could improve the chances that BC can be treated successfully (Braithwaite, Demb, \& Henderson, 2016).

The results of this study should be interpreted in the light of potential limitations of the methodology. Although the non-cancer SEER-Medicare sample of elderly women is a large linked data, it lacks the information related to mammogram screening covered by Medicare but not billed to Medicare. Second, since we used claims database instead of medical records to measure DSCI, the index was measured without laboratory results. However, a study by Chang et al. tested the validity of DCSI without laboratory results and they found that the DCSI without laboratory results and the DCSI with laboratory information perform similarly (Chang et al., 2012b). Finally, the US Preventive Services Task Force (USPSTF) concluded that there is no 
sufficient evidence to assess the importance of screening mammography in women aged 75 years or older because none of the randomized controlled trials evaluating screening mammography included women aged $\geq 74$ years (Walter et al, 2014). However, we included elderly women aged $\geq 74$ years in our cohort for many reasons. First, all other guidelines (ACS, ACOG, ACR, and AGS) do not recommend against having screening mammograms for women older than 74 years. In addition, a study by Galit et al. revealed that regular mammography screening for women aged older than 74 years may be associated with lower risk of late stage diagnosis and lower mortality (Galit et al., 2007).

Despite the potential limitations, this is the first cohort study, to investigate the contribution of the severity of diabetes complications using DCSI to low rates of screening mammograms among elderly women. In addition to use of DCSI as measure of diabetes severity, a study by Young et al. found that this index may be considered as a proxy measure for diabetes duration (Young et al., 2008). Young et al found that severity index of diabetes complications was highly correlated with diabetes duration, and it attenuated the significant impact of diabetes duration on mortality after it was added to the analysis model (Young et al., 2008). Because diabetes may remained undiagnosed for years, using DCSI as a severity measure of long- term complications probably demonstrate the consequences of biologic markers of diabetes duration (Harris \& Eastman, 2000). Moreover, this is the only study that accounts for differences in comorbidities, access to health care, and other factors between non-users, non-persistent, and persistent mammography uses among elderly women with DM. Another major strength of this study is the large size of the studied cohort. Moreover, using a 5\% random sample of Medicare beneficiaries who lived in SEER areas enable us to exclude women with histories of any cancer from the study. Also, women who had any diagnostic code of any type of cancer were excluded from our 
cohort to increase the probability that the identified screening mammograms were indeed for screening.

Overall, the DCSI may be best used for women with diabetes who are at high risk of poor BC preventive care by diabetes management programs, such as Medicare chronic care management (CCM) services that include interventions, monitoring and education. Also, these programs should be directed to primary health care physicians who could effectively promote to BC preventive care since the association between annual visits to PCPs and persistence with screening mammography was very strong. 


\section{REFERENCES}

About the SEER Program - SEER. (2016). Retrieved from http://seer.cancer.gov/about/

ACOG Statement on Breast Cancer Screening Guidelines - ACOG. (2016). Retrieved from http://www.acog.org/About-ACOG/News-Room/Statements/2016/ACOG-Statement-onBreast-Cancer-Screening-Guidelines

Andersen, R. M. (1995). Revisiting the behavioral model and access to medical care: does it matter? J Health Soc Behav, 36(1), 1-10.

Andersen RM, Davidson PL. (2001). Improving access to care in America: individual and contextual indicators. In: Andersen RM, Rice TH, Kominski EF, editors. Changing the U.S. health care system: key issues in health services, policy, and management. San Francisco, CA: Jossey-Bass; pp. 3-30

Baldwin, L. M., Adamache, W., Klabunde, C. N., Kenward, K., Dahlman, C., \& J, L. W. (2002). Linking physician characteristics and medicare claims data: issues in data availability, quality, and measurement. Med Care, 40(8 Suppl), Iv-82-95. doi:10.1097/01.mlr.0000020933.36849.20

Beckman, T. J., Cuddihy, R. M., Scheitel, S. M., Naessens, J. M., Killian, J. M., \& Pankratz, V. S. (2001). Screening mammogram utilization in women with diabetes. Diabetes Care, 24(12), 2049-2053.

Boyle, P., Boniol, M., Koechlin, A., Robertson, C., Valentini, F., Coppens, K., . . Autier, P. (2012). Diabetes and breast cancer risk: a meta-analysis. Br J Cancer, 107(9), 1608-1617. doi:10.1038/bjc.2012.414

Braithwaite, D., Demb, J., \& Henderson, L. M. (2016). Optimal breast cancer screening strategies for older women: current perspectives. Clin Interv Aging, 11, 111-125. doi:10.2147/cia.s65304

Braithwaite, D., Zhu, W., Hubbard, R. A., O'Meara, E. S., Miglioretti, D. L., Geller, B., . . Kerlikowske, K. (2013). Screening outcomes in older US women undergoing multiple mammograms in community practice: does interval, age, or comorbidity score affect tumor characteristics or false positive rates? J Natl Cancer Inst, 105(5), 334-341. doi:10.1093/jnci/djs645

Chang, H. Y., Weiner, J. P., Richards, T. M., Bleich, S. N., \& Segal, J. B. (2012a). Predicting costs with diabetes complications severity index in claims data. Am J Manag Care, 18(4), 213-219.

Chang, H. Y., Weiner, J. P., Richards, T. M., Bleich, S. N., \& Segal, J. B. (2012b). Validating the AdaptedDiabetes Complications Severity Index in Claims Data. Am J Manag Care, 18(4), 213-219. 
Cleveland, R. J., North, K. E., Stevens, J., Teitelbaum, S. L., Neugut, A. I., \& Gammon, M. D. (2012). The association of diabetes with breast cancer incidence and mortality in the Long Island Breast Cancer Study Project. Cancer Causes Control, 23(7), 1193-1203. doi:10.1007/s10552-012-9989-7

Conwell, L. J., \& Boult, C. (2008). The effects of complications and comorbidities on the quality of preventive diabetes care: a literature review. Popul Health Manag, 11(4), 217-228. doi:10.1089/pop.2007.0017

Fisher, K. J., Lee, J. H., Ferrante, J. M., McCarthy, E. P., Gonzalez, E. C., Chen, R., . . Roetzheim, R. G. (2013). The effects of primary care on breast cancer mortality and incidence among Medicare beneficiaries. Cancer, 119(16), 2964-2972. doi: $10.1002 /$ cncr.28148

Fleming, S. T., Love, M. M., \& Bennett, K. (2011). Diabetes and cancer screening rates among Appalachian and non-Appalachian residents of Kentucky. J Am Board Fam Med, 24(6), 682-692. doi:10.3122/jabfm.2011.06.110094

Galit W, Green MS, Lital K. Routine screening mammography in women older than 74 years: a review of the available data. Maturitas. 2007;57(2):109-119

Giovannucci, E., Harlan, D. M., Archer, M. C., Bergenstal, R. M., Gapstur, S. M., Habel, L. A., . . . Yee, D. (2010). Diabetes and cancer: a consensus report. Diabetes Care, 33(7), 16741685. doi:10.2337/dc10-0666

Hellman, S. (1997). Stopping metastases at their source. N Engl J Med, 337(14), 996-997. doi:10.1056/nejm199710023371408

Joish, V. N., Malone, D. C., Wendel, C., Draugalis, J. R., \& Mohler, M. J. (2005). Development and validation of a diabetes mellitus severity index: a risk-adjustment tool for predicting health care resource use and costs. Pharmacotherapy, 25(5), 676-684.

Kagay, C. R., Quale, C., \& Smith-Bindman, R. (2006). Screening mammography in the American elderly. Am J Prev Med, 31(2), 142-149. doi:10.1016/j.amepre.2006.03.029

Lam, E. K., Batty, G. D., Huxley, R. R., Martiniuk, A. L., Barzi, F., Lam, T. H., . . Woodward, M. (2011). Associations of diabetes mellitus with site-specific cancer mortality in the Asia-Pacific region. Ann Oncol, 22(3), 730-738. doi:10.1093/annonc/mdq405

Larsson, S. C., Mantzoros, C. S., \& Wolk, A. (2007). Diabetes mellitus and risk of breast cancer: a meta-analysis. Int J Cancer, 121(4), 856-862. doi:10.1002/ijc.22717

Liao, S., Li, J., Wei, W., Wang, L., Zhang, Y., Wang, C., \& Sun, S. (2011). Association between diabetes mellitus and breast cancer risk: a meta-analysis of the literature. Asian Pac J Cancer Prev, 12(4), 1061-1065. 
Lipscombe, L. L., Fischer, H. D., Austin, P. C., Fu, L., Jaakkimainen, R. L., Ginsburg, O., , . Paszat, L. (2015). The association between diabetes and breast cancer stage at diagnosis: a population-based study. Breast Cancer Res Treat, 150(3), 613-620. doi:10.1007/s10549-015-3323-5

Lipscombe, L. L., Hux, J. E., \& Booth, G. L. (2005). Reduced screening mammography among women with diabetes. Arch Intern Med, 165(18), 2090-2095.

doi:10.1001/archinte.165.18.2090

Luo, J., Hendryx, M., Virnig, B., Wen, S., Chlebowski, R., Chen, C., . . Margolis, K. L. (2015). Pre-existing diabetes and breast cancer prognosis among elderly women. Br J Cancer, 113(5), 827-832. doi:10.1038/bjc.2015.249

Luo, J., Lin, H.-C., He, K., \& Hendryx, M. (2014). Diabetes and prognosis in older persons with colorectal cancer. British Journal of Cancer, 110(7), 1847-1854. doi:doi:10.1038/bjc.2014.68

McBean, A. M., \& Yu, X. (2007). The underuse of screening services among elderly women with diabetes. Diabetes Care, 30(6), 1466-1472. doi:10.2337/dc06-2233

McCarthy, E. P., Burns, R. B., Freund, K. M., Ash, A. S., Shwartz, M., Marwill, S. L., \& Moskowitz, M. A. (2000). Mammography use, breast cancer stage at diagnosis, and survival among older women. J Am Geriatr Soc, 48(10), 1226-1233.

Oeffinger, K. C., Memorial Sloan Kettering Cancer Center, N. Y., New York, Fontham, E. T. H., Louisiana State University School of Public Health, N. O., Etzioni, R., University of Washington and the Fred Hutchinson Cancer Research Center, S., . . . American Cancer Society, A., Georgia. (2015). Breast Cancer Screening for Women at Average Risk: 2015 Guideline Update From the American Cancer Society. JAMA, 314(15), 1599-1614. doi:10.1001/jama.2015.12783

Redaniel, M. T., Jeffreys, M., May, M. T., Ben-Shlomo, Y., \& Martin, R. M. (2012). Associations of type 2 diabetes and diabetes treatment with breast cancer risk and mortality: a population-based cohort study among British women. Cancer Causes Control, 23(11), 1785-1795. doi:10.1007/s10552-012-0057-0

SEER-Medicare. (2016). (DENOM / SUMDENOM) Denominator (DENOM) file. Retrieved from http://healthcaredelivery.cancer.gov/seermedicare/medicare/enroll.html

Shikata, K., Ninomiya, T., \& Kiyohara, Y. (2013). Diabetes mellitus and cancer risk: review of the epidemiological evidence. Cancer Sci, 104(1), 9-14. doi:10.1111/cas.12043

Sun, G., \& Kashyap, S. R. (2011). Cancer risk in type 2 diabetes mellitus: metabolic links and therapeutic considerations. J Nutr Metab, 2011, 708183. doi:10.1155/2011/708183 
Tabassum, I., Mahmood, H., \& Faheem, M. (2016). Type 2 Diabetes Mellitus as a Risk Factor for Female Breast Cancer in the Population of Northern Pakistan. Asian Pac J Cancer Prev, 17(7), 3255-3258.

Timar, B., Timar, R., Schiller, A., Oancea, C., Roman, D., Vlad, M., . . Mazilu, O. (2016). Impact of neuropathy on the adherence to diabetes-related self-care activities: a crosssectional study. Patient Prefer Adherence, 10, 1169-1175. doi:10.2147/ppa.s107621

Tudzarova, S., \& Osman, M. A. (2015). The double trouble of metabolic diseases: the diabetescancer link. Mol Biol Cell, 26(18), 3129-3139. doi:10.1091/mbc.E14-11-1550

Vigneri, P., Frasca, F., Sciacca, L., Pandini, G., \& Vigneri, R. (2009). Diabetes and cancer. Endocr Relat Cancer, 16(4), 1103-1123. doi:10.1677/erc-09-0087

Vyas, A., Madhavan, S., \& Sambamoorthi, U. (2014). Association between persistence with mammography screening and stage at diagnosis among elderly women diagnosed with breast cancer. Breast Cancer Res Treat, 148(3), 645-654. doi:10.1007/s10549-014-32043

Walter, L. C., \& Schonberg, M. A. (2014). Screening Mammography in Older Women: A Review. JAMA, 311(13), 1336-1347. http://doi.org/10.1001/jama.2014.2834

Warren, J. L., Klabunde, C. N., Schrag, D., Bach, P. B., \& Riley, G. F. (2002). Overview of the SEER-Medicare data: content, research applications, and generalizability to the United States elderly population. Med Care, 40(8 Suppl), Iv-3-18.

doi:10.1097/01.mlr.0000020942.47004.03

White, A., Vernon, S. W., Franzini, L., \& Du, X. L. (2011). Racial and ethnic disparities in colorectal cancer screening persisted despite expansion of Medicare's screening reimbursement. Cancer Epidemiol Biomarkers Prev, 20(5), 811-817. doi:10.1158/10559965.epi-09-0963

Yarnall, K. S. H., Pollak, K. I., Østbye, T., Krause, K. M., \& Michener, J. L. (2003). Primary Care: Is There Enough Time for Prevention? Am J Public Health, 93(4), 635-641.

Young, B. A., Lin, E., Von Korff, M., Simon, G., Ciechanowski, P., Ludman, E. J., ... Katon, W. J. (2008). Diabetes complications severity index and risk of mortality, hospitalization, and healthcare utilization. Am J Manag Care, 14(1), 15-23.

Yu, X., McBean, A. M., \& Virnig, B. A. (2007). Physician visits, patient comorbidities, and mammography use among elderly colorectal cancer survivors. J Cancer Surviv, 1(4), 275-282. doi:10.1007/s11764-007-0037-7 
Predisposing factors:

1. Race

2. Age

Enabling factors:

1. Primary care providers (PCP) visits

The external environment factors:

1. Region

2. Metropolitan status

Need factors:

1. Comorbidities

2. Diabetes complications severity

\section{Figure 1: conceptual framework (Anderson's behavioral model)}

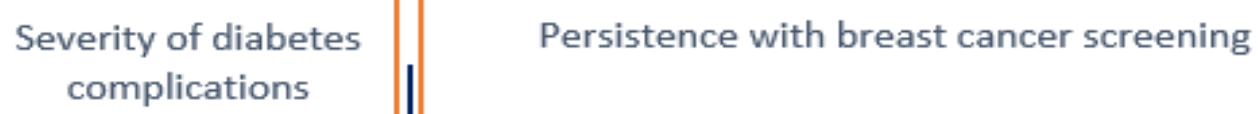

The baseline year

Figure 2: Study design (retrospective cohort study) 


\section{Figure 3: Study Sample Selection Flowchart}

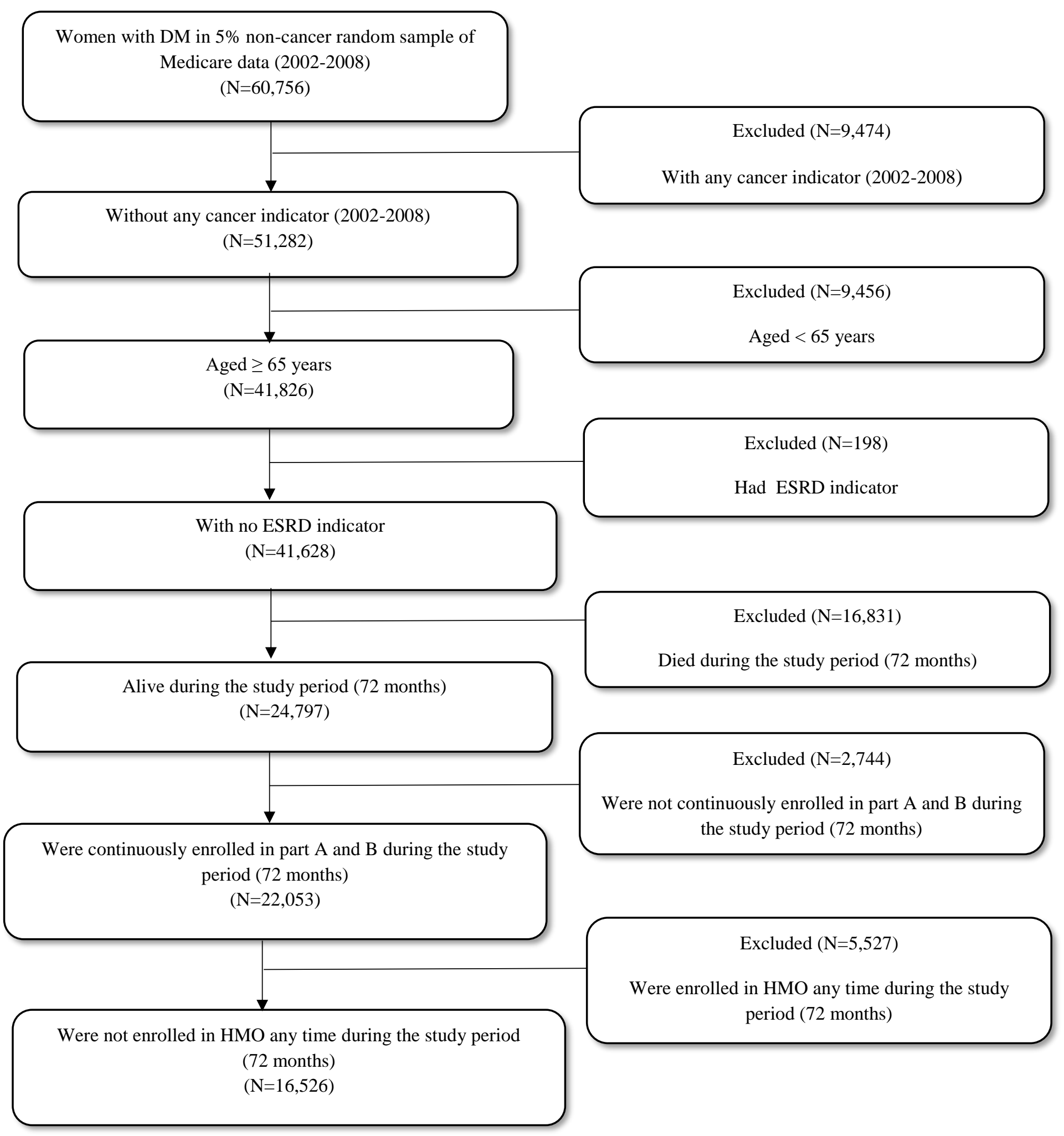




\begin{tabular}{|c|c|c|c|c|c|c|c|c|c|c|c|c|c|c|}
\hline Characteristics & $\begin{array}{l}\text { All } \\
(\mathbf{N}) \\
\end{array}$ & $\%$ & $\begin{array}{c}\text { DCSI }=0 \\
(\mathbf{N})\end{array}$ & $\%$ & $\begin{array}{c}\text { DCSI }=1 \\
(\mathbf{N})\end{array}$ & $\%$ & $\begin{array}{c}\text { DCSI }=2 \\
(\mathbf{N})\end{array}$ & $\%$ & $\begin{array}{c}\text { DCSI }=3 \\
(\mathbf{N})\end{array}$ & $\%$ & $\begin{array}{c}\text { DCSI }=4 \\
(\mathbf{N})\end{array}$ & $\%$ & $\begin{array}{c}\text { DCSI }=\geq \\
5(\mathbf{N})\end{array}$ & $\%$ \\
\hline TOTAL & 16,526 & 100 & 6933 & & 1882 & & 2900 & & 1277 & & 1427 & & 2107 & \\
\hline \multicolumn{15}{|l|}{ Age groups } \\
\hline $65-70$ & 5,896 & 35.7 & 2854 & 41.2 & 743 & 39.5 & 963 & 33.2 & 399 & 31.2 & 356 & 24.9 & 581 & 27.6 \\
\hline $71-74$ & 3,494 & 21.1 & 1562 & 22.5 & 407 & 21.6 & 599 & 20.7 & 252 & 19.7 & 274 & 19.2 & 400 & 19.0 \\
\hline $75-79$ & 3,684 & 22.3 & 1399 & 20.2 & 406 & 21.6 & 666 & 23.0 & 306 & 24.0 & 367 & 25.7 & 540 & 25.6 \\
\hline$>=80$ & 3,452 & 20.9 & 1118 & 16.1 & 326 & 17.3 & 672 & 23.2 & 320 & 25.1 & 430 & 30.1 & 586 & 27.8 \\
\hline \multicolumn{15}{|l|}{ Race } \\
\hline White & 12,147 & 73.5 & 5064 & 73.0 & 1395 & 74.1 & 2174 & 75.0 & 956 & 74.9 & 1056 & 74.0 & 1502 & 71.3 \\
\hline African America & 2,355 & 14.3 & 955 & 13.8 & 237 & 12.6 & 392 & 13.5 & 180 & 14.1 & 203 & 14.2 & 388 & 18.4 \\
\hline Others & 2,024 & 12.2 & 914 & 13.2 & 250 & 13.3 & 334 & 11.5 & 141 & 11.0 & 168 & 11.8 & 217 & 10.3 \\
\hline \multicolumn{15}{|l|}{ Annual PCP visits } \\
\hline $0-3$ & 1,261 & 7.6 & 608 & 8.8 & 166 & 8.8 & 199 & 6.9 & 75 & 5.9 & 77 & 5.4 & 136 & 6.5 \\
\hline $4-5$ & 2,078 & 12.6 & 872 & 12.6 & 222 & 11.8 & 335 & 11.6 & 166 & 13.0 & 190 & 13.3 & 293 & 13.9 \\
\hline 6 & 13,187 & 79.8 & 5453 & 78.7 & 1494 & 79.4 & 2366 & 81.6 & 1036 & 81.1 & 1160 & 81.3 & 1678 & 79.6 \\
\hline \multicolumn{15}{|l|}{ Arthritis } \\
\hline Yes & 6,056 & 36.6 & 1605 & 23.2 & 739 & 39.3 & 1140 & 39.3 & 643 & 50.4 & 684 & 47.9 & 1245 & 59.1 \\
\hline No & 10,470 & 63.4 & 5328 & 76.8 & 1143 & 60.7 & 1760 & 60.7 & 634 & 49.6 & 743 & 52.1 & 862 & 40.9 \\
\hline \multicolumn{15}{|l|}{ Asthma } \\
\hline Yes & 1,896 & 11.5 & 442 & 6.4 & 204 & 10.8 & 393 & 13.6 & 197 & 15.4 & 223 & 15.6 & 437 & 20.7 \\
\hline No & 14,630 & 88.5 & 6491 & 93.6 & 1678 & 89.2 & 2507 & 86.4 & 1080 & 84.6 & 1204 & 84.4 & 1670 & 79.3 \\
\hline \multicolumn{15}{|l|}{ COPD } \\
\hline Yes & 3,283 & 19.9 & 606 & 8.7 & 288 & 15.3 & 668 & 23.0 & 346 & 27.1 & 441 & 30.9 & 934 & 44.3 \\
\hline No & 13,243 & 80.1 & 6327 & 91.3 & 1594 & 84.7 & 2232 & 77.0 & 931 & 72.9 & 986 & 69.1 & 1173 & 55.7 \\
\hline \multicolumn{15}{|l|}{ Dementia } \\
\hline Yes & 1,909 & 11.6 & 243 & 3.5 & 129 & 6.9 & 320 & 11.0 & 204 & 16.0 & 331 & 23.2 & 682 & 32.4 \\
\hline No & 14,617 & 88.4 & 6690 & 96.5 & 1753 & 93.1 & 2580 & 89.0 & 1073 & 84.0 & 1096 & 76.8 & 1425 & 67.6 \\
\hline \multicolumn{15}{|l|}{ Hyperlipidemia } \\
\hline Yes & 10,869 & 65.8 & 3840 & 55.4 & 1311 & 69.7 & 2017 & 69.6 & 968 & 75.8 & 1055 & 73.9 & 1678 & 79.6 \\
\hline No & 5,657 & 34.2 & 3093 & 44.6 & 571 & 30.3 & 883 & 30.4 & 309 & 24.2 & 372 & 26.1 & 429 & 20.4 \\
\hline \multicolumn{15}{|l|}{ Hypertension } \\
\hline Yes & 13,983 & 84.6 & 4974 & 71.7 & 1694 & 90.0 & 2655 & 91.6 & 1216 & 95.2 & 1370 & 96.0 & 2074 & 98.4 \\
\hline No & 2,543 & 15.4 & 1959 & 28.3 & 188 & 10.0 & 245 & 8.4 & 61 & 4.8 & 57 & 4.0 & 33 & 1.6 \\
\hline \multicolumn{15}{|l|}{ Thyroid syndrome } \\
\hline Yes & 4,947 & 29.9 & 1546 & 22.3 & 551 & 29.3 & 953 & 32.9 & 478 & 37.4 & 517 & 36.2 & 902 & 42.8 \\
\hline No & 11,579 & 70.1 & 5387 & 77.7 & 1331 & 70.7 & 1947 & 67.1 & 799 & 62.6 & 910 & 63.8 & 1205 & 57.2 \\
\hline \multicolumn{15}{|l|}{ Osteoporosis } \\
\hline Yes & 2,834 & 17.1 & 729 & 10.5 & 332 & 17.6 & 528 & 18.2 & 293 & 22.9 & 354 & 24.8 & 598 & 28.4 \\
\hline No & 13,692 & 82.9 & 6204 & 89.5 & 1550 & 82.4 & 2372 & 81.8 & 984 & 77.1 & 1073 & 75.2 & 1509 & 71.6 \\
\hline ...Continued & & & & & & & & & & & & & & \\
\hline
\end{tabular}


Table 1: The Baseline Characteristics of the Study Cohort* by Diabetes Complications Severity Index (DSCI)

\begin{tabular}{|c|c|c|c|c|c|c|c|c|c|c|c|c|c|c|}
\hline Characteristics & $\begin{array}{l}\text { All } \\
(\mathbf{N})\end{array}$ & $\%$ & $\begin{array}{c}\text { DCSI }=0 \\
(\mathbf{N})\end{array}$ & $\%$ & $\begin{array}{c}\text { DCSI }=1 \\
(\mathrm{~N})\end{array}$ & $\%$ & $\begin{array}{c}\text { DCSI }=2 \\
(\mathrm{~N})\end{array}$ & $\%$ & $\begin{array}{c}\text { DCSI }=3 \\
(\mathrm{~N})\end{array}$ & $\%$ & $\begin{array}{c}\text { DCSI }=4 \\
(\mathrm{~N})\end{array}$ & $\%$ & $\begin{array}{c}\text { DCSI }=\geq \\
5(\mathrm{~N})\end{array}$ & $\%$ \\
\hline \multicolumn{15}{|l|}{ Anxiety } \\
\hline Yes & 633 & 3.8 & 167 & 2.4 & 77 & 4.1 & 118 & 4.1 & 60 & 4.7 & 77 & 5.4 & 134 & 6.4 \\
\hline No & 15,893 & 96.2 & 6766 & 97.6 & 1805 & 95.9 & 2782 & 95.9 & 1217 & 95.3 & 1350 & 94.6 & 1973 & 93.6 \\
\hline \multicolumn{15}{|l|}{ Depression } \\
\hline Yes & 1,133 & 6.9 & 321 & 4.6 & 120 & 6.4 & 180 & 6.2 & 108 & 8.5 & 133 & 9.3 & 271 & 12.9 \\
\hline No & 15,393 & 93.1 & 6612 & 95.4 & 1762 & 93.6 & 2720 & 93.8 & 1169 & 91.5 & 1294 & 90.7 & 1836 & 87.1 \\
\hline \multicolumn{15}{|l|}{ SEER regions } \\
\hline Northeast & 2,944 & 17.8 & 1197 & 17.3 & 332 & 17.6 & 559 & 19.3 & 237 & 18.6 & 272 & 19.1 & 347 & 16.5 \\
\hline South & 4,205 & 25.4 & 1741 & 25.1 & 466 & 24.8 & 726 & 25.0 & 314 & 24.6 & 360 & 25.2 & 598 & 28.4 \\
\hline North-central & 2,071 & 12.5 & 839 & 12.1 & 239 & 12.7 & 374 & 12.9 & 171 & 13.4 & 178 & 12.5 & 270 & 12.8 \\
\hline West & 5,988 & 36.2 & 2663 & 38.4 & 707 & 37.6 & 997 & 34.4 & 449 & 35.2 & 494 & 34.6 & 678 & 32.2 \\
\hline Missing & 1,318 & 8.0 & 493 & 7.1 & 138 & 7.3 & 244 & 8.4 & 106 & 8.3 & 123 & 8.6 & 214 & 10.2 \\
\hline \multicolumn{15}{|c|}{ Metropolitan status } \\
\hline Metro & 13,157 & 79.7 & 5530 & 79.8 & 1506 & 80.1 & 2331 & 80.5 & 1015 & 79.6 & 1165 & 81.8 & 1610 & 76.5 \\
\hline Urban & 2,942 & 17.8 & 1222 & 17.6 & 335 & 17.8 & 500 & 17.3 & 231 & 18.1 & 224 & 15.7 & 430 & 20.4 \\
\hline Rural & 409 & 2.5 & 175 & 2.5 & 38 & 2.0 & 66 & 2.3 & 29 & 2.3 & 36 & 2.5 & 65 & 3.1 \\
\hline
\end{tabular}

*A cohort of 16,526 elderly women with DM and free of cancer using SEER-Medicare dataset.

DCSI $=$ Diabetes complications severity index; $\mathrm{PCP}=$ Primary care providers;

COPD $=$ Chronic Obstructive Pulmonary Disorder; SEER = Surveillance, Epidemiology, and End Results; BC = Breast cancer. 
Table 2: Characteristics of the Study Cohort* by Persistence with BC screening

\begin{tabular}{|c|c|c|c|c|c|c|c|c|}
\hline \multirow{2}{*}{\multicolumn{2}{|c|}{ Characteristics }} & \multicolumn{2}{|c|}{ Non-user } & \multicolumn{2}{|c|}{ Non-persistent } & \multicolumn{2}{|c|}{ Persistent } & \multirow[b]{2}{*}{ sig } \\
\hline & & $\mathbf{N}$ & $\%$ & $\mathbf{N}$ & $\%$ & $\mathbf{N}$ & $\%$ & \\
\hline Total & & 7021 & & 4637 & & 4868 & & \\
\hline \multirow[t]{7}{*}{ DCSI } & & & & & & & & $* * *$ \\
\hline & $\mathrm{DCSI}=0$ & 2275 & 32.4 & 1831 & 39.5 & 2827 & 58.1 & \\
\hline & DCSI = 1 & 601 & 8.6 & 639 & 13.8 & 642 & 13.2 & \\
\hline & $\mathrm{DCSI}=2$ & 1195 & 17.0 & 883 & 19.0 & 822 & 16.9 & \\
\hline & DCSI $=3$ & 598 & 8.5 & 427 & 9.2 & 252 & 5.2 & \\
\hline & $\mathrm{DCSI}=4$ & 822 & 11.7 & 415 & 8.9 & 190 & 3.9 & \\
\hline & DCSI $>=5$ & 1530 & 21.8 & 442 & 9.5 & 135 & 2.8 & \\
\hline \multicolumn{2}{|c|}{ Age groups } & & & & & & & $* * *$ \\
\hline & $65-70$ & 1806 & 25.7 & 1824 & 39.3 & 2266 & 46.5 & \\
\hline & $71-74$ & 1276 & 18.2 & 1030 & 22.2 & 1188 & 24.4 & \\
\hline & $75-79$ & 1679 & 23.9 & 1049 & 22.6 & 956 & 19.6 & \\
\hline & $>=80$ & 2260 & 32.2 & 734 & 15.8 & 458 & 9.4 & \\
\hline \multicolumn{2}{|l|}{ Race } & & & & & & & $* * *$ \\
\hline & White & 5049 & 71.9 & 3348 & 72.2 & 3750 & 77.0 & \\
\hline & African America & 984 & 14.0 & 702 & 15.1 & 669 & 13.7 & \\
\hline & others & 988 & 14.1 & 587 & 12.7 & 449 & 9.2 & \\
\hline \multicolumn{3}{|c|}{ Number of annual PCP visits } & & & & & & $* * *$ \\
\hline & $\mathrm{PCP}=0-3$ & 686 & 9.8 & 332 & 7.2 & 243 & 5.0 & \\
\hline & $\mathrm{PCP}=4-5$ & 1017 & 14.5 & 599 & 12.9 & 462 & 9.5 & \\
\hline & $\mathrm{PCP}=6$ & 5318 & 75.7 & 3706 & 79.9 & 4163 & 85.5 & \\
\hline \multicolumn{2}{|l|}{ Arthritis } & & & & & & & $* * *$ \\
\hline & Yes & 2922 & 41.6 & 1722 & 37.1 & 1412 & 29.0 & \\
\hline & No & 4099 & 58.4 & 2915 & 62.9 & 3456 & 71.0 & \\
\hline \multicolumn{2}{|l|}{ Asthma } & & & & & & & $* * *$ \\
\hline & Yes & 860 & 12.2 & 592 & 12.8 & 444 & 9.1 & \\
\hline & No & 6161 & 87.8 & 4045 & 87.2 & 4424 & 90.9 & \\
\hline \multicolumn{2}{|l|}{ COPD } & & & & & & & $* * *$ \\
\hline & Yes & 1774 & 25.3 & 945 & 20.4 & 564 & 11.6 & \\
\hline & No & 5247 & 74.7 & 3692 & 79.6 & 4304 & 88.4 & \\
\hline \multicolumn{2}{|l|}{ Dementia } & & & & & & & $* * *$ \\
\hline & Yes & 1539 & 21.9 & 291 & 6.3 & 79 & 1.6 & \\
\hline & No & 5482 & 78.1 & 4346 & 93.7 & 4789 & 98.4 & \\
\hline \multicolumn{2}{|c|}{ Hyperlipidemia } & & & & & & & $* * *$ \\
\hline & Yes & 4229 & 60.2 & 3262 & 70.3 & 3378 & 69.4 & \\
\hline & No & 2792 & 39.8 & 1375 & 29.7 & 1490 & 30.6 & \\
\hline \multicolumn{2}{|c|}{ Hypertension } & & & & & & & $* * *$ \\
\hline & Yes & 5801 & 82.6 & 4131 & 89.1 & 4051 & 83.2 & \\
\hline & No & 1220 & 17.4 & 506 & 10.9 & 817 & 16.8 & \\
\hline \multicolumn{2}{|c|}{...Continued } & & & & & & & \\
\hline
\end{tabular}


Table 2: Characteristics of the Study Cohort* by Persistence with BC screening

\begin{tabular}{|c|c|c|c|c|c|c|c|}
\hline \multirow[t]{2}{*}{ Characteristics } & \multicolumn{2}{|c|}{ Non-user } & \multicolumn{2}{|c|}{ Non-persistent } & \multicolumn{2}{|c|}{ Persistent } & \multirow[b]{2}{*}{ sig } \\
\hline & $\mathbf{N}$ & $\%$ & $\mathbf{N}$ & $\%$ & $\mathbf{N}$ & $\%$ & \\
\hline Thyroid syndrome & & & & & & & $*$ \\
\hline Yes & 2134 & 30.4 & 1422 & 30.7 & 1391 & 28.6 & \\
\hline No & 4887 & 69.6 & 3215 & 69.3 & 3477 & 71.4 & \\
\hline Osteoporosis & & & & & & & $* * *$ \\
\hline Yes & 1369 & 19.5 & 762 & 16.4 & 703 & 14.4 & \\
\hline No & 5652 & 80.5 & 3875 & 83.6 & 4165 & 85.6 & \\
\hline \multicolumn{8}{|l|}{ Anxiety } \\
\hline Yes & 279 & 4.0 & 184 & 4.0 & 170 & 3.5 & \\
\hline No & 6742 & 96.0 & 4453 & 96.0 & 4698 & 96.5 & \\
\hline Depression & & & & & & & $* * *$ \\
\hline Yes & 534 & 7.6 & 338 & 7.3 & 261 & 5.4 & \\
\hline No & 6487 & 92.4 & 4299 & 92.7 & 4607 & 94.6 & \\
\hline \multicolumn{8}{|l|}{ Anxiety } \\
\hline Yes & 279 & 4.0 & 185 & 4.0 & 170 & 3.5 & \\
\hline No & 6742 & 96.0 & 4452 & 96.0 & 4698 & 96.5 & \\
\hline SEER regions & & & & & & & $* * *$ \\
\hline Northeast & 1355 & 19.3 & 780 & 16.8 & 809 & 16.6 & \\
\hline South & 1716 & 24.4 & 1179 & 25.4 & 1310 & 26.9 & \\
\hline North-central & 822 & 11.7 & 569 & 12.3 & 680 & 14.0 & \\
\hline West & 2507 & 35.7 & 1725 & 37.2 & 1756 & 36.1 & \\
\hline Missing & 621 & 8.8 & 384 & 8.3 & 313 & 6.4 & \\
\hline Metropolitan status & & & & & & & $* *$ \\
\hline Metro & 5586 & 79.7 & 3627 & 78.3 & 3944 & 81.0 & \\
\hline Urban & 1227 & 17.5 & 890 & 19.2 & 825 & 17.0 & \\
\hline Rural & 193 & 2.8 & 118 & 2.5 & 98 & 2.0 & \\
\hline
\end{tabular}

$*$ A cohort of 16,526 elderly women with DM and free of cancer using SEER-Medicare dataset.

DCSI $=$ Diabetes complications severity index $; \mathrm{PCP}=$ Primary care providers; $\mathrm{COPD}=$ Chronic Obstructive Pulmonary Disorder; SEER $=$ Surveillance, Epidemiology, and End Results; $\mathrm{BC}=$ Breast cancer; Asterisks represent statistically significant group differences based on $\chi 2$ tests by persistence with mammography screening: $* * * \mathrm{p}<0.001 ; * * 0.001<\mathrm{p}<0.01 ; * 0.01<\mathrm{p}<0.05$ 
Table 3: Association of Diabetes Complication Severity Index with Persistence with Breast Cancer Screening among Elderly women with Diabetes Mellitus

\begin{tabular}{|c|c|c|c|c|c|c|}
\hline \multirow[t]{2}{*}{ Variables } & \multicolumn{3}{|c|}{ Non-persistent } & \multicolumn{3}{|c|}{ Persistent } \\
\hline & OR & $95 \%$ CI & sig & OR & $95 \% \mathrm{CI}$ & sig \\
\hline \multicolumn{7}{|l|}{ Model 1} \\
\hline \multicolumn{7}{|l|}{ DCSI categories } \\
\hline DCSI $=0$ & Ref & & & Ref & & \\
\hline DCSI =1 & 1.32 & {$[1.16,1.50]$} & $* * *$ & 0.86 & {$[0.76,0.97]$} & $*$ \\
\hline DCSI $=2$ & 0.92 & {$[0.83,1.02]$} & & 0.55 & {$[0.50,0.62]$} & $* * *$ \\
\hline DCSI $=3$ & 0.89 & {$[0.77,1.02]$} & & 0.34 & {$[0.29,0.40]$} & $* * *$ \\
\hline DCSI $=4$ & 0.63 & {$[0.55,0.71]$} & $* * *$ & 0.19 & {$[0.16,0.22]$} & $* * *$ \\
\hline $\mathrm{DCSI} \geq 5$ & 0.36 & {$[0.32,0.41]$} & $* * *$ & 0.07 & {$[0.06,0.09]$} & $* * *$ \\
\hline
\end{tabular}

Model 2

DCSI categories

\begin{tabular}{lllllll} 
DCSI $=0$ & Ref & & \multicolumn{5}{l}{ Ref } & & \\
DCSI $=1$ & 1.32 & {$[1.16,1.50]$} & $* * *$ & 0.85 & {$[0.75,0.97]$} & $*$ \\
DCSI $=2$ & 0.90 & {$[0.81,1.01]$} & & 0.54 & {$[0.48,0.60]$} & $* * *$ \\
DCSI $=3$ & 0.87 & {$[0.76,1.00]$} & & 0.33 & {$[0.28,0.38]$} & $* * *$ \\
DCSI $=4$ & 0.61 & {$[0.53,0.70]$} & $* * *$ & 0.18 & {$[0.15,0.21]$} & $* * *$ \\
DCSI $\geq 5$ & 0.35 & {$[0.31,0.40]$} & $* * *$ & 0.07 & {$[0.06,0.08]$} & $* * *$ \\
\hline
\end{tabular}

Model 3

DCSI categories

$\begin{array}{lllllll}\text { DCSI }=0 & \text { Ref } & & & \text { Ref } & & \\ \text { DCSI }=1 & 1.13 & {[0.99,1.30]} & & 0.77 & {[0.68,0.89]} & * * * \\ \text { DCSI }=2 & 0.82 & {[0.73,0.92]} & * * * & 0.54 & {[0.48,0.61]} & * * * \\ \text { DCSI }=3 & 0.78 & {[0.67,0.91]} & * * & 0.34 & {[0.29,0.41]} & * * * \\ \text { DCSI }=4 & 0.59 & {[0.51,0.69]} & * * * & 0.21 & {[0.17,0.25]} & * * * \\ \text { DCSI }>=5 & 0.32 & {[0.28,0.37]} & * * * & 0.08 & {[0.07,0.10]} & * * *\end{array}$

$\overline{\mathrm{DCSI}}=$ Diabetes complications severity index; $\mathrm{BC}=$ Breast cancer; $\mathrm{OR}=$ Odds ratio; $\mathrm{CI}=$ Confidence intervals . Odds ratios and $95 \% \mathrm{CI}$ from the multinomial regression models.

Model 1 included only DCSI; Model 2 adjusted for enabling factor; and Model 3 adjusted for predisposing factors, enabling factor, need factors and external environmental factors.

Asterisks represent statistically significant group differences compared with the reference group:

$* * * \mathrm{p}<0.001 ; * * 0.001<\mathrm{p}<0.01 ; * 0.01<\mathrm{p}<0.05$ 


\section{CHAPTER THREE}

"Association between the Severity of Diabetes-related Complications and

Stage of Breast Cancer at diagnosis among Elderly women with Pre-existing

Diabetes Mellitus" 


\section{ABSTRACT}

Objective: To assess the association between the severity of diabetes complications and stage of breast cancer $(\mathrm{BC})$ at diagnosis among elderly women with pre-existing diabetes mellitus.

Methods: Using Surveillance, Epidemiology and End Results and Medicare linked data (20042011), we identified women with incident $B C$ and pre-existing diabetes $(N=7,729)$. Chi-square tests were used to test for group differences in stage of $\mathrm{BC}$ at diagnosis by the cohort characteristics that included mammography screening, biological factors (severity of diabetes complications using diabetes complications severity index (DCSI), age, race, hormone receptors (HR) status, and comorbid conditions), and non-biological factors such as access to health care and other community related factors. Multinomial logistic regression was used to examine the unadjusted and adjusted associations between the severity of diabetes complications and stage of $\mathrm{BC}$ at diagnosis.

Results: Of women with incident BC and pre-existing diabetes in our study, 45.2\% had cardiovascular complications, $19.5 \%$ had nephropathy, and $13.6 \%$ had neuropathy. Fifteen percent of the BC incident cases were diagnosed at stage $0,38.4 \%$ at stage I, $29.1 \%$ at stage II, and $17.5 \%$ at advanced stages (III/IV). In univariate analyses, stage of BC at diagnosis was associated with severity of diabetes complications, mammography screening use, age, race, progesterone hormone receptor status, estrogen hormone receptor status, other comorbid conditions, having a visit to a primary care physician during the year before $\mathrm{BC}$ diagnosis, having a visit to an endocrinologist during the year before $\mathrm{BC}$ diagnosis, availability of $\mathrm{BC}$ screening centers, census tract education, and census tract household income. In partial adjusted association, severity of diabetes complications ( $\mathrm{DCSI}=2$ and $\mathrm{DCSI} \geq 3$ ) was associated with 
higher likelihood of being diagnosed at advanced stages of BC after controlling for biological and non-biological factors. Women with DCSI $\geq 3$ were $27 \%$ (odds ratio $(\mathrm{OR})=1.27 ; 95 \%$ confidence interval $(\mathrm{CI})=1.05-1.54), 47 \%(\mathrm{OR}=1.47 ; 95 \% \mathrm{CI}=1.20-1.80)$, and $62 \%(\mathrm{OR}=$ $1.62 ; 95 \% \mathrm{CI}=1.30-2.01$ ) more likely to be diagnosed at stage I, stage II, and advanced stages (III/IV), respectively, as compared to those with no diabetes complications. In full adjusted association, the severity of diabetes complications was no longer an independent predictor of $\mathrm{BC}$ stage II or advanced stage (III/IV) at diagnosis after controlling for biological factors, nonbiological factors, and BC screening. However, women with DCSI $=2$ had significantly 1.26 times more likely to be diagnosed at stage I (versus stage 0 ) of $\mathrm{BC}$, compared to those without diabetes complications $(\mathrm{OR}=1.26 ; 95 \% \mathrm{CI}=1.03-1.53)$. Women who had at least one screening mammogram during the last 24 months before $\mathrm{BC}$ diagnosis were $44 \%, 81 \%$, and $91 \%$ less likely to be diagnosed at stage I, stage II, and advanced stages (III/IV), respectively, as compared to women who did not received screening.

Conclusion: The increased likelihood of having advanced-stage BC at diagnosis associated with severity of diabetes-related complications appears to be mediated by lower rates of breast cancer screening among women with pre-existing diabetes. Therefore, reducing disparity in receiving breast cancer screening among women with diabetes may reduce the risk of advanced stage breast cancer diagnosis.

Keywords: Diabetes complications; breast cancer stage; mammography 


\section{INTRODUCTION}

Several previous studies have found that women with diabetes were more likely to be diagnosed in advanced stages of breast cancer (BC) as compared to those without diabetes, and this may contribute to their higher mortality after cancer diagnosis ( Lipscombe et al., 2015; Luo et al., 2015; van de Poll-Franse et al., 2007). A study conducted among Canadian women with incident BC showed that diabetes was associated with $21 \%$ increased risk of Stage III diagnosis and $16 \%$ increased risk of Stage IV diagnosis of $\mathrm{BC}$ as compared to women without diabetes (Lipscombe et al., 2015; Luo et al., 2015).

Many reasons have been put forward to possibly account for later stage diagnosis of BC among women with diabetes. Studies have showed that women with diabetes are more likely to be diagnosed with metastatic $\mathrm{BC}$ and more likely to have larger tumors as compared to those without diabetes (Giovannucci et al., 2010). Lower rates of screening mammography among women with diabetes could also account for later stage diagnosis of BC. Despite the fact that women with diabetes have more frequent primary health care visits than women without diabetes, women with diabetes are less likely to have mammogram screening than women without diabetes (Lipscombe, Hux, \& Booth, 2005). This lower rates of BC screening could play a role in the association between diabetes and risk of advanced stages of $\mathrm{BC}$ at diagnosis.

Age and age-related changes also play a crucial role in the association between diabetes and advanced stage diagnosis of BC. About $40 \%$ of the newly diagnosed BC occur in elderly women (age $\geq 65$ years) with a 3- to 4-fold higher mortality rate after BC diagnosis in

comparison to their counterpart (Cappellani et al., 2013; Tesarova, 2013; Wildiers et al., 2007). Moreover, elderly women are more likely to be diagnosed at advanced stages of breast cancer 
than younger women (Freyer et al., 2006; Khan, Stewart, \& Morrow, 2002). Furthermore, one third of the elderly women population have pre-exiting diabetes (Corriere, Rooparinesingh, \& Kalyani, 2013). Elderly women with diabetes have more frequent microvascular and macrovascular complications as compared to younger population (Corriere et al., 2013; Jin et al., 2012).

Since elderly women with DM have a higher likelihood of complications and advanced stage $\mathrm{BC}$, it is important to determine how the severity of these complications contributes to advanced staged $\mathrm{BC}$ at diagnosis.

Thus, the aim of this study is to determine the association between the severity of diabetes complications and stage of $\mathrm{BC}$ at diagnosis in women with incident $\mathrm{BC}$ and pre-existing diabetes.

\section{Conceptual Framework}

We used Danforth's model to guide the selection of covariates that may affect the association between the severity of diabetes complications and BC stage (Figure1). This model suggests that the differences in BC stage at diagnosis is affected by biological factors, and nonbiological factors ( Danforth, 2013). The biological factors include age at diagnosis, race, hormone receptor (HR) status, and comorbidities. The non-biological factors include community-related factors ( Census tract level socioeconomic status (SES), region, and metropolitan status ) and access to health care (primary care visits, and availability of BC screening facilities in the area of residence) ( Danforth, 2013).

\section{RESEARCH DESIGN AND METHODS}

\section{Study Design}


This was a retrospective observational study in a cohort of elderly women with incident BC diagnosis and pre-existing diabetes. The cohort was followed retrospectively for 24 months prior to the $\mathrm{BC}$ diagnosis to assess the association between the severity of diabetes complications and stage of $\mathrm{BC}$ at diagnosis.

\section{Data Source}

We used the US Surveillance Epidemiology and End Results (SEER) data linked with Medicare claims data (SEER-Medicare). SEER is supported by the US National Cancer Institute (NCI) to collect data from tumor registries which covered $14 \%$ to $25 \%$ of the US population including all incident cases of cancer that occur in persons residing in 18 SEER areas (Atlanta, Connecticut, Detroit, Hawaii, Iowa, New Mexico, San Francisco-Oakland, Seattle-Puget Sound, Utah, Los Angeles and San Jose-Monterey, Rural Georgia, Alaska Native, Greater California, Kentucky, Louisiana, New Jersey, and Greater Georgia) (Hellman, 1997). Information of individuals in the SEER database who have been matched with Medicare enrollment records is in a customized file known as the Patient Entitlement and Diagnosis Summary File (PEDSF). This information includes demographic features, date of cancer diagnosis, cancer site, method of diagnosis, and state of residence. For Medicare claims files, it covers $97 \%$ of the US population who are 65 years or older (Potosky et al., 1993). The claims database consists of Medicare Provider Analysis and Review (MEDPAR), the Carrier Claims (old name Physician/Supplier (NCH)), Outpatient (OUTPT), Home Health Agencies (HHA), Hospice, Durable Medical Equipment (DME) and Part D Event (PDE) files. All of these Medicare data files have been linked with PEDSF file of cancer cases from SEER using an algorithm based on the social security number, last name, first name and date of birth of an individual. Based on the linkage, a common identification number is given to each enrollee in PEDSF and claims files. We also 
linked the Area Resource File (ARF) to the SEER-Medicare dataset using the state and county Federal Information Processing Standards code for each beneficiary to extract the county level information on the availability of mammography facilities.

\section{Study Cohort}

Our cohort consisted of elderly women aged 67 years and older with the first primary diagnosis of incident BC between January 1, 2004 and December 31, 2011 who had pre-existing diabetes. Women must have at least 24 months of continuous enrollment in Medicare part A and $\mathrm{B}$ prior to the $\mathrm{BC}$ diagnosis and must have no enrollment in health maintenance organization (HMO) at any time during the study period. Diabetes was determined on the basis of either a single inpatient claim or at least two outpatient claim diagnoses with International Classification of Diseases, Ninth Edition, Clinical Modification (ICD-9-CM) diagnosis code of 250.xx (Luo et al., 2014) during the 12-month that preceded BC diagnosis. Women who were diagnosed with $\mathrm{BC}$ via death certificate or autopsy, or were with any previous cancer diagnosis, unknown or missing BC stage information were excluded from the study cohort (Figure 2).

\section{Measures}

\section{Outcome variable}

The outcome was cancer staging based on the American Joint Committee on Cancer's staging system. Stage at diagnosis (0-IV) of the cancer/tumor was taken from PEDSF file. For the study purpose, we will group out cohorts into four categories: elderly women with stage 0 , stage I, stage II, and advanced stage (III \& IV) at BC diagnosis.

\section{Key independent variable}


The key independent variable was the severity of diabetes-related complications which was identified during the 12 months that preceded the BC diagnosis. The severity of diabetesrelated complications was measured by end-organ damage of diabetes using the diabetes comorbidity severity index (DCSI). The DCSI was first developed by Young and colleagues to include 7 categories of diabetes complications: cardiovascular disease, nephropathy, retinopathy, peripheral vascular disease, cerebrovascular, neuropathy, and metabolic complications. Theses complications were identified using International Classification of Diseases, Ninth Edition, Clinical Modification (ICD-9-CM) diagnosis code to represent gradations of the diabetes complications severity (Young et al., 2008). The index for each complication was categorized into 2 or 3 levels (no abnormality $=0$, some abnormality $=1$, and severe abnormality $=2$ ), based on the presence and severity of the complication, and the indices of all complications were added together to get the DCSI which is a 13-point scale with a range of 0-13 (Chang et al., 2012a; Young et al., 2008). The study cohort was divided into 4 subgroups consisting of DCSI=0, $\mathrm{DCSI}=1, \mathrm{DCSI}=2$, and $\mathrm{DCSI} \geq 3$.

\section{Other independent variables}

These variables were biological factors, non-biological factors, and mammography screening use.

The biological factors included age at diagnosis, race, HR status, and other comorbid conditions. Age at $\mathrm{BC}$ diagnosis and race were decided using the SEER PEDSF file. Age at diagnosis was categorized as follows (in years): 67-70, 71-74, 75-79, and 80+. Race was categorized based into "White", "African-American", or "Other". ICD-9 diagnosis codes in the Medicare inpatient and outpatient claims were used to identify the comorbid conditions. For HR status, SEER has recorded the estrogen receptor status and progesterone receptor status since 1990 
for breast cancer cases. The hormone receptor status is categorized into positive, negative, and borderline/unknown (Elkin et al., 2006). The comorbid conditions were measured as the presence or absence of the following chronic conditions: thyroid syndrome, arthritis, asthma, Chronic Obstructive Pulmonary Disorder (COPD), dementia, hypertension, osteoporosis, anxiety, and depression.

The non-biological factors include access to health care (PCP visits, endocrinologist visits, and availability of BC screening facilities around area of women's residence) and community-related factors (census tract median household income, census tract-level education, geographic region of residence, and metropolitan status). We defined PCP as providers who had the following specialties: general practice, family medicine, primary care internal medicine, geriatric medicine, and obstetrics and gynecology. PCPs visits and endocrinologist visits were measured during the 12 months prior to $\mathrm{BC}$ diagnosis and was categorized into dichotomous group: yes (having at least one visit during the year that preceded $\mathrm{BC}$ diagnosis) or none. The availability of BC screening facilities in the area around women's residence was derived from the ARF file and dichotomized into yes or no. Education percentage was measured by the census tract survey of percent of people age $>25$ with at least 4 years of college education. Census tract education percentage was categorized into $0-13.29 \%, 13.30 \%-22.83 \%, 22.84 \%-38.55 \%$, and $>38.55 \%$. Income was measured by census tract survey of median income and was divided into $<\$ 25,000, \$ 25,001-50,000, \$ 50,001-75,000$, and $>\$ 75,000$. Breast cancer screening was identified during the 24 months that preceded the BC diagnosis using Healthcare Common Procedure Coding System (HCPCS) codes: 76085, 76092, 77052, 77057, 77063, G0202, and G0203, and ICD-9-CM diagnosis code: V7612. Women must have had at least one 
mammography screening during the past 24 months to be grouped into those who had BC screening.

\section{Statistical Analyses}

Descriptive statistics were obtained using frequencies and percentages for all included factors. Chi-square tests were used to test for significant differences among the four groups based on BC stage at diagnosis (0, I, II, and III/IV) among elderly women with diabetes in their baseline characteristics. The level of statistical significance was defined as a p-value $\leq 0.05$. Only statistically significant covariates in bivariate analyses were used in multivariable multinomial logistic regression models. To examine the associations between stage of $\mathrm{BC}$ at diagnosis and the severity of diabetes-related complications using DCSI, we used three multinomial logistic regression models. The first model assessed the unadjusted association between stage of BC at diagnosis and the severity of diabetes-related complications. The second model was used to partially adjust for biological and non-biological factors (except mammography screening use). The third model was used to assess the full adjusted association between severity of diabetes complication and $\mathrm{BC}$ stage at diagnosis controlling for all covariates: biological factors, nonbiological factors and screening mammography use. The significance of the variables in the models was assessed by the Wald 2 test, odds ratios (ORs), and 95\% confidence intervals (CIs).

\section{RESULTS}

\section{Cohort Characteristics}

Table 1 describes the study cohort of 7,729 elderly women with pre-existing diabetes, aged 67 years and older, diagnosed with a first primary incident BC in 2004-2011. About $15 \%$ of the cohort were diagnosed at stage $0,38.4 \%$ stage I, $29.1 \%$ stage II, and $17.7 \%$ were diagnosed at advanced stages (stage III or stage IV). About $57 \%$ of the study cohort had at least 
one screening mammography during the last 24 months while $42.3 \%$ had no screening mammography. Twenty percent of the study cohort were $\leq 70$ years old, $47.1 \%$ were in the age group 71-79 years, while $31.2 \%$ were $\geq 80$ years old. A majority of the women were white $(75.1$ $\%)$, had census tract income of $\$ 75,000$ or less $(81.6 \%)$, resided in metro areas $(79.3 \%)$, had at least one PCP visit during the 12 months prior to the BC diagnosis $(94.5 \%)$, had no endocrinologist visits in the year that preceded BC diagnosis $(88.1 \%)$, had positive progesterone HRS (71.2\%), and had positive estrogen HRS (82.9\%). For the most common comorbid chronic conditions, 70.4\% had hyperlipidemia, $89.7 \%$ had hypertension, $28.3 \%$ had arthritis, and $15.8 \%$ had depression. With respect to DCSI, $38.4 \%$ had no diabetes-related complications, $13.1 \%$ had a DCSI $=1,23 \%$ had a DCSI $=2$, and $25.4 \%$ had a DCSI $\geq 3$. Compared with women who had no diabetes complications, those with DCSI $\geq 3$ were older, more likely to have had an endocrinologist visit, less likely to have had screening mammography, and more likely to have other comorbid conditions (arthritis, thyroid syndrome, COPD, dementia, hypertension, and depression). The most frequent diabetes-related complications were cardiovascular

complications (45.2\%), nephropathy (19.5\%), neuropathy (13.6\%), while metabolic complications (1\%) and retinopathy (4.9\%), cerebrovascular complications (8.9\%), and peripheral vascular disease $(9.7 \%)$ were less frequent among incident cases of BC with preexisting diabetes (non-tabulated).

\section{Group Differences by Stage of BC at Diagnosis}

Table 2 shows the group differences in all the independent variables by stage of BC at diagnosis. The biological factors that have significant bivariate associations with stage of $\mathrm{BC}$ at diagnosis were DCSI, age, race, progesterone HRS, estrogen HRS, thyroid disease, arthritis, COPD, dementia, hyperlipidemia, osteoporosis, and depression. The non-biological factors that 
were statistically significant in the Chi-square analyses were mammography screening, PCP visits, endocrinologist visits, availability of BC screening centers, census tract education, and census tract household income. Regarding the main predictor, elderly women who were diagnosed with advanced stage (stage III/IV) BC were more likely to have a DCSI $\geq 3$ (29.9\%) as compared to those women who were diagnosed with stage $0(21.7 \%)$. In contrast, elderly women who were diagnosed with stage 0 of $\mathrm{BC}$ were more likely to have no diabetes-related complications (43.9\%) as compared to those who were diagnosed in advanced stage (III/IV) BC $(34.5 \%)$. The proportions of women who had received screening mammography among elderly women with advanced stage (III/IV) BC (27.3\%) and stage II BC (44.7\%) were very low in comparison to women who were diagnosed in stage 0 (82.3\%). For other biological factors, women with advanced stage (III/IV) BC diagnosis were less likely to have positive progesterone HRS, less likely to have thyroid disease, less likely to have hyperlipidemia, and more likely to have COPD, arthritis, and dementia as compared to women who were diagnosed with stage 0 of BC. For the non-biological factors, women with advanced stage BC diagnoses were less likely to have PCP visits, less likely to reside in areas with higher proportion of individuals with at least 4 years of college education as compared to women who were diagnosed with stage 0 of $\mathrm{BC}$.

\section{Associations with Stage of BC at Diagnosis}

The results from the multinomial logistic regressions are reported in table 3. Model 1 presents the unadjusted association between the severity of diabetes complications using DCSI and stage of BC at diagnosis. In the unadjusted model, the severity of diabetes complications was significantly associated with $\mathrm{BC}$ stage at diagnosis. Women who had a DCSI $=2$ were 1.30 times more likely to be diagnosed at stages $\mathrm{I}(\mathrm{OR}=1.30 ; 95 \% \mathrm{CI}=1.08-1.56), 1.45$ times more likely to be diagnosed at stage $\mathrm{II}(\mathrm{OR}=1.45 ; 95 \% \mathrm{CI}=1.20-1.76)$, and 1.57 times more likely to be 
diagnosed at advanced stage (III/IV) $(\mathrm{OR}=1.57 ; 95 \% \mathrm{CI}=1.27-1.93)$, as compared to those with no diabetes complications. Women who had the highest severity of diabetes-related complications $(\mathrm{DCSI} \geq 3)$ were 1.20 times more likely to be diagnosed at stage $\mathrm{I}(\mathrm{OR}=1.20$; $95 \% \mathrm{CI}=1.00-1.43), 1.50$ times more likely to be diagnosed at stage $\mathrm{II}(\mathrm{OR}=1.50 ; 95 \% \mathrm{CI}=$ 1.25-1.81), and 1.77 times more likely to be diagnosed at advanced stage (III/IV) (OR $=1.77 ; 95$ $\% \mathrm{CI}=1.45-2.17)$, as compared to those women with no diabetes complications.

After assessing the partial adjusted association between severity of diabetes complications and stage of $\mathrm{BC}$ at diagnosis, controlling for biological and non-biological factors in model 2, we found that the severity of diabetes complication (a DCSI $=2$ and a DCSI $\geq 3$ ) continue to be significantly associated with $\mathrm{BC}$ stage at diagnosis. For example, women with DCSI $\geq 3$ were $27 \%$ more likely to be diagnosed at stage I, $47 \%$ more likely to be diagnosed at stage II, and $62 \%$ more likely to be diagnosed at advanced stages (III/IV) of BC.

Model 3 shows the fully adjusted association between BC stage at diagnosis and severity of diabetes complications after controlling for biological factors, non-biological factors, and use of screening mammogram. Women with DCSI $=2$ were $26 \%$ more likely to be diagnosed at stage $\mathrm{I}(\mathrm{OR}=1.26 ; 95 \% \mathrm{CI}=1.03-1.53)$ while there was no significant association with the likelihood of being diagnosed at stage II or advanced stages (III/IV) of BC, as compared to those with no diabetes complications. The highest severity of diabetes complications with DCSI $\geq 3$ was no longer an independent predictor of $\mathrm{BC}$ stage at diagnosis. Women who had at least one screening mammogram during the two year that preceded $\mathrm{BC}$ diagnosis were $44 \%$ less likely to be diagnosed at stage $\mathrm{I}(\mathrm{OR}=0.56 ; 95 \% \mathrm{CI}=0.47-0.67), 81 \%$ less likely to be diagnosed at stage II $(\mathrm{OR}=0.19 ; 95 \% \mathrm{CI}=0.16-0.23)$, and $91 \%$ less likely to be diagnosed at advanced stages (III/IV) 
$(\mathrm{OR}=0.09 ; 95 \% \mathrm{CI}=0.08-0.11)$ of $\mathrm{BC}$, as compared to women who did not receive any screening mammogram.

\section{DISCUSSION}

In this study, we examined the relationship between severity of diabetes-related complications and stage of $\mathrm{BC}$ at diagnosis among a large nationally representative sample of elderly women with pre-existing diabetes and an incident BC.

Overall, severity of diabetes-related complications was associated with stage of $\mathrm{BC}$ at diagnosis. Adjustment for other biological and non-biological factors did not attenuate the association between severity of diabetes complications and BC stage at diagnosis. Our findings showed that among elderly women with pre-existing diabetes, women with a moderate severity of diabetes-related complications (a DCSI $=2$ ) were $32 \%, 42 \%$, and $46 \%$ more likely to be diagnosed at stage I, stage II, and advanced stages (III/IV), respectively. Women with highest severity of diabetes-relates complications (DCSI $\geq 3$ ) were $27 \%, 47 \%$, and $62 \%$ more likely to be diagnosed at stage I, stage II, and advanced stages (III/IV), respectively, as compared to women with no diabetes complications. According to Lipscombe et al, presence of diabetes was associated with $11 \%$ increased odds of stage II and advanced stages (III/IV) BC at diagnosis, as compared to women without diabetes ( Lipscombe et al., 2015).

After adjustment for BC screening, women with a moderate severity of diabetes complications (a DCSI =2) were more likely to be diagnosed at stage I versus stage 0 , as compared to women without diabetes complications. However, increased likelihood of being diagnosed at advanced stages of BC for elderly women with pre-existing diabetes did not reach statistical significance. Our results revealed that BC screening may mediate the association 
between the severity of diabetes-related complications and likelihood of having advanced-stages $\mathrm{BC}$ at diagnosis. It is possible that increase in severity of diabetes complications result in decreases in screening mammography use which may lead to delayed diagnosis of BC. Thus, more advanced diabetes-related care is required to deal with the complexity of diabetes disease among elderly women to avoid the risk of serious comorbid condition, such as cancer in advanced stages which burden the disease management. One good example of such care is Medicare's chronic care management that provide a comprehensive care coordination for elderly with multiple chronic conditions to facilitate access to care and receiving preventive care along with disease management (Garwood et al., 2016).

Although previous research (Lipscombe et al., 2015; Luo et al., 2015) found that diabetes was an independent predictor of the risk of advanced stage (III/IV) BC at diagnosis as compared to women without diabetes even after accounting for BC screening mammography, we found that the severity of diabetes-related complications is associated with this risk through its negative impact on BC screening.

The strengths of our study include modeling a comprehensive list of biological factors (e.g. comorbid conditions and hormone receptor status) and non-biological factors (e.g. access to health care, and community-related factors). To assess the severity of diabetes-related complications, we used DCSI which captures both the type and severity of complications while a simple count of complications does not take the severity of each complication into account (Young et al., 2008). In addition to its use as a measure of diabetes severity, a study by Young et al. found that this index may be considered as a proxy measure for diabetes duration (Young et al., 2008). Young et al found that severity index of diabetes complications was highly correlated with diabetes duration, and it attenuated the significant impact of diabetes duration on mortality 
after it was added to the analysis model (Young et al., 2008). Because diabetes may remained undiagnosed for years, using DCSI as a severity measure of long- term complications probably demonstrate the consequences of biologic markers of diabetes duration (Harris \& Eastman, 2000). Also, the use of large population-based data (SEER-Medicare) enabled us to identify incident breast cancer cases and assess all possible risk factors and pre-existing conditions.

However, our study has several potential limitations that should be mentioned. Although we controlled for many biological and non-biological variables that could be associated with BC stage at diagnosis, we lacked data on other factors, such as obesity and family history of BC which could have residual confounding effect. Second, exclusions, such as $6 \%$ of BC cases with missing stage of $\mathrm{BC}$ and $32 \%$ of $\mathrm{BC}$ cases with no continuous enrollment in part $\mathrm{A} \& \mathrm{~B}$ or enrollment in HMO any time during the study period may have affected the generalizability of our findings. Third, since we used claims database instead of medical records to measure DSCI, the index was measured without laboratory results. However, a study by Chang et al. tested the validity of DCSI without laboratory results and they found that the DCSI without laboratory results and the DCSI with laboratory information perform similarly (Chang et al., 2012b). Other limitations include lack of some biological information, such as blood glucose level, and glycosylated hemoglobin A1c lab results.

In conclusion, our study provides evidence that the severity of diabetes-related complications is associated with stage of $\mathrm{BC}$ at diagnosis and has an indirect association with the risk of advanced-stages diagnosis of $\mathrm{BC}$ among women with pre-existing diabetes. The increased likelihood of advanced-stage BC diagnosis that is associated with the severity of diabetes-related complications may be mainly driven by lower rates of BC screening among those with diabetes complications. 


\section{REFERENCES}

Cappellani, A., Di Vita, M., Zanghi, A., Cavallaro, A., Piccolo, G., Majorana, M., . . Berretta, M. (2013). Prognostic factors in elderly patients with breast cancer. BMC Surg, $13 \mathrm{Suppl}$ 2, S2. doi:10.1186/1471-2482-13-s2-s2

Chang, H. Y., Weiner, J. P., Richards, T. M., Bleich, S. N., \& Segal, J. B. (2012a). Predicting costs with diabetes complications severity index in claims data. Am J Manag Care, 18(4), 213-219.

Chang, H. Y., Weiner, J. P., Richards, T. M., Bleich, S. N., \& Segal, J. B. (2012b). Validating the AdaptedDiabetes Complications Severity Index in Claims Data. Am J Manag Care, 18(4), 213-219.

Corriere, M., Rooparinesingh, N., \& Kalyani, R. R. (2013). Epidemiology of diabetes and diabetes complications in the elderly: an emerging public health burden. Curr Diab Rep, 13(6), 805-813. doi:10.1007/s11892-013-0425-5

David N Danforth, J. (2013). Disparities in breast cancer outcomes between Caucasian and African American women: a model for describing the relationship of biological and nonbiological factors. doi:10.1186/bcr3429

Elkin, E. B., Hurria, A., Mitra, N., Schrag, D., \& Panageas, K. S. (2006). Adjuvant Chemotherapy and Survival in Older Women With Hormone Receptor-Negative Breast Cancer: Assessing Outcome in a Population-Based, Observational Cohort. doi:10.1200/JCO.2005.03.6053

Freyer, G., Braud, A. C., Chaibi, P., Spielmann, M., Martin, J. P., Vilela, G., . . Zelek, L. (2006). Dealing with metastatic breast cancer in elderly women: results from a French study on a large cohort carried out by the 'Observatory on Elderly Patients'. Ann Oncol, 17(2), 211-216. doi:10.1093/annonc/mdj043

Garwood, C. L., Korkis, B., Mohammad, I., Lepczyk, M., \& Risko, K. (2016). Implementation of chronic care management services in primary care practice. Am J Health Syst Pharm, 73(23), 1924-1932. doi:10.2146/ajhp150985

Giovannucci, E., Harlan, D. M., Archer, M. C., Bergenstal, R. M., Gapstur, S. M., Habel, L. A., . .. Yee, D. (2010). Diabetes and Cancer: A consensus report. In Diabetes Care (Vol. 33, pp. 1674-1685).

Jin, Q. H., Chen, H. H., Yu, H. L., \& Li, T. L. (2012). [The relationship between sleep quality and glucose level, diabetic complications in elderly type 2 diabetes mellitus]. Zhonghua Nei Ke Za Zhi, 51(5), 357-361. 
Joish, V. N., Malone, D. C., Wendel, C., Draugalis, J. R., \& Mohler, M. J. (2005). Development and validation of a diabetes mellitus severity index: a risk-adjustment tool for predicting health care resource use and costs. Pharmacotherapy, 25(5), 676-684.

Khan, S. A., Stewart, A. K., \& Morrow, M. (2002). Does aggressive local therapy improve survival in metastatic breast cancer? Surgery, 132(4), 620-626; discussion 626-627.

Lipscombe, L. L., Fischer, H. D., Austin, P. C., Fu, L., Jaakkimainen, R. L., Ginsburg, O., . . . Paszat, L. (2015). The association between diabetes and breast cancer stage at diagnosis: a population-based study. Breast Cancer Res Treat, 150(3), 613-620.

doi:10.1007/s10549-015-3323-5

Lipscombe, L. L., Hux, J. E., \& Booth, G. L. (2005). Reduced screening mammography among women with diabetes. Arch Intern Med, 165(18), 2090-2095.

doi:10.1001/archinte.165.18.2090

Luo, J., Hendryx, M., Virnig, B., Wen, S., Chlebowski, R., Chen, C., . . Margolis, K. L. (2015). Pre-existing diabetes and breast cancer prognosis among elderly women. Br J Cancer, 113(5), 827-832. doi:10.1038/bjc.2015.249

Luo, J., Lin, H.-C., He, K., \& Hendryx, M. (2014). Diabetes and prognosis in older persons with colorectal cancer. British Journal of Cancer, 110(7), 1847-1854.

doi:doi:10.1038/bjc.2014.68

Potosky, A. L., Riley, G. F., Lubitz, J. D., Mentnech, R. M., \& Kessler, L. G. (1993). Potential for cancer related health services research using a linked Medicare-tumor registry database. Med Care, 31(8), 732-748.

Tesarova, P. (2013). Breast cancer in the elderly—Should it be treated differently? In Rep Pract Oncol Radiother (Vol. 18, pp. 26-33).

van de Poll-Franse, L. V., Houterman, S., Janssen-Heijnen, M. L., Dercksen, M. W., Coebergh, J. W., \& Haak, H. R. (2007). Less aggressive treatment and worse overall survival in cancer patients with diabetes: a large population based analysis. Int J Cancer, 120(9), 1986-1992. doi:10.1002/ijc.22532

Wildiers, H., Kunkler, I., Biganzoli, L., Fracheboud, J., Vlastos, G., Bernard-Marty, C., . . . Aapro, M. (2007). Management of breast cancer in elderly individuals: recommendations of the International Society of Geriatric Oncology. Lancet Oncol, 8(12), 1101-1115. doi:10.1016/s1470-2045(07)70378-9

Young, B. A., Lin, E., Von Korff, M., Simon, G., Ciechanowski, P., Ludman, E. J., . . Katon, W. J. (2008). Diabetes complications severity index and risk of mortality, hospitalization, and healthcare utilization. Am J Manag Care, 14(1), 15-23. 


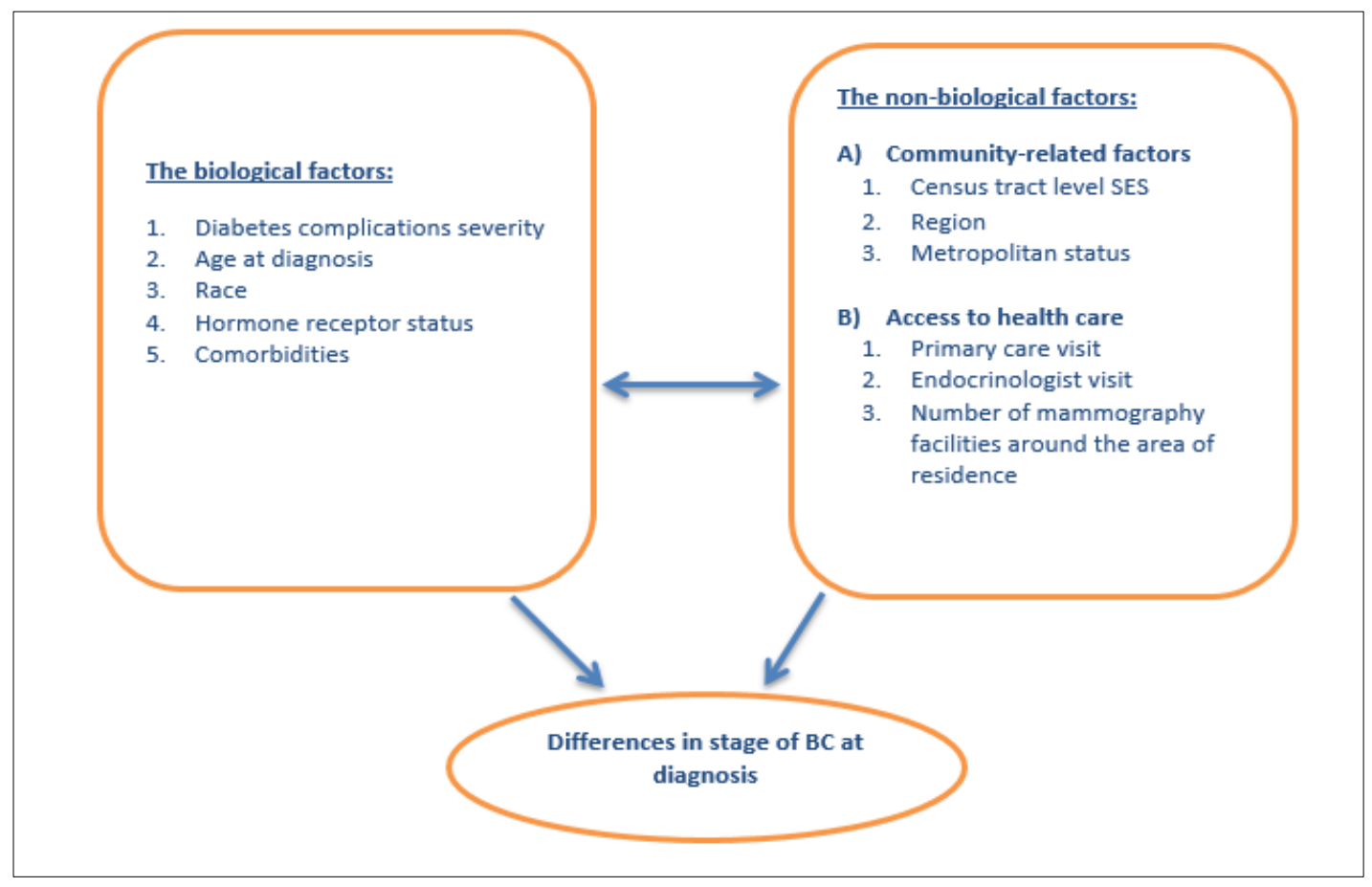

Figure 1: Conceptual framework based on Danforth's model 


\section{Figure 2: Study Cohort Selection Flowchart}

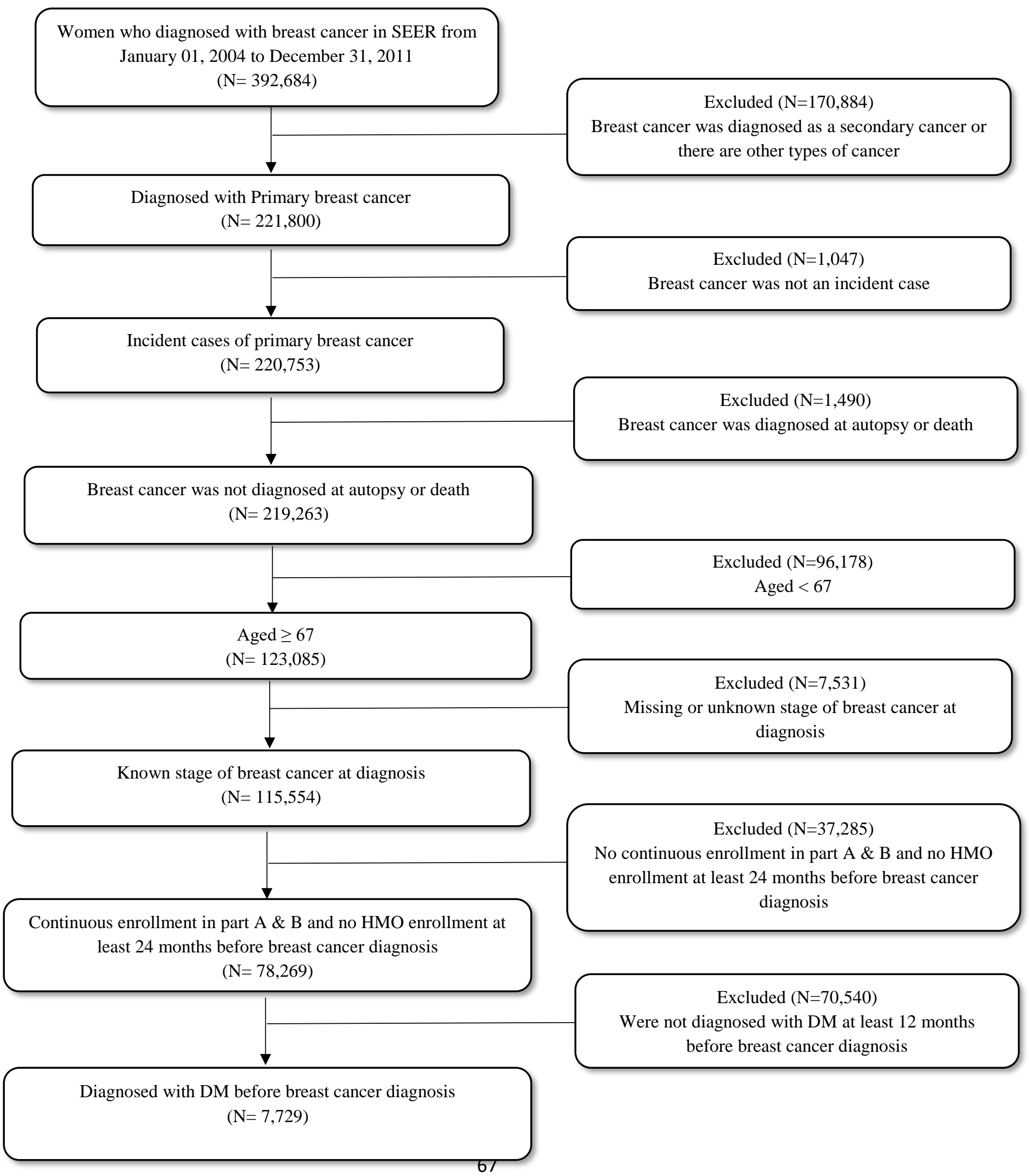


Table 1: The Baseline Characteristics of the Study Cohort* by Diabetes Complications Severity Index

\begin{tabular}{|c|c|c|c|c|c|c|c|c|c|c|}
\hline \multirow[b]{2}{*}{ Characteristic } & \multicolumn{2}{|c|}{$\begin{array}{c}\text { All Women, } \\
\mathrm{N}=\mathbf{7 7 2 9}\end{array}$} & \multicolumn{2}{|c|}{$\begin{array}{l}\text { DCSI=0, } \\
\text { N= 2968 }\end{array}$} & \multicolumn{2}{|c|}{$\begin{array}{l}\text { DCSI=1, } \\
\mathrm{N}=1009\end{array}$} & \multicolumn{2}{|c|}{$\begin{array}{l}\text { DCSI=2, } \\
\mathbf{N}=\mathbf{1 7 8 8}\end{array}$} & \multicolumn{2}{|c|}{$\begin{array}{l}\text { DCSI } \geq 3, \\
N=1964\end{array}$} \\
\hline & No. & $\%$ & No. & $\%$ & No. & $\%$ & No. & $\%$ & No. & $\%$ \\
\hline \multicolumn{11}{|l|}{ Mammography screening } \\
\hline Annual/biennial & 4463 & 57.7 & 1951 & 65.7 & 654 & 64.8 & 941 & 52.6 & 917 & 46.7 \\
\hline No screening & 3266 & 42.3 & 1017 & 34.3 & 355 & 35.2 & 847 & 47.4 & 1047 & 53.3 \\
\hline \multicolumn{11}{|l|}{ Age group } \\
\hline $67-70$ & 1677 & 21.7 & 774 & 26.1 & 239 & 23.7 & 301 & 16.8 & 363 & 18.5 \\
\hline $71-74$ & 2075 & 26.8 & 858 & 28.9 & 278 & 27.6 & 477 & 26.7 & 462 & 23.5 \\
\hline $75-79$ & 1566 & 20.3 & 572 & 19.3 & 201 & 19.9 & 371 & 20.7 & 422 & 21.5 \\
\hline$>=80$ & 2411 & 31.2 & 764 & 25.7 & 291 & 28.8 & 639 & 35.7 & 717 & 36.5 \\
\hline \multicolumn{11}{|l|}{ Race } \\
\hline White & 5804 & 75.1 & 2271 & 76.5 & 758 & 75.1 & 1373 & 76.8 & 1402 & 71.4 \\
\hline African American & 1370 & 17.7 & 443 & 14.9 & 175 & 17.3 & 303 & 16.9 & 449 & 22.9 \\
\hline Others & 555 & 7.2 & 254 & 8.6 & 76 & 7.5 & 112 & 6.3 & 113 & 5.8 \\
\hline \multicolumn{11}{|l|}{ Progesterone receptor status } \\
\hline Positive & 4840 & 62.6 & 1888 & 63.6 & 658 & 65.2 & 1119 & 62.6 & 1175 & 59.8 \\
\hline Negative & 1957 & 25.3 & 756 & 25.5 & 244 & 24.2 & 435 & 24.3 & 522 & 26.6 \\
\hline Borderline/Unknown & 932 & 12.1 & 324 & 10.9 & 107 & 10.6 & 234 & 13.1 & 267 & 13.6 \\
\hline \multicolumn{11}{|l|}{ Estrogen receptor status } \\
\hline Positive & 5718 & 74.0 & 2243 & 75.6 & 759 & 75.2 & 1313 & 73.4 & 1403 & 71.4 \\
\hline Negative & 1177 & 15.2 & 447 & 15.1 & 155 & 15.4 & 262 & 14.7 & 313 & 15.9 \\
\hline Borderline/Unknown & 834 & 10.8 & 278 & 9.4 & 95 & 9.4 & 213 & 11.9 & 248 & 12.6 \\
\hline \multicolumn{11}{|l|}{ Thyroid syndrome } \\
\hline Yes & 1862 & 24.1 & 592 & 19.9 & 264 & 26.2 & 459 & 25.7 & 547 & 27.9 \\
\hline No & 5867 & 75.9 & 2376 & 80.1 & 745 & 73.8 & 1329 & 74.3 & 1417 & 72.1 \\
\hline \multicolumn{11}{|l|}{ Arthritis } \\
\hline Yes & 2188 & 28.3 & 736 & 24.8 & 313 & 31.0 & 518 & 29.0 & 621 & 31.6 \\
\hline No & 5541 & 71.7 & 2232 & 75.2 & 696 & 69.0 & 1270 & 71.0 & 1343 & 68.4 \\
\hline \multicolumn{11}{|l|}{ Asthma } \\
\hline Yes & 624 & 8.1 & 170 & 5.7 & 73 & 7.2 & 195 & 10.9 & 186 & 9.5 \\
\hline No & 7105 & 91.9 & 2798 & 94.3 & 936 & 92.8 & 1593 & 89.1 & 1778 & 90.5 \\
\hline \multicolumn{11}{|l|}{ COPD } \\
\hline Yes & 1222 & 15.8 & 239 & 8.1 & 118 & 11.7 & 380 & 21.3 & 485 & 24.7 \\
\hline No & 6507 & 84.2 & 2729 & 91.9 & 891 & 88.3 & 1408 & 78.7 & 1479 & 75.3 \\
\hline \multicolumn{11}{|l|}{ Dementia } \\
\hline Yes & 625 & 8.1 & 148 & 5.0 & 66 & 6.5 & 162 & 9.1 & 249 & 12.7 \\
\hline No & 7104 & 91.9 & 2820 & 95.0 & 943 & 93.5 & 1626 & 90.9 & 1715 & 87.3 \\
\hline \multicolumn{11}{|l|}{ Hyperlipidemia } \\
\hline Yes & 5443 & 70.4 & 2046 & 68.9 & 754 & 74.7 & 1242 & 69.5 & 1401 & 71.3 \\
\hline No & 2286 & 29.6 & 922 & 31.1 & 255 & 25.3 & 546 & 30.5 & 563 & 28.7 \\
\hline ...Continued & & & & & & & & & & \\
\hline
\end{tabular}


Table 1: The Baseline Characteristics of the Study Cohort* by Diabetes Complications Severity Index

\begin{tabular}{|c|c|c|c|c|c|c|c|c|c|c|}
\hline \multirow[b]{2}{*}{ Characteristic } & \multicolumn{2}{|c|}{$\begin{array}{c}\text { All Women, } \\
\mathbf{N}=\mathbf{7 7 2 9}\end{array}$} & \multicolumn{2}{|c|}{$\begin{array}{l}\text { DCSI =0, } \\
\text { N= 2968 }\end{array}$} & \multicolumn{2}{|c|}{$\begin{array}{l}\text { DCSI=1, } \\
\mathrm{N}=1009\end{array}$} & \multicolumn{2}{|c|}{$\begin{array}{l}\text { DCSI=2, } \\
N=1788\end{array}$} & \multicolumn{2}{|c|}{$\begin{array}{l}\text { DCSI } \geq 3, \\
N=1964\end{array}$} \\
\hline & No. & $\%$ & No. & $\%$ & No. & $\%$ & No. & $\%$ & No. & $\%$ \\
\hline \multicolumn{11}{|l|}{ Hypertension } \\
\hline Yes & 6936 & 89.7 & 2489 & 83.9 & 919 & 91.1 & 1648 & 92.2 & 1880 & 95.7 \\
\hline No & 793 & 10.3 & 479 & 16.1 & 90 & 8.9 & 140 & 7.8 & 84 & 4.3 \\
\hline \multicolumn{11}{|l|}{ Osteoporosis } \\
\hline Yes & 626 & 8.1 & 219 & 7.4 & 79 & 7.8 & 172 & 9.6 & 156 & 7.9 \\
\hline No & 7103 & 91.9 & 2749 & 92.6 & 930 & 92.2 & 1616 & 90.4 & 1808 & 92.1 \\
\hline \multicolumn{11}{|l|}{ Anxiety } \\
\hline Yes & 767 & 9.9 & 217 & 7.3 & 115 & 11.4 & 200 & 11.2 & 235 & 12.0 \\
\hline No & 6962 & 90.1 & 2751 & 92.7 & 894 & 88.6 & 1588 & 88.8 & 1729 & 88.0 \\
\hline \multicolumn{11}{|l|}{ Depression } \\
\hline Yes & 1221 & 15.8 & 340 & 11.5 & 172 & 17.0 & 311 & 17.4 & 398 & 20.3 \\
\hline No & 6508 & 84.2 & 2628 & 88.5 & 837 & 83.0 & 1477 & 82.6 & 1566 & 79.7 \\
\hline \multicolumn{11}{|l|}{ PCP visit } \\
\hline Yes & 7301 & 94.5 & 2743 & 92.4 & 958 & 94.9 & 1714 & 95.9 & 1886 & 96.0 \\
\hline No & 428 & 5.5 & 225 & 7.6 & 51 & 5.1 & 74 & 4.1 & 78 & 4.0 \\
\hline \multicolumn{11}{|l|}{ Endocrinologist visit } \\
\hline Yes & 919 & 11.9 & 252 & 8.5 & 143 & 14.2 & 198 & 11.1 & 326 & 16.6 \\
\hline No & 6810 & 88.1 & 2716 & 91.5 & 866 & 85.8 & 1590 & 88.9 & 1638 & 83.4 \\
\hline \multicolumn{11}{|c|}{ Availability of BC screening centers } \\
\hline Yes & 3661 & 47.4 & 1408 & 47.4 & 470 & 46.6 & 856 & 47.9 & 927 & 47.2 \\
\hline No & 4068 & 52.6 & 1560 & 52.6 & 539 & 53.4 & 932 & 52.1 & 1037 & 52.8 \\
\hline \multicolumn{11}{|c|}{ Census tract education percentage } \\
\hline $0-13.29 \%$ & 1614 & 20.9 & 589 & 19.8 & 206 & 20.4 & 387 & 21.6 & 432 & 22.0 \\
\hline $13.30 \%-22.83 \%$ & 1773 & 22.9 & 703 & 23.7 & 215 & 21.3 & 387 & 21.6 & 468 & 23.8 \\
\hline $22.84 \%-38.55 \%$ & 1499 & 19.4 & 587 & 19.8 & 205 & 20.3 & 343 & 19.2 & 364 & 18.5 \\
\hline$>38.55 \%$ & 1251 & 16.2 & 502 & 16.9 & 168 & 16.7 & 298 & 16.7 & 283 & 14.4 \\
\hline Missing & 1592 & 20.6 & 587 & 19.8 & 215 & 21.3 & 373 & 20.9 & 417 & 21.2 \\
\hline \multicolumn{11}{|c|}{ Census tract household median income } \\
\hline$<\$ 25,000$ & 488 & 6.4 & 178 & 6.0 & 62 & 6.2 & 106 & 6.0 & 142 & 7.3 \\
\hline$\$ 25,001-50,000$ & 3327 & 43.3 & 1245 & 42.2 & 446 & 44.7 & 751 & 42.2 & 885 & 45.4 \\
\hline$\$ 50,001-75,000$ & 2447 & 31.9 & 974 & 33.0 & 314 & 31.5 & 555 & 31.2 & 604 & 31.0 \\
\hline$>\$ 75,000$ & 1413 & 18.4 & 553 & 18.7 & 175 & 17.6 & 366 & 20.6 & 319 & 16.4 \\
\hline \multicolumn{11}{|l|}{ SEER region } \\
\hline Northeast & 1336 & 17.3 & 494 & 16.6 & 174 & 17.2 & 344 & 19.2 & 324 & 16.5 \\
\hline South & 2346 & 30.4 & 835 & 28.1 & 288 & 28.5 & 561 & 31.4 & 662 & 33.7 \\
\hline North-central & 1332 & 17.2 & 527 & 17.8 & 188 & 18.6 & 283 & 15.8 & 334 & 17.0 \\
\hline West & 2715 & 35.1 & 1112 & 37.5 & 359 & 35.6 & 600 & 33.6 & 644 & 32.8 \\
\hline
\end{tabular}


Table 1: The Baseline Characteristics of the Study Cohort* by Diabetes Complications Severity Index

\begin{tabular}{|c|c|c|c|c|c|c|c|c|c|c|}
\hline \multirow[b]{2}{*}{ Characteristic } & \multicolumn{2}{|c|}{$\begin{array}{c}\text { All Women, } \\
\text { N=7729 }\end{array}$} & \multicolumn{2}{|c|}{$\begin{array}{l}\text { DCSI }=0, \\
N=2968\end{array}$} & \multicolumn{2}{|c|}{$\begin{array}{l}\text { DCSI=1, } \\
N=1009\end{array}$} & \multicolumn{2}{|c|}{$\begin{array}{l}\text { DCSI }=2, \\
N=1788\end{array}$} & \multicolumn{2}{|c|}{$\begin{array}{l}\mathrm{DCSI} \geq 3, \\
\mathrm{~N}=1964\end{array}$} \\
\hline & No. & $\%$ & No. & $\%$ & No. & $\%$ & No. & $\%$ & No. & $\%$ \\
\hline \multicolumn{11}{|c|}{ Metropolitan status } \\
\hline Metro & 6131 & 79.3 & 2315 & 78.0 & 821 & 81.4 & 1420 & 79.4 & 1575 & 80.2 \\
\hline Urban & 1391 & 18.0 & 573 & 19.3 & 161 & 16.0 & 324 & 18.1 & 333 & 17.0 \\
\hline Rural & 205 & 2.7 & 79 & 2.7 & 27 & 2.7 & 44 & 2.5 & 55 & 2.8 \\
\hline
\end{tabular}

*A cohort of 7,729 elderly women with incident breast cancer and pre-existing DM using SEER-Medicare dataset 2004-2011.

DCSI = Diabetes complications severity index PCP $=$ Primary care providers;

COPD = Chronic Obstructive Pulmonary Disorder; SEER = Surveillance, Epidemiology, and End Results; BC = Breast cancer. 
Table 2: Description of Elderly Women with Incident Breast Cancer and Pre-existing Diabetes mellitus by Stage at Diagnosis, SEER-Medicare 2004-2011 cases

\begin{tabular}{|c|c|c|c|c|c|c|c|c|c|c|}
\hline \multirow[b]{2}{*}{ Variables } & & \multicolumn{2}{|c|}{ Stage 0} & \multicolumn{2}{|c|}{ Stage I } & \multicolumn{2}{|c|}{ Stage II } & \multicolumn{2}{|c|}{ Stage III/IV } & \multirow[b]{2}{*}{ sig } \\
\hline & & $\mathbf{N}$ & $\%$ & $\mathbf{N}$ & $\%$ & $\mathbf{N}$ & $\%$ & $\mathbf{N}$ & $\%$ & \\
\hline Total & & 1161 & 100 & 2968 & 100 & 2246 & 100 & 1354 & 100 & \\
\hline \multirow[t]{5}{*}{ DCSI } & & & & & & & & & & $* * *$ \\
\hline & DCSI $=0$ & 510 & 43.9 & 1173 & 39.5 & 818 & 36.4 & 467 & 34.5 & \\
\hline & DCSI $=1$ & 168 & 14.5 & 413 & 13.9 & 274 & 12.2 & 154 & 11.4 & \\
\hline & $\mathrm{DCSI}=2$ & 231 & 19.9 & 688 & 23.2 & 541 & 24.1 & 328 & 24.2 & \\
\hline & $\mathrm{DCSI} \geq 3$ & 252 & 21.7 & 694 & 23.4 & 613 & 27.3 & 405 & 29.9 & \\
\hline \multicolumn{2}{|c|}{ Mammography screening } & & & & & & & & & $* * *$ \\
\hline & Annual/biennial & 956 & 82.3 & 2133 & 71.9 & 1005 & 44.7 & 369 & 27.3 & \\
\hline & No screening & 205 & 17.7 & 835 & 28.1 & 1241 & 55.3 & 985 & 72.7 & \\
\hline \multicolumn{2}{|l|}{ Age group } & & & & & & & & & $* * *$ \\
\hline & $67-70$ & 317 & 27.3 & 666 & 22.4 & 448 & 19.9 & 246 & 18.2 & \\
\hline & $71-74$ & 367 & 31.6 & 803 & 27.1 & 565 & 25.2 & 340 & 25.1 & \\
\hline & $75-79$ & 213 & 18.3 & 629 & 21.2 & 457 & 20.3 & 267 & 19.7 & \\
\hline & $>=80$ & 264 & 22.7 & 870 & 29.3 & 776 & 34.6 & 501 & 37.0 & \\
\hline \multirow[t]{4}{*}{ Race } & & & & & & & & & & $* * *$ \\
\hline & White & 809 & 69.7 & 2339 & 78.8 & 1683 & 74.9 & 973 & 71.9 & \\
\hline & African American & 265 & 22.8 & 423 & 14.3 & 400 & 17.8 & 282 & 20.8 & \\
\hline & Others & 87 & 7.5 & 206 & 6.9 & 163 & 7.3 & 99 & 7.3 & \\
\hline \multicolumn{3}{|c|}{ Progesterone receptor status } & & & & & & & & $* * *$ \\
\hline & Positive & 586 & 50.5 & 2121 & 71.5 & 1440 & 64.1 & 693 & 51.2 & \\
\hline & Negative & 221 & 19.0 & 635 & 21.4 & 647 & 28.8 & 454 & 33.5 & \\
\hline & Borderline/Unknown & 354 & 30.5 & 212 & 7.1 & 159 & 7.1 & 207 & 15.3 & \\
\hline \multicolumn{2}{|c|}{ Estrogen receptor status } & & & & & & & & & $* * *$ \\
\hline & Positive & 707 & 60.9 & 2453 & 82.6 & 1704 & 75.9 & 854 & 63.1 & \\
\hline & Negative & 142 & 12.2 & 329 & 11.1 & 401 & 17.9 & 305 & 22.5 & \\
\hline & Borderline/Unknown & 312 & 26.9 & 186 & 6.3 & 141 & 6.3 & 195 & 14.4 & \\
\hline \multirow[t]{3}{*}{ Thyroid } & & & & & & & & & & $* * *$ \\
\hline & Yes & 281 & 24.2 & 768 & 25.9 & 548 & 24.4 & 265 & 19.6 & \\
\hline & No & 880 & 75.8 & 2200 & 74.1 & 1698 & 75.6 & 1089 & 80.4 & \\
\hline \multirow[t]{3}{*}{ Arthritis } & & & & & & & & & & $*$ \\
\hline & Yes & 287 & 24.7 & 854 & 28.8 & 645 & 28.7 & 402 & 29.7 & \\
\hline & No & 874 & 75.3 & 2114 & 71.2 & 1601 & 71.3 & 952 & 70.3 & \\
\hline \multicolumn{11}{|l|}{ Asthma } \\
\hline & Yes & 93 & 8.0 & 257 & 8.7 & 187 & 8.3 & 87 & 6.4 & \\
\hline & No & 1068 & 92.0 & 2711 & 91.3 & 2059 & 91.7 & 1267 & 93.6 & \\
\hline
\end{tabular}


Table 2: Description of Elderly Women with Incident Breast Cancer and Pre-existing Diabetes mellitus by Stage at Diagnosis, SEER-Medicare 2004-2011 cases

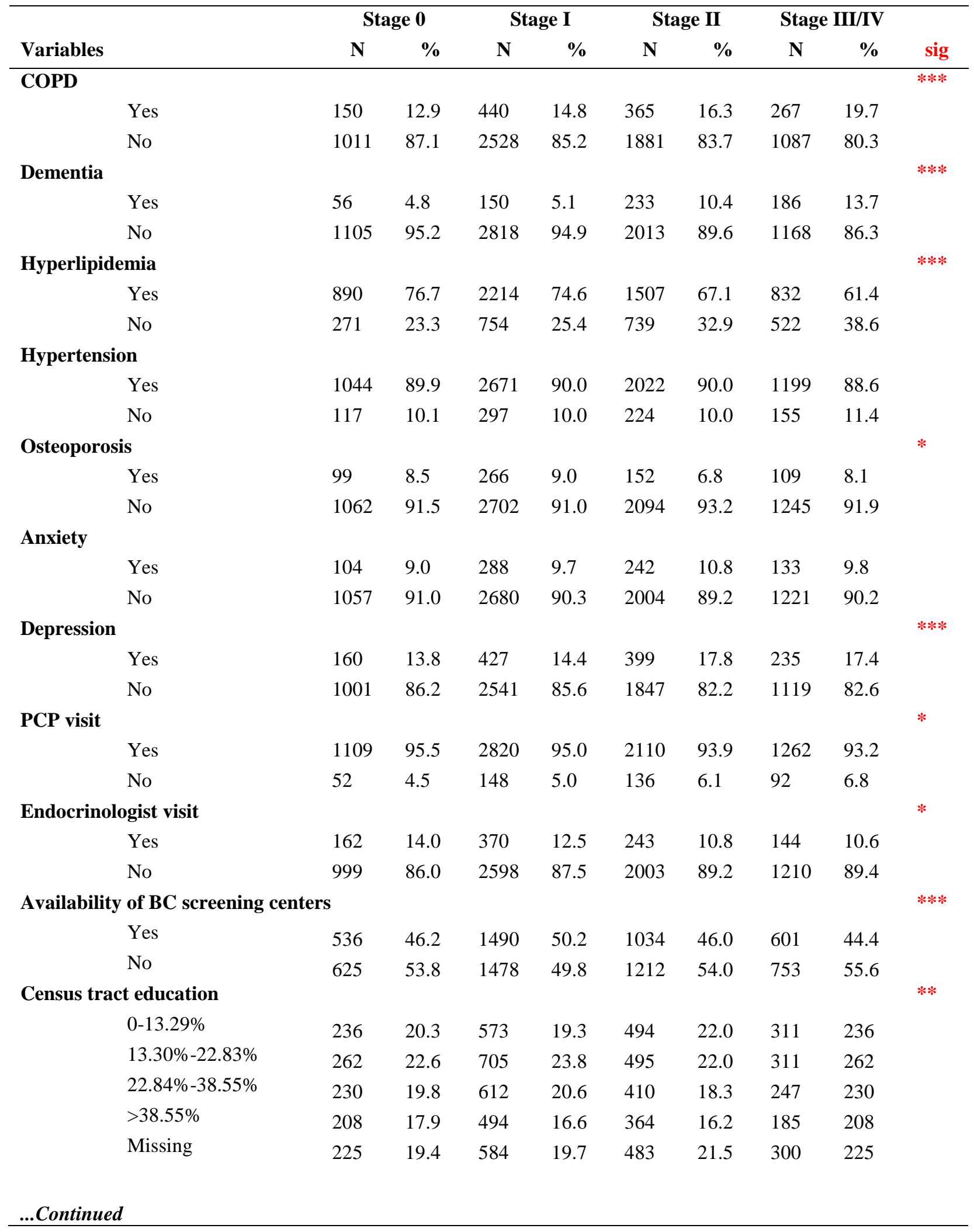


Table 2: Description of Elderly Women with Incident Breast Cancer and Pre-existing Diabetes mellitus by Stage at Diagnosis, SEER-Medicare 2004-2011 cases

\begin{tabular}{|c|c|c|c|c|c|c|c|c|c|}
\hline \multirow[b]{2}{*}{ Variables } & \multicolumn{2}{|c|}{ Stage 0} & \multicolumn{2}{|c|}{ Stage I } & \multicolumn{2}{|c|}{ Stage II } & \multicolumn{2}{|c|}{ Stage III/IV } & \multirow[b]{2}{*}{ sig } \\
\hline & $\mathbf{N}$ & $\%$ & $\mathbf{N}$ & $\%$ & $\mathbf{N}$ & $\%$ & $\mathbf{N}$ & $\%$ & \\
\hline Census tract household income & & & & & & & & & $*$ \\
\hline$<\$ 25,000$ & 72 & 6.3 & 174 & 5.9 & 142 & 6.4 & 100 & 7.5 & \\
\hline$\$ 25,001-50,000$ & 490 & 42.5 & 1245 & 42.2 & 977 & 43.7 & 615 & 45.9 & \\
\hline$\$ 50,001-75,000$ & 360 & 31.3 & 953 & 32.3 & 716 & 32.0 & 418 & 31.2 & \\
\hline$>\$ 75,000$ & 230 & 20.0 & 576 & 19.5 & 400 & 17.9 & 207 & 15.4 & \\
\hline \multicolumn{10}{|l|}{ SEER region } \\
\hline Northeast & 194 & 16.7 & 492 & 16.6 & 393 & 17.5 & 257 & 19.0 & \\
\hline South & 338 & 29.1 & 897 & 30.2 & 679 & 30.2 & 432 & 31.9 & \\
\hline North-central & 225 & 19.4 & 503 & 16.9 & 374 & 16.7 & 230 & 17.0 & \\
\hline West & 404 & 34.8 & 1076 & 36.3 & 800 & 35.6 & 435 & 32.1 & \\
\hline \multicolumn{10}{|l|}{ Metropolitan status } \\
\hline Metro & 940 & 81.0 & 2321 & 78.2 & 1782 & 79.3 & 1088 & 80.4 & \\
\hline Urban & 195 & 16.8 & 562 & 18.9 & 400 & 17.8 & 234 & 17.3 & \\
\hline Rural & 26 & 2.2 & 84 & 2.8 & 64 & 2.8 & 31 & 2.3 & \\
\hline
\end{tabular}

DCSI $=$ Diabetes complications severity index $\mathrm{PCP}=$ Primary care providers; $\mathrm{COPD}=$ Chronic Obstructive Pulmonary Disorder; SEER $=$ Surveillance, Epidemiology, and End Results; BC $=$ Breast cancer; DM $=$ Diabetes mellitus.

Asterisks represent statistically significant group differences based on $\chi 2$ tests by stage of $\mathrm{BC}$ at diagnosis:

$* * * \mathrm{p}<0.001 ; * * 0.001<\mathrm{p}<0.01 ; * 0.01<\mathrm{p}<0.05$ 
Table 3: Association of Diabetes Complication Severity Index with Breast Cancer Stage at Diagnosis among Elderly women with pre-existing Diabetes mellitus

\begin{tabular}{|c|c|c|c|c|c|c|c|c|c|}
\hline \multirow[b]{2}{*}{ Variables } & \multicolumn{3}{|c|}{ Stage I } & \multicolumn{3}{|c|}{ Stage II } & \multicolumn{3}{|c|}{ Stage III/IV } \\
\hline & OR & $95 \% \mathrm{CI}$ & Sig & OR & $95 \% \mathrm{CI}$ & Sig & OR & $95 \% \mathrm{CI}$ & Sig \\
\hline \multicolumn{10}{|l|}{ Model 1} \\
\hline \multicolumn{10}{|l|}{ DCSI } \\
\hline DCSI $=0$ & Ref & & & & & & & & \\
\hline DCSI $=1$ & 1.06 & {$[0.86,1.30]$} & & 1.01 & {$[0.81,1.26]$} & & 0.99 & {$[0.77,1.28]$} & \\
\hline DCSI $=2$ & 1.30 & {$[1.08,1.56]$} & $* *$ & 1.45 & {$[1.20,1.76]$} & $* * *$ & 1.57 & {$[1.27,1.93]$} & $* * *$ \\
\hline DCSI $\geq 3$ & 1.20 & {$[1.00,1.43]$} & $*$ & 1.50 & {$[1.25,1.81]$} & $* * *$ & 1.77 & {$[1.45,2.17]$} & $* * *$ \\
\hline \multicolumn{10}{|l|}{ Model 2} \\
\hline \multicolumn{10}{|l|}{ DCSI } \\
\hline DCSI $=0$ & Ref & & & & & & & & \\
\hline DCSI $=1$ & 1.05 & {$[0.84,1.31]$} & & 0.99 & {$[0.79,1.25]$} & & 1.00 & {$[0.77,1.30]$} & \\
\hline DCSI $=2$ & 1.32 & {$[1.09,1.61]$} & $* *$ & 1.42 & {$[1.16,1.74]$} & $* * *$ & 1.46 & {$[1.17,1.83]$} & $* * *$ \\
\hline DCSI $\geq 3$ & 1.27 & {$[1.05,1.54]$} & $*$ & 1.47 & {$[1.20,1.80]$} & $* * *$ & 1.62 & {$[1.30,2.01]$} & $* * *$ \\
\hline \multicolumn{10}{|l|}{ Model 3} \\
\hline \multicolumn{10}{|l|}{ DCSI } \\
\hline $\mathrm{DCSI}=0$ & Ref & & & & & & & & \\
\hline $\mathrm{DCSI}=1$ & 1.05 & {$[0.84,1.31]$} & & 0.98 & {$[0.77,1.25]$} & & 0.97 & {$[0.74,1.29]$} & \\
\hline DCSI $=2$ & 1.26 & {$[1.03,1.53]$} & $*$ & 1.22 & {$[0.99,1.51]$} & & 1.17 & {$[0.93,1.48]$} & \\
\hline DCSI $\geq 3$ & 1.18 & {$[0.97,1.44]$} & & 1.17 & {$[0.95,1.44]$} & & 1.16 & {$[0.92,1.46]$} & \\
\hline \multicolumn{10}{|c|}{ Mammography screening } \\
\hline $\begin{array}{l}\text { Annual/biennial } \\
\text { No screening }\end{array}$ & $\begin{array}{l}0.56 \\
\text { Ref }\end{array}$ & {$[0.47,0.67]$} & $* * *$ & 0.19 & {$[0.16,0.23]$} & $* * *$ & 0.09 & {$[0.08,0.11]$} & $* * *$ \\
\hline
\end{tabular}

DCSI $=$ Diabetes complications severity index; $\mathrm{BC}=$ Breast cancer; $\mathrm{OR}=$ Odds ratio; AOR, adjusted odds ratio; $\mathrm{CI}$ $=$ Confidence intervals.

Model 1 contains DCSI only. Model 2 contains DCSI plus age, race. progesterone receptor status, estrogen receptor status, comorbid conditions (thyroid, arthritis, COPD, dementia, hyperlipidemia, osteoporosis, and depression), PCP visit, endocrinologist visit, availability of mammography screening centers, census tract education, and census tract household income. Model 3 contains Model 2 plus mammography screening.

Odds ratios and $95 \% \mathrm{CI}$ from the multinomial logistic regression models

Asterisks represent statistically significant group differences compared with the reference group:

$* * * \mathrm{p}<.001 ; * * .001<\mathrm{p}<.01 ; * .01<\mathrm{p}<.05$ 


\section{CHAPTER FOUR}

"The Severity of Diabetes Complications in Relation to All-cause Mortality in Elderly Women with pre-exiting Diabetes and Incident Breast Cancer" 


\begin{abstract}
Objective: Since pre-existing diabetes has been associated with increased risk of all-cause mortality in incident breast cancer (BC) cases, it is prudent to investigate how diabetes-related complications and diabetes severity contribute to its impact on all-cause mortality of newly diagnosed $\mathrm{BC}$ cases. Therefore, the aim of this study was to explore the relationship between severity of diabetes complications and all-cause mortality in elderly women diagnosed with BC and pre-existing diabetes.
\end{abstract}

Methods: Using the linked SEER-Medicare data, we included a cohort of women age $\geq 67$ years diagnosed with $\mathrm{BC}$ from 2007 to 2011 and having pre-existing diabetes $(\mathrm{N}=4,307)$ among Medicare beneficiaries who were continuously enrolled in Parts A and B 24 months before BC diagnosis and 6 months after $\mathrm{BC}$ diagnosis, and were continuously enrolled in Part $\mathrm{D}$ three months after BC diagnosis. Chi-square tests were used to test for significant difference in 3-years all-cause mortality based on severity of diabetes complications and other independent variables. Unadjusted and adjusted Cox proportional hazards models were used to estimate hazards ratios (HR) of all-cause mortality within 3 years of BC diagnosis based on severity of diabetes-related complications controlling for antidiabetic medication, cancer characteristics, patients-related factors and cancer treatment.

Results: Adjusting for all available covariates among elderly women with pre-existing diabetes and incident $\mathrm{BC}$, severity of diabetes complication was significantly associated with all-cause mortality within three years of $\mathrm{BC}$ diagnosis. Women with a DCSI $=1$, DCSI $=2$, and DCSI $\geq 3$ had $34 \%(\mathrm{HR}=1.34 ; 95 \% \mathrm{CI}=1.02-1.75), 69 \%(\mathrm{HR}=1.69 ; 95 \% \mathrm{CI}=1.39-2.05)$, and $124 \%$ 
$(\mathrm{HR}=2.24 ; 95 \% \mathrm{CI}=1.86-2.70)$ increased risk of death within 3 years after $\mathrm{BC}$ diagnosis, respectively, as compared to those without diabetes complications.

Conclusions: Our findings suggest that severity of diabetes-related complications increase the risk of all-cause mortality of incidence breast cancer in elderly women with pre-existing diabetes. The continuum of diabetes care to control its complications after $\mathrm{BC}$ diagnosis along with cancer care is necessary to reduce mortality rates in incident BC cases with pre-existing diabetes.

Keywords: All-cause mortality, Breast cancer, Diabetes, Diabetes Complications Severity Index 


\section{INTRODUCTION}

Elderly women with diabetes are burdened with aging process, disease complexity, comorbid conditions, and diabetes-related complications that are negatively impact their health outcomes (Laiteerapong, Huang, \& Chin, 2011). Past studies have shown that diabetes-related complications are the major cause of deaths among individuals with diabetes (Cusick et al., 2005). A study by Cusick et al showed that the risk of mortality increases as the degree of diabetes complications worsens (Cusick et al., 2005)

Also, elderly women with diabetes are at elevated risk of incident breast cancer (BC) through its direct pathophysiological effects and by its negative impact on BC screening use (Bernard et al., 2016; Onitilo et al., 2014). Approximately $16 \%$ of elderly women with BC have pre-existing diabetes (Wolf et al., 2005). Diabetes is also associated with high mortality rate after $\mathrm{BC}$ diagnosis among women with diabetes as compared to women without diabetes (Barone et al., 2008; Cleveland et al., 2012; De Bruijn et al., 2013; Lam et al., 2011). Both age and diabetes are associated with decreased overall survival in elderly with incident breast cancer (Patnaik et al., 2011). A meta-analyses by Peairs et al demonstrated that diabetes was associated with a $49 \%$ increase in risk of all-cause mortality among women with BC (Peairs et al., 2011).

Although the severity of diabetes complications could contribute to higher mortality among women with diabetes, little is known about the impact of severity of diabetes-related complications on risk of all-cause mortality among incident BC cases. Evidence from previous literature has revealed that the presence of some diabetes complications could affect cancer therapy (Morsy \& Heeba, 2016; Peairs et al., 2011; Volkova \& Russell, 2011), which could 
impact patients' health outcomes. However, there are limited evidence in the literature on the direct impact of overall severity of diabetes-related complications on all-cause mortality of incident $\mathrm{BC}$ after controlling for cancer therapy and other possible risk factors.

Therefore, the objective of this study was to evaluate the relationship between sev erity of diabetes complications and all-cause mortality among elderly women with incident BC and pre-existing diabetes.

\section{Conceptual framework}

We used the model of comorbidity and cancer (Geraci et al., 2005) to guide our study. This model is useful to assess the potential impact of pre-existing specific comorbidity on cancer prognosis (e.g. survival and mortality) based on multivariable analyses (Geraci et al., 2005). This model has been widely used and validated among patients with breast, ovarian, and pancreatic cancers (Du et al., 2002; Hershman et al., 2004; Krzyzanowska, Weeks, \& Earle, 2003).The model assumes that the overall likelihood of survival of patients with cancer decreases as the burden of comorbid conditions increases (Piccirillo et al., 2004). Based on this model, all-cause mortality of incident $\mathrm{BC}$ was predicted by burden of pre-existing diabetes, which was measured by diabetes complications severity index (DCSI) controlling for the characteristics of incident $\mathrm{BC}$, patient factors, and cancer treatment.

\section{RESEARCH DESIGN AND METHODS}

\section{Study Design \& Data Source}

This was a retrospective cohort study in elderly women with incident BC diagnosis and pre-existing diabetes using the linked SEER-Medicare dataset. 
The SEER program is supported by the National Cancer Institute (NCI) to collect data from cancer registries including all incident cases of cancer that occur in SEER areas (Hellman, 1997). For each incident cancer identified, the SEER program collects information in a customized file known as the Patient Entitlement and Diagnosis Summary File (PEDSF) which contains demographic features, date of cancer diagnosis, cancer site, method of diagnosis, and state of residence. PEDSF file has been linked with Medicare data files using an algorithm based on the social security number, last name, first name and date of birth of an individual. Medicare claims files consists of Medicare Provider Analysis and Review (MEDPAR), the Carrier Claims (old name Physician/Supplier (NCH)), Outpatient (OUTPT), Home Health Agencies (HHA), Hospice, Durable Medical Equipment (DME) and Part D Event (PDE) files. Based on the linkage, a common identification number is given to each enrollee in PEDSF and claims files. We also linked the Area Resource File (ARF) to the SEER-Medicare dataset using the state and county Federal Information Processing Standards code for each beneficiary to extract the county level information on the availability of mammography facilities and oncology centers in women's area of residence.

\section{Study Cohort}

The study was conducted in a cohort of women of 67 years or older with the first primary diagnosis of incident BC between January 1, 2007 and December 31, 2011 who had pre-existing diabetes. Figure 1 shows the flow chart to obtain final study cohort. Eligible Medicare beneficiaries were continuously enrolled in Medicare Part A and B fee-for-service programs at least 24 months before $\mathrm{BC}$ diagnosis and 6 months after $\mathrm{BC}$ diagnosis, and they were continuously enrolled in Part D at least 3 months after BC diagnosis. Also, they must have no enrollment in health maintenance organization (HMO) at any time during the study period. Pre- 
existing diabetes was determined based on either a single inpatient claim or at least two outpatient claims diagnoses with International Classification of Diseases, Ninth Edition, Clinical Modification (ICD-9-CM) diagnosis code of 250.xx during the 24-month that preceded BC diagnosis. Women whose $\mathrm{BC}$ was diagnosed via a death certificate or autopsy, or who were with any previous cancer diagnosis were excluded from the study cohort.

\section{Measures}

\section{Outcome variable}

The study outcome was all-cause mortality that included breast cancer-specific mortality, diabetes-specific mortality and mortality from other causes (Patnaik et al., 2011). All-cause mortality is the most commonly used outcome for research on cancer survivorship (Patnaik et al., 2011) because it is not affected by bias in classifying cause of death in comparison to diseasespecific mortality (Black, Haggstrom, \& Welch, 2002; Hanna et al., 2012). The study cohort was followed to death or to the end of third year after BC diagnosis, whichever occurred first. Observations were censored for women who were alive more than 3 years after BC diagnosis.

\section{Key independent variable}

The main predictor of all-cause mortality in this study was the diabetes severity which was identified during the 12 months before BC diagnosis. The severity of diabetes-related complications was measured by end-organ damage of diabetes using the diabetes comorbidity severity index (DCSI). The DCSI was first developed by Young and colleagues to include 7 categories of diabetes complications: cardiovascular disease, nephropathy, retinopathy, peripheral vascular disease, cerebrovascular, neuropathy, and metabolic complications. Theses complications were identified using International Classification of Diseases, Ninth Edition, 
Clinical Modification (ICD-9-CM) diagnosis code to represent gradations of the diabetes complications severity (Young et al., 2008). The index for each complication was categorized into 2 or 3 levels (no abnormality $=0$, some abnormality $=1$, and severe abnormality $=2$ ), based on the presence and severity of the complication, and the indices of all complications were added together to get the DCSI which is a 13-point scale with a range of 0-13 (Chang et al., 2012a; Young et al., 2008). The study cohort was divided into 4 subgroups consisting of DCSI=0, DCSI $=1$, DCSI $=2$, and DCSI $\geq 3$.

\section{Other independent variables}

The variables were classified based on the model of comorbidity and cancer into the characteristics of incident BC, patient's factors, and cancer treatment.

The characteristics of incident BC are BC stage at diagnosis and HR status. Stage of BC at diagnosis was identified based on the American Joint Committee on Cancer's staging system. Stage at diagnosis (0-IV) of the cancer/tumor was taken from the SEER PEDSF file. For the study purpose, we grouped out cohorts into two categories: women with early stage diagnosis (stages 0 , I \& II) and women with advanced stage diagnosis (stages III \& IV) of BC. HR status (progesterone and estrogen) was categorized into positive, negative, and borderline/unknown.

Patient factors included age at diagnosis, race, SEER areas, metropolitan status, Census tract education percentage, Census tract median household income, pre-existing comorbidities, and diabetes medications. Age was categorized into 67-70, 71-74, 75-79, and 80+. Race was categorized into white, African-American, and others. SEER regions were Northeast, South, North Central, and West. Metropolitan status of patients' residence was classified as metro, urban, and rural. Census tract education percentage was measured by the census tract survey of percent of people age $>25$ with at least 4 years of college education. Census tract education 
percentage was divided into four categories: $0-13.29 \%, 13.30 \%-22.83 \%, 22.84 \%-38.55 \%$, and $>38.55 \%$. Income was measured by census tract survey of median income and was also divided into four categories: $<\$ 25,000, \$ 25,001-50,000, \$ 50,001-75,000$, and $>\$ 75,000$. Pre-existing comorbidities was identified during the 12 months before $\mathrm{BC}$ diagnosis through the presence or absence of the certain chronic conditions: thyroid syndrome, arthritis, asthma, chronic obstructive pulmonary disorder (COPD), dementia, hyperlipidemia, hypertension, osteoporosis, anxiety, and depression. We also include antidiabetic medications: metformin use (yes/no), insulin use (yes/no), and sum of other oral diabetes medications (ODMs) $(0,1$, or $\geq 2$ medications). These other diabetes medications included sulfonylureas, thiazolidinediones, meglitinides, alpha-glucosidase, glucagonlike peptide-1 agonists, dipeptidyl peptidase IV inhibitors, amylinomimetics, bile acid sequestrates, and dopamine agonists. Women were defined as users of any of diabetes medication including insulin, metformin and ODMs during the baseline period if they had $\geq 1$ dispensing of a medication during the first 3 months after the incident BC diagnosis. These medications were identified from Part D claims using generic names.

Cancer treatment was identified from MEDPAR, Outpatient, and NCH data files using ICD-9 diagnostic and procedure, and Current Procedural Terminology/ Healthcare Common Procedure Coding System (CPT/HCPCS) which was discussed in previous research (LeMasters, Madhavan, \& Sambamoorthi, 2016) . These codes were used to determine whether a woman had received chemotherapy, radiation or had undergone any surgery within 180 days from the date of $\mathrm{BC}$ diagnosis. We also controlled for primary care providers (PCPs) visits, endocrinologist visits, and oncologist visits. We defined PCPs as providers who had the following specialties: general practice, family medicine, primary care internal medicine, geriatric medicine, and obstetrics and 
gynecology. PCPs visits, endocrinologist visits, and oncologist visits were measured during the 6 months after BC diagnosis. PCPs visits and endocrinologist visits were categorized into dichotomous group: yes (having at least one visit during the 6 months after BC diagnosis) or no. Oncologist visits was divided into $0-10,11-20$, and $\geq 20$ visits.

\section{Statistical Analyses}

Descriptive analyses were performed for all study variables as mean and standard deviation $(\mathrm{SD})$ or frequencies and percentages. Chi-square tests of general associations were used to test for significant group differences between independent measures and women who were dead or alive 3 years after $\mathrm{BC}$ diagnosis, with significance level at $P \leq 0.05$. Cox proportional hazards regression models were used to estimate the risk of death at any time within 3 years of $\mathrm{BC}$ diagnosis based on the index of diabetes-related complications, adjusting for other independent variables. Patients with incident $\mathrm{BC}$ and pre-existing diabetes were considered at risk from baseline (the 12-months period that preceded BC diagnosis), and then they were followed till the death or the end of third year whichever comes first. Parameter estimates calculated in the regression models were presented as unadjusted and adjusted hazard ratios (HR) with their corresponding 95\% confidence intervals (CI). All analyses were conducted using SAS version 9.4 software (SAS Institute Inc., Cary, NC).

\section{RESULTS}

\section{Cohort Characteristics}

Among elderly women with incident BC (2007-2011) and pre-existing diabetes, the average time-to-death was $874.61(S D= \pm 535.63)$ days and the average diabetes complications severity index was $1.46(S D= \pm 1.76)$. Characteristics of the 4,307 women with incident $\mathrm{BC}$ and pre-existing diabetes are described in details in Table 1 . The majority of women in the cohort were white $(73.8 \%)$, diagnosed with early stages $(0$, I, \& II) of BC (85.1\%), had no diabetes 
complications (45.8\%), had positive progesterone HR status (65.0\%) and positive estrogen HR status (76.4\%), lived in metro areas (77.8\%), lived in areas with availability of oncology treatment centers (68.9\%), lived in areas where the average annual income was greater than $\$ 25,000(90.0 \%)$, and lived in areas where $13.3 \%$ or more of the population was college educated (72.6\%). Regarding pre-existing comorbidities, most of the women had hyperlipidemia (69.9\%), and hypertension (87.7\%), while $27.4 \%$ had arthritis, $23.8 \%$ had thyroid syndrome, 15.3\% had depression, $14.6 \%$ had COPD, $10.1 \%$ had anxiety, $8.4 \%$ had asthma, $8.3 \%$ had dementia, and 7.8\% had osteoporosis. For the visits to physicians in the first 6 months after BC diagnosis, most women had at least one PCP visit (78.3\%), had at least 11 oncologist visits (75.6\%), and had no endocrinologist visit (90.8\%). The most frequent diabetes-related complications were cardiovascular complications (39.6\%), nephropathy (17.9\%), neuropathy (11.9\%), while metabolic complications (0.7\%), retinopathy (4.4\%), cerebrovascular complications (7.4\%), and peripheral vascular disease (8.5\%) were less frequent among incident cases of $\mathrm{BC}$ with pre-existing diabetes. Most of women with incident $\mathrm{BC}$ and pre-existing diabetes had received surgical treatment in the first 6 months after BC diagnosis (86.0\%), 36\% had received radiation while only $18 \%$ had received chemotherapy. There were 1021 (23.7\%) women who used insulin in the first 3 months after BC diagnosis, 1490 (34.6\%) used metformin, and 1744 (40.5\%) used at least one of the other oral diabetes medications. Compared with women who had no diabetes complications ( $\mathrm{DCSI}=0$ ), those with $\mathrm{DCSI} \geq 3$ were older, more likely to use insulin, less likely to use metformin, less likely to use ODMs, less likely to receive radiotherapy, more likely to have $\mathrm{PCP}$ visits, and more likely to have other pre-existing comorbid conditions (thyroid syndrome, arthritis, COPD, dementia, hypertension, and depression). 


\section{Group Differences by 3-Year Mortality}

Table 2 shows the group differences in all the independent variables by 3 -year mortality. Among a cohort of women with incident BC and pre-existing diabetes, $21.8 \%$ died by the end of three years after BC diagnosis. The variables that were significantly different between women who died within 3 years after BC diagnosis, and those who were alive by the end of the third year included severity of diabetes-related complications, insulin use, metformin use, age, race, stage of BC at diagnosis, HR status, chemotherapy reception, radiation reception, surgery, endocrinologist visit, number of oncologists visits, availability of oncology treatment centers, and SEER regions. The pre-existing comorbid conditions that were significantly associated with 3-year all-cause mortality included asthma, COPD, dementia, hyperlipidemia, anxiety, and depression.

Severity of Diabetes Complications and 3-year All-cause Mortality

Among women who died within the first 3 years after BC diagnosis, a higher proportion $(37.6 \%)$ had highest severity of diabetes complication (DCSI $\geq 3)$ as compared to those who were still alive 3 years after BC diagnosis (17.3\%). In contrast, a lower proportion of women who died within 3 years after BC diagnosis were without diabetes complications as compared to those who were still alive 3 years after BC diagnosis (29.4\% vs. $50.4 \%)$.

Other independent variables and 3-year All-cause Mortality

Among women who died within three years after BC, the percentage of those who were diagnosed at late stages (III/IV) of BC was higher than those who were still alive three years after BC diagnosis (35.3\% vs. 9.8\%). The percentages of women with positive progesterone HR status $(50.9 \%)$ or positive estrogen HR status $(62.6 \%)$ were lower among women who died with 
three years after BC diagnosis as compared to women who were still alive three years after BC diagnosis (68.9\% and $80.3 \%$ respectively). A higher proportion of women who died within 3 years after BC diagnosis were insulin users as compared to those who were still alive three years after BC diagnosis (34.8\% vs. 20.6\%). In contrast, a lower proportion of women who died within 3 years after BC diagnosis were metformin user as compared to those who were still alive three years after BC diagnosis (22.6\% vs. 37.9\%). For other oral diabetes medications, there was no significant association between the number of medications and all-cause mortality. Among women who were alive three years after BC diagnosis, the proportion of women who had received surgery $(91.6 \%$ vs. $66 \%)$ or radiation $(41.7 \%$ vs. $19.3 \%)$ was higher than those who died with the first three years after BC diagnosis. Women who died within three years after BC diagnosis were more likely to have pre-existing COPD, dementia, and depression and were less likely to have hyperlipidemia as compared to those who were alive three years after BC diagnosis.

\section{Risk of Death within 3 Years of Diagnosis}

Results from multivariable analyses of incident BC cases with pre-existing diabetes are shown in table 3 . In the unadjusted analyses (model 1), there was a significant association between severity of diabetes complications and risk of all-cause mortality. Women who had a severity of diabetes complications with DCSI $=2 \& \mathrm{DCSI} \geq 3$ were $2.06(\mathrm{HR}=2.06 ; 95 \% \mathrm{CI}=$ 1.70-2.48) and 3.30 ( $\mathrm{HR}=3.30 ; 95 \% \mathrm{CI}=2.78-3.92)$ times respectively, more likely to die within 3 years of BC diagnosis, than women with no diabetes complications.

In Model 2, severity of diabetes-related complications was significantly associated with the risk of all-cause mortality after controlling for diabetes medications, cancer treatment, HR 
status, race, age, and other pre-existing comorbid conditions. A severity of diabetes

complications with DCSI $=1, \mathrm{DCSI}=2$, and DCSI $\geq 3$ was associated with $33 \%(\mathrm{HR}=1.22 ; 95 \%$

$\mathrm{CI}=1.01-1.74), 67 \%(\mathrm{HR}=1.67 ; 95 \% \mathrm{CI}=1.38-2.03)$, and $127 \%(\mathrm{HR}=2.27 ; 95 \% \mathrm{CI}=1.89-$

2.73) increase in risk of death, respectively, within 3 years after BC diagnosis as compared to

those without diabetes complications.

In Model 3, severity of diabetes-related complications was still significantly associated with the risk of all-cause mortality after controlling for diabetes medications, cancer treatment, HR status, race, age, other pre-existing comorbid conditions, and SEER regions. Women with DCSI $=1, \mathrm{DCSI}=2$, and DCSI $\geq 3$ had $34 \%(\mathrm{HR}=1.34 ; 95 \% \mathrm{CI}=1.02-1.75), 69 \%(\mathrm{HR}=1.69$; $95 \% \mathrm{CI}=1.39-2.05)$, and $124 \%(\mathrm{HR}=2.24 ; 95 \% \mathrm{CI}=1.86-2.70)$ increased risk of death within 3 years after BC diagnosis, respectively, as compared to those without diabetes complications. Women who used insulin had 58\% ( $\mathrm{HR}=1.58 ; 95 \% \mathrm{CI}=1.35-1.84)$ increased risk of death, compared to those who did not use insulin after controlling for diabetes severity, other diabetes medications, cancer treatment, cancer characteristics, and other patient's factors. Conversely, women who used metformin had $26 \%(\mathrm{HR}=0.74 ; 95 \% \mathrm{CI}=0.63-0.88)$ decreased risk of death, compared to those who did not use metformin after controlling for diabetes severity, other diabetes medications, cancer treatment, cancer characteristics, and other patient's factors.

In addition, women who received radiation therapy within the first 6 months after BC diagnosis had $37 \%(\mathrm{HR}=0.63 ; 95 \% \mathrm{CI}=0.52-0.76)$ decreased risk of death, compared to women who did not receive any radiation therapy after controlling for cancer characteristics, patient's factors, diabetes severity, and diabetes medications. Women receiving surgery within the first 6 months after $\mathrm{BC}$ diagnosis had a $55 \%(\mathrm{HR}=0.45 ; 95 \% \mathrm{CI}=0.38-0.53)$ decrease in 
the risk of death, compared to women who having no surgery after adjusting for cancer characteristics, patient's factors, diabetes severity, and diabetes medications.

Women with progesterone HR \& estrogen HR positive tumors had a 26\% (HR = 0.74; $95 \% \mathrm{CI}, 0.60,0.92)$ and $38 \%(\mathrm{HR}=0.62 ; 95 \% \mathrm{CI}, 0.49,0.79)$ decrease in the risk of death within three years of diagnosis respectively, then women with progesterone HR \& estrogen HR negative tumors.

Further, women who had $\geq 20$ oncologist visits during the first 6 months were $1.39(\mathrm{HR}=$ $1.39 ; 95 \% \mathrm{CI}=1.12-1.72)$ times more likely to die within 3 years of $\mathrm{BC}$ diagnosis, compared to women who had a maximum of 10 oncologist visits. Also, having at least one endocrinologist visit during the first 6 months was associated with $25 \%$ (HR=0.75; 95\% CI=0.56-0.98) decrease in the risk of death within 3 years of $\mathrm{BC}$ diagnosis as compared to women who do not have any endocrinologist visit.

\section{DISCUSSION}

\section{Overall Findings}

The main finding of this study is that severity of diabetes-related complications is independently associated with all-cause mortality among elderly women with incident BC and pre-existing diabetes, irrespective of diabetes medication, other comorbidities, cancer characteristics, cancer treatment, and other patient-related factors. Women with a DCSI $=1$ had a $34 \%$ increased risk of death, women with a DCSI $=2$ had a $69 \%$ increased risk of death, and women with a DCSI $\geq 3$ had a $124 \%$ increased risk of death within 3 years of BC diagnosis as compared to those without diabetes complications. This indicated that as the severity of diabetes complication increases, the risk of mortality increases. Also, this finding shows that having any 
diabetes complications is significantly associated with increased risk of all-cause mortality as compared to women without diabetes complications.

Previous studies have revealed women with diabetes have a higher risk of mortality, compared to women without diabetes (Lipscombe et al., 2008; Luo et al., 2015; Verlato et al., 2003). However, to the best of our knowledge, no research has investigated the influence of diabetes complications severity on the high rates of mortality among incident BC cases using an established index. Thus, this study expands the existing literature by showing in a large population the impact of biological factors and severity of diabetes measured by end-organ damage on this association after controlling for a comprehensive list of factors that could contribute to this association. Studies have shown the significance of using DCSI as a measure of diabetes severity to predict costs, health resource utilizations, hospitalization, and mortality among individuals with diabetes (Chang et al., 2012; Hazel-Fernandez et al., 2015; Young et al., 2008). However, when it comes to cancer prognosis, many biological factors become less important as compared to cancer severity and cancer treatment (Battafarano et al., 2002; Bugge et al., 2016; Shavers \& Brown, 2002). Our findings revealed that DCSI was a significant predictor of all-cause mortality among women with incident BC diagnosis even after controlling for diabetes medications, cancer characteristics, cancer treatment, and other patient-related factors.

A study by Young et al showed that in adjusted analyses, having a DCSI $=1$ or a DCSI = 2 was not significantly associated with risk of all-cause mortality among individual with diabetes while having a DCSI $\geq 3$ was associated with all-cause mortality (Young et al., 2008). However, our study showed that among a cohort of women with incident BC and pre-existing diabetes, the 
association between the severity of diabetes complications and all-cause mortality is significant starting from a DCSI $=1$.

\section{Diabetes Medications, Endocrinologist visits \& All-cause Mortality}

In addition to severity of diabetes, using insulin and/or metformin was significantly associated with all-cause mortality after controlling for all possible factors. Metformin use was significantly associated with a $26 \%$ decrease in risk of death within three years of BC diagnosis. In contrast, a recent meta-analysis of randomized controlled trials (RCT) data showed that there is no significant impact of metformin on all-cause mortality among individuals with diabetes and cancer (Stevens et al., 2012). However, lack of adjusted estimates, heterogeneity of trials, and certain sources of bias could weaken the conclusion regarding the lack of significant impact of metformin on survival rates among cancer patients who had pre-existing diabetes. Also, a study conducted in Canada among elderly women with incident BC cancer and pre-existing diabetes found that there is no association between metformin use and survival rate (Lega et al., 2013).

Although some of these studies accounted for cancer treatment, other diabetes medications, and/or comorbidity, none of them they controlled for diabetes severity and cancer stage which have significant effects on all-cause mortality, and may have biased the results (Holman, 2007). Therefore, by including a comprehensive list of potential predictors including cancer severity and diabetes severity in our multivariable analyses, our results provided a robust evidence about the positive impact of metformin use on health outcomes of incident BC cases with pre-existing diabetes.

Insulin use was significantly associated with 58\% increase in hazard of death within 3 years of BC diagnosis as compared to women who did not use insulin. Generally, insulin helps 
the body to regulate the level of blood glucose and helps cells grow, but people with diabetes and obesity usually have high insulin levels (hyperinsulinemia) because their bodies are not sensitive to insulin (insulin-resistance) (Mokdad et al., 2003; Schwartz \& Porte, 2005). Many studies have linked the pathophysiology of insulin-resistance to a worse prognosis of $\mathrm{BC}$ among obese patients with pre-existing diabetes (Duggan et al., 2011; Goodwin, 2015). Although we controlled for many diabetes-related factors and cancer-related factors, we did not control for obesity which is a possible covariate in this association.

In addition to diabetes medications, endocrinologist visits during the first 6 months of $\mathrm{BC}$ diagnosis was a significant predictor of all-cause mortality. Having at least one endocrinologist visits within the first 6 months of BC diagnosis was significantly associated with $26 \%$ decrease in all-cause mortality. A previous study suggested that endocrinologist visits provide a better understanding of diabetes and its complications which may have a substantial impact on improvements in glycemic control for poorly controlled diabetes (Salti et al., 2011). However, few incident $\mathrm{BC}$ cases and pre-existing diabetes are seen by an endocrinologist (Oppong et al., 2014). In our study, only 398 (9.2\%) out of 4307 women with incident BC and pre-existing diabetes had seen an endocrinologist during the first 6 months of $\mathrm{BC}$ diagnosis. Our findings showed that contribution of endocrinologists in health care of incident BC cases with preexisting diabetes may help in improving health outcomes and reducing the risk of death after BC diagnosis. Therefore, our study suggests a comprehensive team approach including endocrinologists for patients with $\mathrm{BC}$ and pre-existing diabetes to control diabetes and severity of diabetes-related complications, and thereby reduce their impact on cancer outcomes.

\section{Cancer Treatment and All-cause Mortality}


For cancer treatment, a high proportion $(86.2 \%)$ of the study cohort were treated with surgery within the first 6 months of $\mathrm{BC}$ diagnosis, $36 \%$ received radiation while a low proportion received chemotherapy (18.0\%). This was consistent with previous research that indicated that elderly women with $\mathrm{BC}$ and diabetes are less likely to receive chemotherapy as compared to those without diabetes due to increased risk of chemotherapy-related toxicities compared with nondiabetic patients (Gold et al., 2014; Srokowski et al., 2009).

With respect to the adjusted association with all-cause mortality, our results showed that surgery and radiotherapy were associated with $55 \%$ and $37 \%$ decrease in the risk of all-cause mortality, respectively, within three years of $\mathrm{BC}$ diagnosis while there was no significant association between chemotherapy and all-cause mortality. Similar to previous research, radiotherapy use was associated with an improvement in overall survival among incident $\mathrm{BC}$ and pre-existing diabetes (Lega et al., 2013). However, our results regarding surgery and all-cause mortality were not consistent with previous studies that showed that women with diabetes were more likely to die within a few months following surgery than those without diabetes (Plodkowski \& Edelman, 2001). In our study, after we controlled for insulin use, other diabetes medications, severity of diabetes complications, stage of BC, and all other possible factors, we found that surgery was associated with improvement in survival among women with diabetes as compared to women who did not received surgery.

Unlike previous research that suggested that receipt of chemotherapy may be associated with an increased risk of death (Alenzi \& Kelley, 2017; Brunello, Kapoor, \& Extermann, 2011; Crawford et al., 2008; Lega et al., 2013; Matias Cdo et al., 2013; Peairs et al., 2011), our findings revealed that chemotherapy was not associated with all-cause mortality after controlling for diabetes severity, cancer severity and all other possible covariates. This may indicate that the 
association between chemotherapy-related toxicity and mortality is mediated by diabetes severity since all the previous studies did not control for diabetes severity.

\section{Strengths and Limitations}

This study has several potential limitations that should be considered when interpreting the results. First, we lacked data on some biological factors, such as obesity which could have residual confounding effect on the risk of mortality. Second, individuals within the SEERMedicare data tend to be more urban and affluent and with higher concentrations of racial and ethnic minorities, as compared to the US population (Warren et al., 2002). Third, since we used a claims database instead of medical records to measure DSCI, the index was measured without laboratory results. However, a study by Chang et al. tested the validity of DCSI without laboratory results and they found that the DCSI without laboratory results and the DCSI with laboratory information perform similarly (Chang et al., 2012b). Fourth, socio-demographic characteristics such as income and education were aggregate census level measures, rather than individual level measures. Since we included elderly women who were continuously enrolled in Medicare part D for three months, we could not identify the reception of oral therapies, such as oral chemotherapy (e.g. tamoxifen) during the first 6 months that followed BC screening. Other limitations include lack of other biological information, such as blood glucose level, glycosylated hemoglobin A1c lab results, and diabetes duration.

Despite the potential limitations, the current study has many strengths. First, using a valid and reliable index to measure diabetes severity which enabled us to capture the severity of the disease and its-related complications, assessing its impact on all-cause mortality, and controlling for diabetes severity to assess the adjusted association of other factors with all-cause mortality. 
To assess the severity of diabetes-related complications, we used DCSI which captures both the type and severity of diabetes complications while a simple count of complications does not take the severity of each complication into account (Young et al., 2008). In addition to its use as measure of diabetes severity, a study by Young et al. found that this index may be considered as a proxy measure for diabetes duration (Young et al., 2008). Young et al found that severity index of diabetes complications was highly correlated with diabetes duration, and it attenuated the significant impact of diabetes duration on mortality after it was added to the analysis model (Young et al., 2008). Because diabetes may remain undiagnosed for years, using DCSI as a severity measure of long- term complications probably demonstrates the consequences of biologic markers of diabetes duration (Harris \& Eastman, 2000).

In conclusion, both existence and severity of diabetes-related complications are independently associated with all-cause mortality among elderly women with incident BC and pre-existing diabetes as compared to women without diabetes complications. It is essential that incident $\mathrm{BC}$ cases with pre-existing diabetes medications receive optimal diabetes care along with cancer therapy through a close collaboration between oncologists and endocrinologists. 


\section{REFERENCES}

Alenzi, E. O., \& Kelley, G. A. (2017). The association of hyperglycemia and diabetes mellitus and the risk of chemotherapy-induced neutropenia among cancer patients: A systematic review with meta-analysis. J Diabetes Complications, 31(1), 267-272. doi:10.1016/j.jdiacomp.2016.09.006

Barone, B. B., Yeh, H. C., Snyder, C. F., Peairs, K. S., Stein, K. B., Derr, R. L., . . Brancati, F. L. (2008). Long-term all-cause mortality in cancer patients with preexisting diabetes mellitus: a systematic review and meta-analysis. Jama, 300(23), 2754-2764. doi:10.1001/jama.2008.824

Battafarano, R. J., Piccirillo, J. F., Meyers, B. F., Hsu, H. S., Guthrie, T. J., Cooper, J. D., \& Patterson, G. A. (2002). Impact of comorbidity on survival after surgical resection in patients with stage I non-small cell lung cancer. J Thorac Cardiovasc Surg, 123(2), 280287.

Bernard, L., Reix, N., Benabu, J. C., Gabriele, V., \& Mathelin, C. (2016). [Breast cancer and diabetes mellitus: Complex interactions]. Gynecol Obstet Fertil, 44(12), 701-711. doi:10.1016/j.gyobfe.2016.09.004

Black, W. C., Haggstrom, D. A., \& Welch, H. G. (2002). All-cause mortality in randomized trials of cancer screening. J Natl Cancer Inst, 94(3), 167-173.

Brunello, A., Kapoor, R., \& Extermann, M. (2011). Hyperglycemia during chemotherapy for hematologic and solid tumors is correlated with increased toxicity. Am J Clin Oncol, 34(3), 292-296. doi:10.1097/COC.0b013e3181e1d0c0

Bugge, A., Kongerud, J., Brunborg, C., Solberg, S., \& Lund, M. B. (2016). Gender-specific survival after surgical resection for early stage non-small cell lung cancer. Acta Oncol, 17. doi:10.1080/0284186x.2016.1253862

Chang, H. Y., Weiner, J. P., Richards, T. M., Bleich, S. N., \& Segal, J. B. (2012a). Predicting costs with diabetes complications severity index in claims data. Am J Manag Care, 18(4), 213-219.

Chang, H. Y., Weiner, J. P., Richards, T. M., Bleich, S. N., \& Segal, J. B. (2012b). Validating the AdaptedDiabetes Complications Severity Index in Claims Data. Am J Manag Care, 18(4), 213-219.

Cleveland, R. J., North, K. E., Stevens, J., Teitelbaum, S. L., Neugut, A. I., \& Gammon, M. D. (2012). The association of diabetes with breast cancer incidence and mortality in the Long Island Breast Cancer Study Project. Cancer Causes Control, 23(7), 1193-1203. doi:10.1007/s10552-012-9989-7 
Crawford, J., Dale, D. C., Kuderer, N. M., Culakova, E., Poniewierski, M. S., Wolff, D., \& Lyman, G. H. (2008). Risk and timing of neutropenic events in adult cancer patients receiving chemotherapy: the results of a prospective nationwide study of oncology practice. J Natl Compr Canc Netw, 6(2), 109-118.

Cusick, M., Meleth, A. D., Agron, E., Fisher, M. R., Reed, G. F., Knatterud, G. L., . . Chew, E. Y. (2005). Associations of mortality and diabetes complications in patients with type 1 and type 2 diabetes: early treatment diabetic retinopathy study report no. 27 . Diabetes Care, 28(3), 617-625.

De Bruijn, K. M., Arends, L. R., Hansen, B. E., Leeflang, S., Ruiter, R., \& van Eijck, C. H. (2013). Systematic review and meta-analysis of the association between diabetes mellitus and incidence and mortality in breast and colorectal cancer. Br J Surg, 100(11), 14211429. doi:10.1002/bjs.9229

Diabetes Raises Risk of Death In Cancer Surgery Patients - 03/29/2010. (2016). Retrieved from http://www.hopkinsmedicine.org/news/media/releases/diabetes_raises_risk_of_death_in_ cancer_surgery_patients_

Du, X., Freeman, J. L., Nattinger, A. B., \& Goodwin, J. S. (2002). Survival of women after breast conserving surgery for early stage breast cancer. Breast Cancer Res Treat, 72(1), 23-31.

Duggan, C., Irwin, M. L., Xiao, L., Henderson, K. D., Smith, A. W., Baumgartner, R. N., . . . McTiernan, A. (2011). Associations of insulin resistance and adiponectin with mortality in women with breast cancer. J Clin Oncol, 29(1), 32-39. doi:10.1200/jco.2009.26.4473

Geraci, J. M., Escalante, C. P., Freeman, J. L., \& Goodwin, J. S. (2005). Comorbid disease and cancer: the need for more relevant conceptual models in health services research. $J$ Clin Oncol, 23(30), 7399-7404. doi:10.1200/jco.2004.00.9753

Gold, H. T., Makarem, N., Nicholson, J. M., \& Parekh, N. (2014). Treatment and outcomes in diabetic breast cancer patients. Breast Cancer Res Treat, 143(3), 551-570. doi:10.1007/s10549-014-2833-x

Goodwin, P. J. (2015). Obesity, insulin resistance and breast cancer outcomes. Breast, 24 Suppl 2, S56-59. doi:10.1016/j.breast.2015.07.014

Hanna, N., Bikov, K. A., McNally, D., Onwudiwe, N. C., Dalal, M., \& Mullins, C. D. (2012). Impact of venous thromboembolism on mortality of elderly Medicare patients with stage III colon cancer. Oncologist, 17(9), 1191-1197. doi:10.1634/theoncologist.2012-0093

Harris, M. I., \& Eastman, R. C. (2000). Early detection of undiagnosed diabetes mellitus: a US perspective. Diabetes Metab Res Rev, 16(4), 230-236. 
Hazel-Fernandez, L., Li, Y., Nero, D., Moretz, C., Slabaugh, L., Meah, Y., . . Bouchard, J. R. (2015). Relationship of diabetes complications severity to healthcare utilization and costs among Medicare Advantage beneficiaries. Am J Manag Care, 21(1), e62-70.

Hershman, D., Fleischauer, A. T., Jacobson, J. S., Grann, V. R., Sundararajan, V., \& Neugut, A. I. (2004). Patterns and outcomes of chemotherapy for elderly patients with stage II ovarian cancer: a population-based study. Gynecol Oncol, 92(1), 293-299.

Holden, S. E., Jenkins-Jones, S., \& Currie, C. J. (2016). Association between Insulin Monotherapy versus Insulin plus Metformin and the Risk of All-Cause Mortality and Other Serious Outcomes: A Retrospective Cohort Study. PLoS One, 11(5), e0153594. doi:10.1371/journal.pone.0153594

Holman, R. (2007). Metformin as first choice in oral diabetes treatment: the UKPDS experience. Journ Annu Diabetol Hotel Dieu, 13-20.

Krzyzanowska, M. K., Weeks, J. C., \& Earle, C. C. (2003). Treatment of locally advanced pancreatic cancer in the real world: population-based practices and effectiveness. J Clin Oncol, 21(18), 3409-3414. doi:10.1200/jco.2003.03.007

Laiteerapong, N., Huang, E. S., \& Chin, M. H. (2011). Prioritization of care in adults with diabetes and comorbidity. Ann N Y Acad Sci, 1243, 69-87. doi:10.1111/j.17496632.2011.06316.x

Lam, E. K., Batty, G. D., Huxley, R. R., Martiniuk, A. L., Barzi, F., Lam, T. H., ... Woodward, M. (2011). Associations of diabetes mellitus with site-specific cancer mortality in the Asia-Pacific region. Ann Oncol, 22(3), 730-738. doi:10.1093/annonc/mdq405

Lega, I. C., Austin, P. C., Gruneir, A., Goodwin, P. J., Rochon, P. A., \& Lipscombe, L. L. (2013). Association between metformin therapy and mortality after breast cancer: a population-based study. Diabetes Care, 36(10), 3018-3026. doi:10.2337/dc12-2535

LeMasters, T., Madhavan, S. S., \& Sambamoorthi, U. (2016). Comparison of the Initial LocoRegional Treatment Received for Early-Stage Breast Cancer between Elderly Women in Appalachia and a United States - Based Population: Good and Bad News. Global J Breast Cancer Res, 4, 10-19. doi:10.20941/2309-4419.2016.04.2

Lipscombe, L. L., Goodwin, P. J., Zinman, B., McLaughlin, J. R., \& Hux, J. E. (2008). The impact of diabetes on survival following breast cancer. Breast Cancer Res Treat, 109(2), 389-395. doi:10.1007/s10549-007-9654-0

Luo, J., Hendryx, M., Virnig, B., Wen, S., Chlebowski, R., Chen, C., . . Margolis, K. L. (2015). Pre-existing diabetes and breast cancer prognosis among elderly women. Br J Cancer, 113(5), 827-832. doi:10.1038/bjc.2015.249 
Margel, D., Urbach, D. R., Lipscombe, L. L., Bell, C. M., Kulkarni, G., Austin, P. C., \& Fleshner, N. (2013). Metformin use and all-cause and prostate cancer-specific mortality among men with diabetes. J Clin Oncol, 31(25), 3069-3075. doi:10.1200/jco.2012.46.7043

Matias Cdo, N., Lima, V., Teixeira, H. M., Souto, F. R., \& Magalhães, V. (2013). Hyperglycemia increases the complicated infection and mortality rates during induction therapy in adult acute leukemia patients. Rev Bras Hematol Hemoter, 35(1), 39-43. doi:10.5581/1516-8484.20130013

Mokdad, A. H., Ford, E. S., Bowman, B. A., Dietz, W. H., Vinicor, F., Bales, V. S., \& Marks, J. S. (2003). Prevalence of obesity, diabetes, and obesity-related health risk factors, 2001. Jama, 289(1), 76-79.

Morsy, M. A., \& Heeba, G. H. (2016). Nebivolol Ameliorates Cisplatin-Induced Nephrotoxicity in Rats. Basic Clin Pharmacol Toxicol, 118(6), 449-455. doi:10.1111/bcpt.12538

Onitilo, A. A., Stankowski, R. V., Berg, R. L., Engel, J. M., Glurich, I., Williams, G. M., \& Doi, S. A. (2014). Breast cancer incidence before and after diagnosis of type 2 diabetes mellitus in women: increased risk in the prediabetes phase. Eur J Cancer Prev, 23(2), 7683. doi:10.1097/CEJ.0b013e32836162aa

Oppong, B. A., Pharmer, L. A., Oskar, S., Eaton, A., Stempel, M., Patil, S., \& King, T. A. (2014). The effect of metformin on breast cancer outcomes in patients with type 2 diabetes. Cancer Med, 3(4), 1025-1034. doi:10.1002/cam4.259

Patnaik, J. L., Byers, T., DiGuiseppi, C., Dabelea, D., \& Denberg, T. D. (2011). Cardiovascular disease competes with breast cancer as the leading cause of death for older females diagnosed with breast cancer: a retrospective cohort study. Breast Cancer Res, 13(3), R64. doi:10.1186/bcr2901

Patnaik, J. L., Byers, T., Diguiseppi, C., Denberg, T. D., \& Dabelea, D. (2011). The influence of comorbidities on overall survival among older women diagnosed with breast cancer. $J$ Natl Cancer Inst, 103(14), 1101-1111. doi:10.1093/jnci/djr188

Peairs, K. S., Barone, B. B., Snyder, C. F., Yeh, H. C., Stein, K. B., Derr, R. L., . . Wolff, A. C. (2011). Diabetes mellitus and breast cancer outcomes: a systematic review and metaanalysis. J Clin Oncol, 29(1), 40-46. doi:10.1200/jco.2009.27.3011

Piccirillo, J. F., Tierney, R. M., Costas, I., Grove, L., \& Spitznagel, E. L., Jr. (2004). Prognostic importance of comorbidity in a hospital-based cancer registry. Jama, 291(20), 24412447. doi:10.1001/jama.291.20.2441

Plodkowski, R. A., \& Edelman, S. V. (2001). Pre-Surgical Evaluation of Diabetic Patients. doi:10.2337/diaclin.19.2.92 
Salti, H., Cavallerano, J. D., Salti, N., Jawhari, D. J., Haddad, S., Sun, J. K., . . Aiello, L. P. (2011). Nonmydriatic retinal image review at time of endocrinology visit results in shortterm HbA1c reduction in poorly controlled patients with diabetic retinopathy. Telemed $J$ E Health, 17(6), 415-419. doi:10.1089/tmj.2010.0180

Schwartz, M. W., \& Porte, D., Jr. (2005). Diabetes, obesity, and the brain. Science, 307(5708), 375-379. doi:10.1126/science.1104344

Shavers, V. L., \& Brown, M. L. (2002). Racial and ethnic disparities in the receipt of cancer treatment. J Natl Cancer Inst, 94(5), 334-357.

Srokowski, T. P., Fang, S., Hortobagyi, G. N., \& Giordano, S. H. (2009). Impact of Diabetes Mellitus on Complications and Outcomes of Adjuvant Chemotherapy in Older Patients With Breast Cancer. J Clin Oncol, 27(13), 2170-2176. doi:10.1200/jco.2008.17.5935

Stevens, R. J., Ali, R., Bankhead, C. R., Bethel, M. A., Cairns, B. J., Camisasca, R. P., . . Holman, R. R. (2012). Cancer outcomes and all-cause mortality in adults allocated to metformin: systematic review and collaborative meta-analysis of randomised clinical trials. Diabetologia, 55(10), 2593-2603. doi:10.1007/s00125-012-2653-7

Verlato, G., Zoppini, G., Bonora, E., \& Muggeo, M. (2003). Mortality from site-specific malignancies in type 2 diabetic patients from Verona. Diabetes Care, 26(4), 1047-1051.

Volkova, M., \& Russell, R., 3rd. (2011). Anthracycline cardiotoxicity: prevalence, pathogenesis and treatment. Curr Cardiol Rev, 7(4), 214-220.

Warren, J. L., Klabunde, C. N., Schrag, D., Bach, P. B., \& Riley, G. F. (2002). Overview of the SEER-Medicare data: content, research applications, and generalizability to the United States elderly population. Med Care, 40(8 Suppl), Iv-3-18. doi:10.1097/01.mlr.0000020942.47004.03

Wolf, I., Sadetzki, S., Catane, R., Karasik, A., \& Kaufman, B. (2005). Diabetes mellitus and breast cancer. Lancet Oncol, 6(2), 103-111. doi:10.1016/s1470-2045(05)01736-5

Young, B. A., Lin, E., Von Korff, M., Simon, G., Ciechanowski, P., Ludman, E. J., . . Katon, W. J. (2008). Diabetes complications severity index and risk of mortality, hospitalization, and healthcare utilization. Am J Manag Care, 14(1), 15-23.

Yu, O. H., Yin, H., \& Azoulay, L. (2015). The combination of DPP-4 inhibitors versus sulfonylureas with metformin after failure of first-line treatment in the risk for major cardiovascular events and death. Can J Diabetes, 39(5), 383-389.

doi:10.1016/j.jcjd.2015.02.002 


\section{Figure 1: Study Cohort Selection Flowchart}

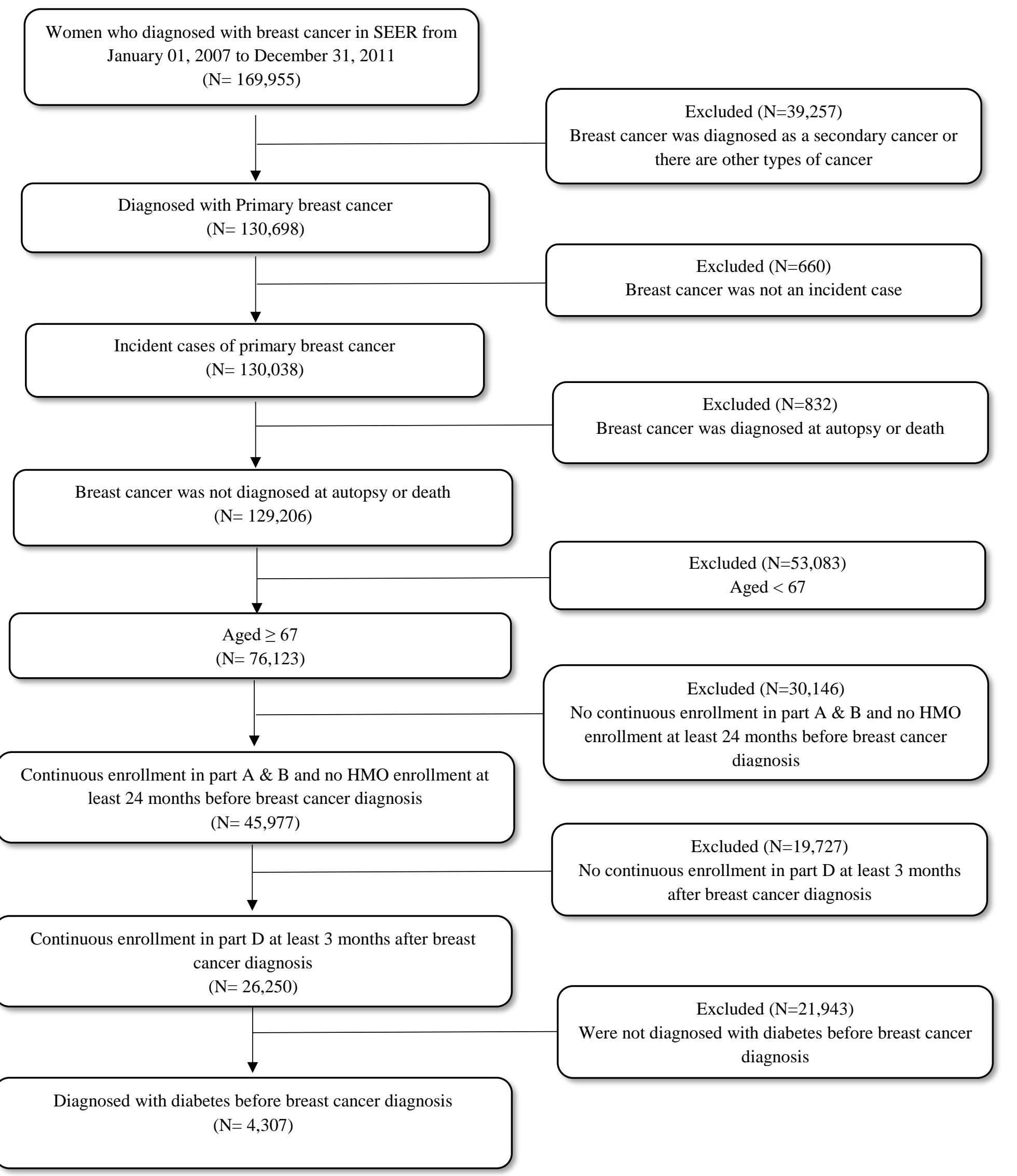


Table 1: The Characteristics of the Study Cohort* by Diabetes Complications Severity Index

\begin{tabular}{|c|c|c|c|c|c|c|c|c|c|c|}
\hline \multirow[b]{2}{*}{ Characteristics } & \multicolumn{2}{|c|}{$\begin{array}{c}\text { All Women, } \\
\mathrm{N}=4307\end{array}$} & \multicolumn{2}{|c|}{$\begin{array}{l}\text { DCSI }=0, \\
N=1972\end{array}$} & \multicolumn{2}{|c|}{$\begin{array}{c}\text { DCSI }=1, \\
N=496\end{array}$} & \multicolumn{2}{|c|}{$\begin{array}{c}\text { DCSI }=2, \\
\mathrm{~N}=902\end{array}$} & \multicolumn{2}{|c|}{$\begin{array}{c}\mathrm{DCSI} \geq 3, \\
\mathrm{~N}=937\end{array}$} \\
\hline & No. & $\%$ & No. & $\%$ & No. & $\%$ & No. & $\%$ & No. & $\%$ \\
\hline \multicolumn{11}{|l|}{ Insulin use } \\
\hline Yes & 1021 & 23.7 & 323 & 16.4 & 109 & 22.0 & 226 & 25.1 & 363 & 38.7 \\
\hline No & 3286 & 76.3 & 1649 & 83.6 & 387 & 78.0 & 676 & 74.9 & 574 & 61.3 \\
\hline \multicolumn{11}{|l|}{ Metformin use } \\
\hline Yes & 1490 & 34.6 & 833 & 42.2 & 209 & 42.1 & 252 & 27.9 & 196 & 20.9 \\
\hline No & 2817 & 65.4 & 1139 & 57.8 & 287 & 57.9 & 650 & 72.1 & 741 & 79.1 \\
\hline \multicolumn{11}{|l|}{ Other diabetes medications } \\
\hline 0 & 2563 & 59.5 & 1165 & 59.1 & 285 & 57.5 & 528 & 58.5 & 585 & 62.4 \\
\hline 1 & 1403 & 32.6 & 637 & 32.3 & 168 & 33.9 & 301 & 33.4 & 297 & 31.7 \\
\hline$\geq 2$ & 341 & 7.9 & 170 & 8.6 & 43 & 8.7 & 73 & 8.1 & 55 & 5.9 \\
\hline \multicolumn{11}{|l|}{ Age } \\
\hline $67-70$ & 938 & 21.8 & 470 & 23.8 & 133 & 26.8 & 154 & 17.1 & 181 & 19.3 \\
\hline $71-74$ & 1155 & 26.8 & 572 & 29.0 & 137 & 27.6 & 234 & 25.9 & 212 & 22.6 \\
\hline $75-79$ & 818 & 19.0 & 371 & 18.8 & 86 & 17.3 & 171 & 19.0 & 190 & 20.3 \\
\hline$>=80$ & 1396 & 32.4 & 559 & 28.3 & 140 & 28.2 & 343 & 38.0 & 354 & 37.8 \\
\hline \multicolumn{11}{|l|}{ Race } \\
\hline White & 3180 & 73.8 & 1479 & 75.0 & 364 & 73.4 & 689 & 76.4 & 648 & 69.2 \\
\hline African American & 724 & 16.8 & 283 & 14.4 & 77 & 15.5 & 134 & 14.9 & 230 & 24.5 \\
\hline Others & 403 & 9.4 & 210 & 10.6 & 55 & 11.1 & 79 & 8.8 & 59 & 6.3 \\
\hline \multicolumn{11}{|l|}{ Stage at diagnosis } \\
\hline Early stage & 3435 & 85.1 & 1600 & 85.7 & 406 & 86.6 & 715 & 84.9 & 714 & 83.4 \\
\hline Advanced stage & 600 & 14.9 & 268 & 14.3 & 63 & 13.4 & 127 & 15.1 & 142 & 16.6 \\
\hline \multicolumn{11}{|c|}{ Progesterone receptor status } \\
\hline Positive & 2798 & 65.0 & 1297 & 65.8 & 335 & 67.5 & 592 & 65.6 & 574 & 61.3 \\
\hline Negative & 1057 & 24.5 & 494 & 25.1 & 115 & 23.2 & 207 & 22.9 & 241 & 25.7 \\
\hline Borderline/Unknown & 452 & 10.5 & 181 & 9.2 & 46 & 9.3 & 103 & 11.4 & 122 & 13.0 \\
\hline \multicolumn{11}{|l|}{ Estrogen receptor status } \\
\hline Positive & 3291 & 76.4 & 1549 & 78.5 & 376 & 75.8 & 692 & 76.7 & 674 & 71.9 \\
\hline Negative & 611 & 14.2 & 267 & 13.5 & 77 & 15.5 & 118 & 13.1 & 149 & 15.9 \\
\hline Borderline/Unknown & 405 & 9.4 & 156 & 7.9 & 43 & 8.7 & 92 & 10.2 & 114 & 12.2 \\
\hline \multicolumn{11}{|l|}{ Had chemotherapy } \\
\hline Yes & 776 & 18.0 & 387 & 19.6 & 94 & 19.0 & 146 & 16.2 & 149 & 15.9 \\
\hline No & 3531 & 82.0 & 1585 & 80.4 & 402 & 81.0 & 756 & 83.8 & 788 & 84.1 \\
\hline \multicolumn{11}{|l|}{ Had radiation } \\
\hline Yes & 1586 & 36.8 & 818 & 41.5 & 196 & 39.5 & 321 & 35.6 & 251 & 26.8 \\
\hline No & 2721 & 63.2 & 1154 & 58.5 & 300 & 60.5 & 581 & 64.4 & 686 & 73.2 \\
\hline \multicolumn{11}{|l|}{ Had any surgery } \\
\hline Yes & 3705 & 86.0 & 1745 & 88.5 & 448 & 90.3 & 754 & 83.6 & 758 & 80.9 \\
\hline No & 602 & 14.0 & 227 & 11.5 & 48 & 9.7 & 148 & 16.4 & 179 & 19.1 \\
\hline \multicolumn{11}{|l|}{ Thyroid syndrome } \\
\hline Yes & 1024 & 23.8 & 388 & 19.7 & 135 & 27.2 & 246 & 27.3 & 255 & 27.2 \\
\hline No & 3283 & 76.2 & 1584 & 80.3 & 361 & 72.8 & 656 & 72.7 & 682 & 72.8 \\
\hline Arthritis & & & & & & & & & & \\
\hline Yes & 1182 & 27.4 & 461 & 23.4 & 156 & 31.5 & 264 & 29.3 & 301 & 32.1 \\
\hline No & 3125 & 72.6 & 1511 & 76.6 & 340 & 68.5 & 638 & 70.7 & 636 & 67.9 \\
\hline Asthma & & & & & & & & & & \\
\hline Yes & 361 & 8.4 & 126 & 6.4 & 33 & 6.7 & 103 & 11.4 & 99 & 10.6 \\
\hline No & 3946 & 91.6 & 1846 & 93.6 & 463 & 93.3 & 799 & 88.6 & 838 & 89.4 \\
\hline ...Continued & & & & & & & & & & \\
\hline
\end{tabular}


Table 1: The Characteristics of the Study Cohort* by Diabetes Complications Severity Index

\begin{tabular}{|c|c|c|c|c|c|c|c|c|c|c|}
\hline \multirow[b]{2}{*}{ Characteristics } & \multicolumn{2}{|c|}{$\begin{array}{c}\text { All Women, } \\
\text { N=4307 }\end{array}$} & \multicolumn{2}{|c|}{$\begin{array}{l}\text { DCSI }=0, \\
N=1972\end{array}$} & \multicolumn{2}{|c|}{$\begin{array}{c}\text { DCSI }=1, \\
N=496\end{array}$} & \multicolumn{2}{|c|}{$\begin{array}{c}\text { DCSI }=2, \\
\mathrm{~N}=902\end{array}$} & \multicolumn{2}{|c|}{$\begin{array}{c}\mathrm{DCSI} \geq 3, \\
\mathrm{~N}=937\end{array}$} \\
\hline & No. & $\%$ & No. & $\%$ & No. & $\%$ & No. & $\%$ & No. & $\%$ \\
\hline \multicolumn{11}{|l|}{ COPD } \\
\hline Yes & 630 & 14.6 & 158 & 8.0 & 45 & 9.1 & 183 & 20.3 & 244 & 26.0 \\
\hline No & 3677 & 85.4 & 1814 & 92.0 & 451 & 90.9 & 719 & 79.7 & 693 & 74.0 \\
\hline \multicolumn{11}{|l|}{ Dementia } \\
\hline Yes & 358 & 8.3 & 111 & 5.6 & 34 & 6.9 & 77 & 8.5 & 136 & 14.5 \\
\hline No & 3949 & 91.7 & 1861 & 94.4 & 462 & 93.1 & 825 & 91.5 & 801 & 85.5 \\
\hline \multicolumn{11}{|l|}{ Hyperlipidemia } \\
\hline Yes & 3010 & 69.9 & 1318 & 66.8 & 371 & 74.8 & 638 & 70.7 & 683 & 72.9 \\
\hline No & 1297 & 30.1 & 654 & 33.2 & 125 & 25.2 & 264 & 29.3 & 254 & 27.1 \\
\hline \multicolumn{11}{|l|}{ Hypertension } \\
\hline Yes & 3776 & 87.7 & 1589 & 80.6 & 445 & 89.7 & 836 & 92.7 & 906 & 96.7 \\
\hline No & 531 & 12.3 & 383 & 19.4 & 51 & 10.3 & 66 & 7.3 & 31 & 3.3 \\
\hline \multicolumn{11}{|l|}{ Osteoporosis } \\
\hline Yes & 337 & 7.8 & 146 & 7.4 & 41 & 8.3 & 82 & 9.1 & 68 & 7.3 \\
\hline No & 3970 & 92.2 & 1826 & 92.6 & 455 & 91.7 & 820 & 90.9 & 869 & 92.7 \\
\hline \multicolumn{11}{|l|}{ Anxiety } \\
\hline Yes & 435 & 10.1 & 143 & 7.3 & 62 & 12.5 & 114 & 12.6 & 116 & 12.4 \\
\hline No & 3872 & 89.9 & 1829 & 92.7 & 434 & 87.5 & 788 & 87.4 & 821 & 87.6 \\
\hline \multicolumn{11}{|l|}{ Depression } \\
\hline Yes & 657 & 15.3 & 210 & 10.6 & 72 & 14.5 & 170 & 18.8 & 205 & 21.9 \\
\hline No & 3650 & 84.7 & 1762 & 89.4 & 424 & 85.5 & 732 & 81.2 & 732 & 78.1 \\
\hline \multicolumn{11}{|l|}{ PCP visit } \\
\hline Yes & 3374 & 78.3 & 1505 & 76.3 & 384 & 77.4 & 727 & 80.6 & 758 & 80.9 \\
\hline No & 933 & 21.7 & 467 & 23.7 & 112 & 22.6 & 175 & 19.4 & 179 & 19.1 \\
\hline \multicolumn{11}{|l|}{ Endocrinologist visit } \\
\hline Yes & 398 & 9.2 & 156 & 7.9 & 55 & 11.1 & 76 & 8.4 & 111 & 11.8 \\
\hline No & 3909 & 90.8 & 1816 & 92.1 & 441 & 88.9 & 826 & 91.6 & 826 & 88.2 \\
\hline \multicolumn{11}{|l|}{ \# of oncologists visits } \\
\hline $0-10$ & 1051 & 24.4 & 524 & 26.6 & 116 & 23.4 & 198 & 22.0 & 213 & 22.7 \\
\hline $11-20$ & 1705 & 39.6 & 794 & 40.3 & 193 & 38.9 & 365 & 40.5 & 353 & 37.7 \\
\hline$\geq 20$ & 1551 & 36.0 & 654 & 33.2 & 187 & 37.7 & 339 & 37.6 & 371 & 39.6 \\
\hline \multicolumn{11}{|c|}{ Availability of oncology centers } \\
\hline Yes & 2967 & 68.9 & 1362 & 69.1 & 338 & 68.1 & 623 & 69.1 & 644 & 68.7 \\
\hline No & 1340 & 31.1 & 610 & 30.9 & 158 & 31.9 & 279 & 30.9 & 293 & 31.3 \\
\hline \multicolumn{11}{|c|}{ Census tract education } \\
\hline $0-13.29 \%$ & 1179 & 27.4 & 496 & 25.2 & 134 & 27.1 & 269 & 29.9 & 280 & 29.9 \\
\hline $13.30 \%-22.83 \%$ & 1288 & 30.0 & 608 & 30.9 & 133 & 26.9 & 258 & 28.6 & 289 & 30.9 \\
\hline $22.84 \%-38.55 \%$ & 969 & 22.6 & 429 & 21.8 & 120 & 24.2 & 206 & 22.9 & 214 & 22.9 \\
\hline$>38.55 \%$ & 860 & 20.0 & 432 & 22.0 & 108 & 21.8 & 168 & 18.6 & 152 & 16.3 \\
\hline Census tract househ & me & & & & & & & & & \\
\hline$<\$ 25,000$ & 305 & 7.1 & 132 & 6.7 & 36 & 7.3 & 55 & 6.1 & 82 & 8.8 \\
\hline$\$ 25,001-50,000$ & 1882 & 43.7 & 809 & 41.0 & 219 & 44.2 & 410 & 45.5 & 444 & 47.4 \\
\hline$\$ 50,001-75,000$ & 1338 & 31.1 & 651 & 33.0 & 147 & 29.6 & 278 & 30.8 & 262 & 28.0 \\
\hline$>\$ 75,000$ & 782 & 18.2 & 380 & 19.3 & 94 & 19.0 & 159 & 17.6 & 149 & 15.9 \\
\hline SEER region & & & & & & & & & & \\
\hline Northeast & 805 & 18.7 & 373 & 18.9 & 96 & 19.4 & 171 & 19.0 & 165 & 17.6 \\
\hline South & 1280 & 29.7 & 529 & 26.8 & 137 & 27.6 & 279 & 30.9 & 335 & 35.8 \\
\hline North-central & 658 & 15.3 & 307 & 15.6 & 81 & 16.3 & 115 & 12.7 & 155 & 16.5 \\
\hline $\begin{array}{c}\text { West } \\
\text {...Continued }\end{array}$ & 1564 & 36.3 & 763 & 38.7 & 182 & 36.7 & 337 & 37.4 & 282 & 30.1 \\
\hline
\end{tabular}


Table 1: The Characteristics of the Study Cohort* by Diabetes Complications Severity Index

\begin{tabular}{|c|c|c|c|c|c|c|c|c|c|c|}
\hline \multirow[b]{2}{*}{ Characteristics } & \multicolumn{2}{|c|}{$\begin{array}{c}\text { All Women, } \\
\text { N=4307 }\end{array}$} & \multicolumn{2}{|c|}{$\begin{array}{l}\text { DCSI }=0, \\
N=1972\end{array}$} & \multicolumn{2}{|c|}{$\begin{array}{c}\text { DCSI }=1, \\
N=496\end{array}$} & \multicolumn{2}{|c|}{$\begin{array}{c}\text { DCSI }=2, \\
\mathrm{~N}=902\end{array}$} & \multicolumn{2}{|c|}{$\begin{array}{c}\text { DCSI } \geq 3, \\
\mathrm{~N}=937\end{array}$} \\
\hline & No. & $\%$ & No. & $\%$ & No. & $\%$ & No. & $\%$ & No. & $\%$ \\
\hline Metropolitan st & & & & & & & & & & \\
\hline Metro & 3347 & 77.8 & 1532 & 77.8 & 392 & 79.0 & 685 & 76.0 & 738 & 78.8 \\
\hline Urban & 824 & 19.1 & 379 & 19.2 & 86 & 17.3 & 188 & 20.9 & 171 & 18.2 \\
\hline Rural & 132 & 3.1 & 58 & 2.9 & 18 & 3.6 & 28 & 3.1 & 28 & 3.0 \\
\hline
\end{tabular}

*A cohort of 4,307 elderly women with incident breast cancer and pre-existing diabetes using SEER-Medicare dataset 2007-2011.

DCSI = Diabetes complications severity index; PCP = Primary care providers;

COPD $=$ Chronic Obstructive Pulmonary Disorder; SEER = Surveillance, Epidemiology, and End Results; $\mathrm{BC}=$

Breast cancer. 
Table 2: Description of Elderly Women with Incident Breast Cancer and Preexisting Diabetes by 3-Year All-cause Mortality, SEER-Medicare 2007-2011

\begin{tabular}{|c|c|c|c|c|c|c|}
\hline \multirow[t]{2}{*}{ Variables } & & \multicolumn{2}{|c|}{ Dead } & \multicolumn{2}{|c|}{ Alive } & \multirow[b]{2}{*}{ sig } \\
\hline & & $\mathbf{N}$ & $\%$ & $\mathbf{N}$ & $\%$ & \\
\hline Total & & 939 & 100 & 3368 & 100 & \\
\hline \multirow[t]{5}{*}{ DCSI } & & & & & & **** \\
\hline & DCSI $=0$ & 276 & 29.4 & 1696 & 50.4 & \\
\hline & DCSI $=1$ & 77 & 8.2 & 419 & 12.4 & \\
\hline & $\mathrm{DCSI}=2$ & 233 & 24.8 & 669 & 19.9 & \\
\hline & $\mathrm{DCSI} \geq 3$ & 353 & 37.6 & 584 & 17.3 & \\
\hline \multicolumn{6}{|c|}{ Insulin use in 3 Months after BC Diagnosis } & $* * *$ \\
\hline & Yes & 327 & 34.8 & 694 & 20.6 & \\
\hline & No & 612 & 65.2 & 2674 & 79.4 & \\
\hline \multicolumn{6}{|c|}{ Metformin Use in 3 Months after BC Diagnosis } & $* * *$ \\
\hline & Yes & 212 & 22.6 & 1278 & 37.9 & \\
\hline & No & 727 & 77.4 & 2090 & 62.1 & \\
\hline \multicolumn{7}{|c|}{ Other Diabetes Medication } \\
\hline & 0 & 579 & 61.7 & 1984 & 58.9 & \\
\hline & 1 & 295 & 31.4 & 1108 & 32.9 & \\
\hline & $\geq 2$ & 65 & 6.9 & 276 & 8.2 & \\
\hline \multicolumn{6}{|l|}{ Age group } & $* * *$ \\
\hline & $67-70$ & 129 & 13.7 & 809 & 24.0 & \\
\hline & $71-74$ & 170 & 18.1 & 985 & 29.2 & \\
\hline & $75-79$ & 170 & 18.1 & 648 & 19.2 & \\
\hline & $>=80$ & 470 & 50.1 & 926 & 27.5 & \\
\hline \multicolumn{6}{|l|}{ Race } & $* * *$ \\
\hline & White & 689 & 73.4 & 2491 & 74.0 & \\
\hline & African American & 193 & 20.6 & 531 & 15.8 & \\
\hline & Others & 57 & 6.1 & 346 & 10.3 & \\
\hline \multicolumn{6}{|c|}{ Stage of BC at Diagnosis } & $* * *$ \\
\hline & Early stage & 518 & 64.7 & 2917 & 90.2 & \\
\hline & Advanced stage & 283 & 35.3 & 317 & 9.8 & \\
\hline \multicolumn{6}{|c|}{ Progesterone receptor status } & $* * *$ \\
\hline & Positive & 478 & 50.9 & 2320 & 68.9 & \\
\hline & Negative & 304 & 32.4 & 753 & 22.4 & \\
\hline & Borderline/Unknown & 157 & 16.7 & 295 & 8.8 & \\
\hline \multicolumn{6}{|c|}{ Estrogen receptor status } & $* * *$ \\
\hline & Positive & 588 & 62.6 & 2703 & 80.3 & \\
\hline & Negative & 203 & 21.6 & 408 & 12.1 & \\
\hline & Borderline/Unknown & 148 & 15.8 & 257 & 7.6 & \\
\hline \multicolumn{6}{|c|}{ Had Chemotherapy } & $*$ \\
\hline & Yes & 194 & 20.7 & 582 & 17.3 & \\
\hline & No & 745 & 79.3 & 2786 & 82.7 & \\
\hline \multicolumn{6}{|c|}{ Had Radiation } & $* * *$ \\
\hline & Yes & 181 & 19.3 & 1405 & 41.7 & \\
\hline & No & 758 & 80.7 & 1963 & 58.3 & \\
\hline \multicolumn{6}{|c|}{ Had any Surgery } & $* * *$ \\
\hline & Yes & 620 & 66.0 & 3085 & 91.6 & \\
\hline & No & 319 & 34.0 & 283 & 8.4 & \\
\hline \multicolumn{7}{|c|}{ Thyroid Syndrome } \\
\hline & Yes & 229 & 24.4 & 795 & 23.6 & \\
\hline & No & 710 & 75.6 & 2573 & 76.4 & \\
\hline \multicolumn{7}{|c|}{...Continued } \\
\hline
\end{tabular}


Table 2: Description of Elderly Women with Incident Breast Cancer and Preexisting Diabetes by 3-Year All-cause Mortality, SEER-Medicare 2007-2011

\begin{tabular}{|c|c|c|c|c|c|c|}
\hline \multirow[t]{2}{*}{ Variables } & & \multicolumn{2}{|c|}{ Dead } & \multicolumn{2}{|c|}{ Alive } & \multirow[b]{2}{*}{ sig } \\
\hline & & $\mathbf{N}$ & $\%$ & $\mathbf{N}$ & $\%$ & \\
\hline \multicolumn{7}{|l|}{ Arthritis } \\
\hline & Yes & 262 & 27.9 & 920 & 27.3 & \\
\hline & No & 677 & 72.1 & 2448 & 72.7 & \\
\hline \multirow{3}{*}{ Asthma } & & & & & & $*$ \\
\hline & Yes & 64 & 6.8 & 297 & 8.8 & \\
\hline & No & 875 & 93.2 & 3071 & 91.2 & \\
\hline \multirow[t]{3}{*}{ COPD } & & & & & & $* * *$ \\
\hline & Yes & 229 & 24.4 & 401 & 11.9 & \\
\hline & No & 710 & 75.6 & 2967 & 88.1 & \\
\hline \multirow[t]{3}{*}{ Dementia } & & & & & & $* * *$ \\
\hline & Yes & 173 & 18.4 & 185 & 5.5 & \\
\hline & No & 766 & 81.6 & 3183 & 94.5 & \\
\hline \multicolumn{2}{|c|}{ Hyperlipidemia } & & & & & $* * *$ \\
\hline & Yes & 538 & 57.3 & 2472 & 73.4 & \\
\hline & No & 401 & 42.7 & 896 & 26.6 & \\
\hline \multicolumn{7}{|c|}{ Hypertension } \\
\hline & Yes & 840 & 89.5 & 2936 & 87.2 & \\
\hline & No & 99 & 10.5 & 432 & 12.8 & \\
\hline \multicolumn{7}{|c|}{ Osteoporosis } \\
\hline & Yes & 66 & 7.0 & 271 & 8.0 & \\
\hline \multirow{4}{*}{ Anxiety } & No & 873 & 93.0 & 3097 & 92.0 & \\
\hline & & & & & & $*$ \\
\hline & Yes & 115 & 12.2 & 320 & 9.5 & \\
\hline & No & 824 & 87.8 & 3048 & 90.5 & \\
\hline \multirow[t]{3}{*}{ Depression } & & & & & & $* * *$ \\
\hline & Yes & 205 & 21.8 & 452 & 13.4 & \\
\hline & No & 734 & 78.2 & 2916 & 86.6 & \\
\hline \multicolumn{7}{|l|}{ PCP visit } \\
\hline & Yes & 748 & 79.7 & 2626 & 78.0 & \\
\hline & No & 191 & 20.3 & 742 & 22.0 & \\
\hline \multicolumn{3}{|c|}{ Endocrinologist visit } & & & & * \\
\hline & Yes & 70 & 7.5 & 328 & 9.7 & \\
\hline & No & 869 & 92.5 & 3040 & 90.3 & \\
\hline \multicolumn{3}{|c|}{ Number of Oncologists visits } & & & & $* * *$ \\
\hline & $0-10$ & 253 & 26.9 & 798 & 23.7 & \\
\hline & $11-20$ & 318 & 33.9 & 1387 & 41.2 & \\
\hline & $\geq 20$ & 368 & 39.2 & 1183 & 35.1 & \\
\hline \multicolumn{7}{|c|}{ Availability of Oncology Treatment Centers } \\
\hline & Yes & 632 & 67.3 & 2335 & 69.3 & \\
\hline & No & 307 & 32.7 & 1033 & 30.7 & \\
\hline \multicolumn{7}{|c|}{ Census tract education } \\
\hline & $0-13.29 \%$ & 264 & 28.2 & 915 & 27.2 & \\
\hline & $13.30 \%-22.83 \%$ & 302 & 32.3 & 986 & 29.3 & \\
\hline & $22.84 \%-38.55 \%$ & 203 & 21.7 & 766 & 22.8 & \\
\hline & $>38.55 \%$ & 167 & 17.8 & 693 & 20.6 & \\
\hline ...Continue & & & & & & \\
\hline
\end{tabular}


Table 2: Description of Elderly Women with Incident Breast Cancer and Preexisting Diabetes by 3-Year All-cause Mortality, SEER-Medicare 2007-2011

\begin{tabular}{|c|c|c|c|c|c|}
\hline \multirow[t]{2}{*}{ Variables } & \multicolumn{2}{|c|}{ Dead } & \multicolumn{2}{|c|}{ Alive } & \multirow[b]{2}{*}{ sig } \\
\hline & $\mathbf{N}$ & $\%$ & $\mathbf{N}$ & $\%$ & \\
\hline \multicolumn{6}{|l|}{ Census tract household income } \\
\hline$<\$ 25,000$ & 65 & 6.9 & 240 & 7.1 & \\
\hline$\$ 25,001-50,000$ & 441 & 47.0 & 1441 & 42.8 & \\
\hline$\$ 50,001-75,000$ & 278 & 29.6 & 1060 & 31.5 & \\
\hline$>\$ 75,000$ & 155 & 16.5 & 627 & 18.6 & \\
\hline SEER region & & & & & $* *$ \\
\hline Northeast & 165 & 17.6 & 640 & 19.0 & \\
\hline South & 322 & 34.3 & 958 & 28.4 & \\
\hline North-central & 149 & 15.9 & 509 & 15.1 & \\
\hline West & 303 & 32.3 & 1261 & 37.4 & \\
\hline \multicolumn{6}{|l|}{ Metropolitan status } \\
\hline Metro & 725 & 77.3 & 2622 & 77.9 & \\
\hline Urban & 183 & 19.5 & 641 & 19.0 & \\
\hline Rural & 30 & 3.2 & 102 & 3.0 & \\
\hline
\end{tabular}

DCSI $=$ Diabetes complications severity index $; \mathrm{PCP}=$ Primary care providers; $\mathrm{COPD}=$ Chronic Obstructive Pulmonary Disorder; SEER $=$ Surveillance, Epidemiology, and End Results; $\mathrm{BC}=$ Breast cancer; $\mathrm{DM}=$ Diabetes mellitus.

Asterisks represent statistically significant group differences based on $\chi 2$ tests by stage of $\mathrm{BC}$ at diagnosis:

$* * * \mathrm{p}<0.001 ; * * 0.001<\mathrm{p}<0.01 ; * 0.01<\mathrm{p} \leq 0.05$ 
Table 3: Association of Diabetes Complication Severity Index with Hazard of 3 Years All-cause Mortality After Breast Cancer Diagnosis among Elderly women with pre-existing Diabetes Mellitus

\begin{tabular}{|c|c|c|c|c|c|c|c|c|c|}
\hline & \multicolumn{3}{|c|}{ Model 1} & \multicolumn{3}{|c|}{ Model 2a } & \multicolumn{3}{|c|}{ Model 3 $^{\text {b }}$} \\
\hline Variables & HR & $95 \% \mathrm{CI}$ & Sig. & HR & $95 \% \mathrm{CI}$ & Sig. & HR & $95 \% \mathrm{CI}$ & Sig. \\
\hline \multicolumn{10}{|l|}{ DCSI } \\
\hline DCSI $=0$ & 1.00 & - & & 1.00 & - & & 1.00 & - & \\
\hline DCSI $=1$ & 1.21 & {$[0.92,1.58]$} & & 1.33 & {$[1.01,1.74]$} & $*$ & 1.34 & {$[1.02,1.75]$} & * \\
\hline DCSI $=2$ & 2.06 & {$[1.70,2.48]$} & **** & 1.67 & {$[1.38,2.03]$} & $* * *$ & 1.69 & {$[1.39,2.05]$} & $* * *$ \\
\hline $\mathrm{DCSI} \geq 3$ & 3.30 & {$[2.78,3.92]$} & $* * *$ & 2.27 & {$[1.89,2.73]$} & $* * *$ & 2.24 & {$[1.86,2.70]$} & $* * *$ \\
\hline \multicolumn{10}{|c|}{ Diabetes Medications Use in 3 Months after BC Diagnosis } \\
\hline Metformin & - & - & - & 0.75 & {$[0.63,0.89]$} & $* * *$ & 0.74 & {$[0.63,0.88]$} & $* * *$ \\
\hline Insulin & - & - & - & 1.55 & {$[1.33,1.80]$} & $* * *$ & 1.58 & {$[1.35,1.84]$} & $* * *$ \\
\hline \multicolumn{10}{|l|}{ Cancer Therapy } \\
\hline Had Chemotherapy & - & - & - & 0.98 & {$[0.80,1.18]$} & & 0.85 & {$[0.69,1.05]$} & \\
\hline Had Radiation & - & - & - & 0.69 & {$[0.58,0.83]$} & $* * *$ & 0.63 & {$[0.52,0.76]$} & $* * *$ \\
\hline Had any Surgery & - & - & - & 0.45 & {$[0.38,0.53]$} & $* * *$ & 0.45 & {$[0.38,0.53]$} & $* * *$ \\
\hline \multicolumn{10}{|c|}{ Progesterone receptor status } \\
\hline Positive & - & - & - & 0.75 & {$[0.61,0.92]$} & ** & 0.74 & {$[0.60,0.92]$} & ** \\
\hline Negative & - & - & - & 1.00 & - & & 1.00 & - & \\
\hline Borderline/Unknown & - & - & - & 0.46 & {$[0.20,1.04]$} & & 0.45 & {$[0.20,1.02]$} & \\
\hline \multicolumn{10}{|l|}{ Estrogen receptor status } \\
\hline Positive & - & - & - & 0.62 & {$[0.49,0.79]$} & $* * *$ & 0.62 & {$[0.49,0.79]$} & $* * *$ \\
\hline Negative & - & - & - & 1.00 & - & & 1.00 & - & \\
\hline Borderline/Unknown & - & - & - & 1.72 & {$[0.73,4.03]$} & & 1.74 & {$[0.74,4.11]$} & \\
\hline \multicolumn{10}{|l|}{ Number of Oncologists visits } \\
\hline $0-10$ & - & - & - & - & - & - & 1.00 & - & \\
\hline $11-20$ & - & - & - & - & - & - & 0.98 & {$[0.81,1.19]$} & \\
\hline$\geq 20$ & - & - & - & - & - & - & 1.39 & {$[1.12,1.72]$} & ** \\
\hline \multicolumn{10}{|l|}{ Had Endocrinologist Visit } \\
\hline Yes & - & - & - & - & - & - & 0.74 & {$[0.56,0.98]$} & * \\
\hline No & - & - & - & - & - & - & 1.00 & - & \\
\hline
\end{tabular}

$\mathrm{HR}=$ hazard ratio; $\mathrm{CI}=$ Confidence interval; DCSI $=$ Diabetes complications severity index; $\mathrm{BC}=$ Breast cancer.

a Adjusted for stage of BC at diagnosis, race, age, and comorbid conditions (asthma, COPD, dementia, hyperlipidemia, anxiety, and depression).

b Adjusted for stage of BC at diagnosis, race, age, comorbid conditions (asthma, COPD, dementia, hyperlipidemia, anxiety, and depression), and SEER region.

Asterisks represent statistically significant group differences compared with the reference group:

$* * * \mathrm{p}<0.001 ; * * 0.001<\mathrm{p}<0.01 ; * 0.01<\mathrm{p}<0.05$ 
CHAPTER FIVE 


\section{DISCUSSION}

\section{Overview}

The current study was conducted to assess the relationship of severity of pre-existing diabetes complications with persistence with breast cancer (BC) screening, stage of $\mathrm{BC}$ at diagnosis, and all-cause mortality of incident BC in elderly women with pre-existing diabetes (Figure1). To accomplish the overall goal of this study, we pursued three main aims.

The first aim was to examine the association between the severity of diabetes complications and persistence with BC screening among elderly women with diabetes, comparing them to women with no diabetes complications. We also assessed the association of possible covariates with persistence with BC screening. Theses covariates include predisposing factors, enabling factors, need factors, health behaviors and external environmental factors.

The second aim was to explore how the severity of diabetes complications influences the association between diabetes and stage of $\mathrm{BC}$ at diagnosis in incident $\mathrm{BC}$ cases with pre-existing diabetes. We also investigated the group differences in stage of $\mathrm{BC}$ at diagnosis by the cohort characteristics that included mammography screening, biological factors (age, race, hormone receptors (HR) status, and comorbid conditions), and non-biological factors (access to health care and community related factors).

In the third aim, we evaluated the relationship between severity of pre-existing diabetes complications and all-cause mortality within three years of $\mathrm{BC}$ diagnosis among elderly women with pre-existing diabetes. In addition, we explored the association of other independent variables: cancer characteristics, patient-related factors, cancer treatment, and diabetes medications with all-cause mortality among incident BC cases with pre-existing diabetes. 
In the first aim, we used the 5\% random sample of linked Surveillance, Epidemiology, and End Results (SEER)-Medicare data to include elderly women with diabetes who were free of cancer during years 2002 to 2008 . This data has been used to assess rates of cancer screening and to address factors associated with lower rates of cancer screening among Medicare populations who are free of cancer (Kagay, Quale, \& Smith-Bindman, 2006; McBean \& Yu, 2007; White et al., 2011). In the second and third aim, we used SEER-Medicare of breast cancer cases data which is a large national-based data of cancer-related information along with availability of medical claims data. The use of the SEER-Medicare data in the second aim enabled us to identify incident $\mathrm{BC}$ cases and assessing all possible risk factors and pre-existing conditions. In the third aim, using SEER-Medicare enabled us to assess the impact of pre-existing conditions on BC outcomes. Also, we linked the data to area health resources file (AHRF) and US census tract information to control for county level variables, such as the availability of oncology centers or the density of mammography facilities in areas of women residence. This cancer registry data that was linked with medical claims in a large population-based database, and linked to county level information enabled us to control for a comprehensive list of possible covariates. This allowed for the assessment of the independent role of the severity of pre-existing diabetes complications on BC screening, stage of BC at diagnosis, and all-cause mortality of incident BC.

This is also the first study to investigate the independent role of the severity of preexisting diabetes complications on $\mathrm{BC}$ spectrum of care: prevention, diagnosis, and prognosis.

\section{The Main Findings}

The severity of diabetes-related complications was significantly associated with persistence with $\mathrm{BC}$ screening, stage of $\mathrm{BC}$ at diagnosis, and all-cause mortality within 3 years of $\mathrm{BC}$ diagnosis. 
Both the persistence with BC screening among elderly women with diabetes and the risk of death after BC diagnosis in elderly women with pre-existing diabetes were significantly associated with diabetes complication severity index (DCSI) after controlling for all possible covariates. Based on our results from aim 1 and aim3, we found that there is an independent role of diabetes complications severity on lower persistence with BC screening and higher risk of mortality within 3 years of BC diagnosis among elderly women with pre-existing diabetes. Also, having any diabetes complication could predict lower persistence with BC screening and higher risk of death within 3 years after $\mathrm{BC}$, and this impact is increasing as the severity of diabetes complications increases.

In aim 2, the impact of diabetes complication severity on stage of $\mathrm{BC}$ at diagnosis was mostly mediated by BC screening, except the association between having a DCSI =2 and stage I of $\mathrm{BC}$ at diagnosis. Since women with more severe diabetes complications are less likely to have BC screening, they are more likely to be diagnosed at an advanced-stage of BC as compared to those without diabetes complications.

\section{Characteristics of the Cohorts}

For the cohorts' size, the first study included 16,726 of elderly women with diabetes, the second study had 7,729 elderly women with incident BC and pre-existing diabetes, and the last study had 4,307 elderly women with incident BC and pre-existing diabetes. In all cohorts, the majority were white, lived in metro areas, had been diagnosed with early stages ( 0 , I, or II) of BC at diagnosis, and had positive hormone receptor (HR) status. For other comorbid conditions, most all cohorts had hypertension, hyperlipidemia, and thyroid syndrome. From $38.4 \%$ to $45.8 \%$ of the cohorts had no diabetes complications. For visits to physicians, the majority of all cohorts 
had primary care providers (PCP) visits, and a small proportion of women had endocrinologist visits.

\section{Other Predictors of Persistence with BC screening, Stage of BC at diagnosis, and Risk of Mortality}

The common variables that were significantly associated with persistence with BC screening, stage of $\mathrm{BC}$ at diagnosis, and all-cause mortality were age groups, race, having a preexisting chronic obstructive pulmonary disorder (COPD), dementia, and hyperlipidemia. Women who had pre-existing COPD and dementia were less likely to be persistent in BC screening, more likely to be diagnosed an advanced stage of BC, and more likely to die within three years of BC diagnosis. Women who had pre-existing hyperlipidemia were more likely to be persistent in BC screening, less likely to be diagnosed in advanced stages of $\mathrm{BC}$, and less likely to die three years of BC diagnosis.

For other factors, having annual PCP visits was associated with significant increase in persistence with BC screening, and decrease in the likelihood of being diagnosed at advanced stages of BC among women with pre-existing diabetes. Also, women who had thyroid syndrome were more likely to be persistent with BC screening and less likely to be diagnosed at advanced stages of $\mathrm{BC}$ while women who had arthritis were less likely to be persistent with $\mathrm{BC}$ screening and more likely to be diagnosed with advanced stages of BC among women with pre-existing diabetes. Women with positive progesterone HR status were less likely to be diagnosed at advanced stages of $\mathrm{BC}$ diagnosis and less likely to die within three years of BC diagnosis.

\section{Limitations}


The study should be interpreted in the light of several limitations. For the database, although the SEER-Medicare data provide a population-based database of elderly population, this data lacked information related to mammogram screening covered by Medicare but not billed to Medicare. Also, this data is limited to Medicare enrollees who live in SEER areas, and SEER areas tend to have higher income, and have lower percentages of whites as compared to the U.S. population (Warren et al., 2002). Also, SEER-Medicare data lacked information, such as physical activity and diet which significantly impact diabetes control and cancer outcomes.

Furthermore, in cases where women are non-users or non-persistent in receiving screening mammogram during the 60 months, we could not determine whether the patient had refused to obtain the recommended screening or the primary care physicians had not referred the patient.

Also, although we controlled for many potential factors that are associated with BC stage at diagnosis and all-cause mortality after incident BC, data was lacking on some biological factors, such as obesity, family history of BC, blood glucose level, glycosylated hemoglobin A1c lab results, and diabetes duration which could have had residual confounding effect on the study outcomes. Also, exclusions of incident BC cases with missing stage of BC and others with no continuous enrollment in parts $\mathrm{A}, \mathrm{B}, \& \mathrm{D}$ or enrollment in an HMO at any time during the study period may have affected the generalizability of our findings.

\section{Strengths}

This was the first study, to the best of the authors' knowledge, that investigated the relationship of diabetes complications severity with persistence with BC screening, stage of BC at diagnosis, and all-cause mortality among elderly women with pre-existing diabetes. To assess 
the severity of diabetes-related complications, we used DCSI which captures both the type and severity of complications while a simple count of complications does not take into account the severity of each complication. (Young et al., 2008). DCSI is a valid and reliable index to measure diabetes severity which enabled us to capture the severity of the disease and its-related complications, assessing its impact on study outcomes. In addition to its use as measure of diabetes severity, a study by Young et al. found that this index may be considered as a proxy measure for diabetes duration (Young et al., 2008). Young et al. found that the DCSI was highly correlated diabetes duration, and it attenuated the significant impact of diabetes duration on mortality after it was added to the analysis model (Young et al., 2008). Because diabetes may remained undiagnosed for years, using DCSI as a severity measure of long- term complications probably demonstrate the consequences of biologic markers of diabetes duration (Harris \& Eastman, 2000). Moreover, in aim1, women who had any diagnostic code of any type of cancer were excluded to increase the probability that the identified screening mammograms were indeed for screening. In aim 2 and aim3, the (SEER-Medicare) database enabled us to identify incident breast cancer cases and assess all possible risk factors and pre-existing conditions. In addition to assessing diabetes severity, the study accounted for a comprehensive list of biological factors (e.g. comorbid conditions and hormone receptor status) and non-biological factors (e.g. access to health care, and community-related factors) that may impact the associations of interest. Another major strength of this study is the large size of the study cohorts, and this increased the statistical power of the reported results.

\section{Conclusion \& Future Research}

In short, this study suggests that severity of diabetes complications has a direct association with BC screening, and all cause-mortality of incident BC and has an indirect 
association with stage of BC at diagnosis in elderly women with pre-existing diabetes (figure 2). The results suggest that as severity of diabetes increases, the priority of breast cancer screening decreases. Also, our results revealed that severity of diabetes-related complications is strongly associated with death even after controlling for diabetes medications, cancer treatment, biological characteristics of cancer, and other patient-related factors among incident BC cases. Management of theses complications among women with $\mathrm{BC}$ requires more than the treatment of $\mathrm{BC}$ and controlling blood glucose since these complications include many types of end-organ damage.

Therefore, new strategies of coordination and comprehensive care from a wide variety of providers (e.g. endocrinologists, oncologists, and general practitioners) are needed for elderly women with incident BC and pre-existing diabetes complications who have complex health needs.

Future research should test this association in other types of cancer. More studies are needed to assess whether improvement in management of diabetes complications leads to improvement in health outcome of cancer patients with pre-existing diabetes. 


\section{REFERENCES}

Harris, M. I., \& Eastman, R. C. (2000). Early detection of undiagnosed diabetes mellitus: a US perspective. Diabetes Metab Res Rev, 16(4), 230-236.

Kagay, C. R., Quale, C., \& Smith-Bindman, R. (2006). Screening mammography in the American elderly. Am J Prev Med, 31(2), 142-149. doi:10.1016/j.amepre.2006.03.029

McBean, A. M., \& Yu, X. (2007). The underuse of screening services among elderly women with diabetes. Diabetes Care, 30(6), 1466-1472. doi:10.2337/dc06-2233

McCarthy, E. P., Burns, R. B., Freund, K. M., Ash, A. S., Shwartz, M., Marwill, S. L., \& Moskowitz, M. A. (2000). Mammography use, breast cancer stage at diagnosis, and survival among older women. J Am Geriatr Soc, 48(10), 1226-1233.

Warren, J. L., Klabunde, C. N., Schrag, D., Bach, P. B., \& Riley, G. F. (2002). Overview of the SEER-Medicare data: content, research applications, and generalizability to the United States elderly population. Med Care, 40(8 Suppl), Iv-3-18.

doi:10.1097/01.mlr.0000020942.47004.03

White, A., Vernon, S. W., Franzini, L., \& Du, X. L. (2011). Racial and ethnic disparities in colorectal cancer screening persisted despite expansion of Medicare's screening reimbursement. Cancer Epidemiol Biomarkers Prev, 20(5), 811-817. doi:10.1158/10559965.epi-09-0963

Young, B. A., Lin, E., Von Korff, M., Simon, G., Ciechanowski, P., Ludman, E. J., ... Katon, W. J. (2008). Diabetes complications severity index and risk of mortality, hospitalization, and healthcare utilization. Am J Manag Care, 14(1), 15-23. 


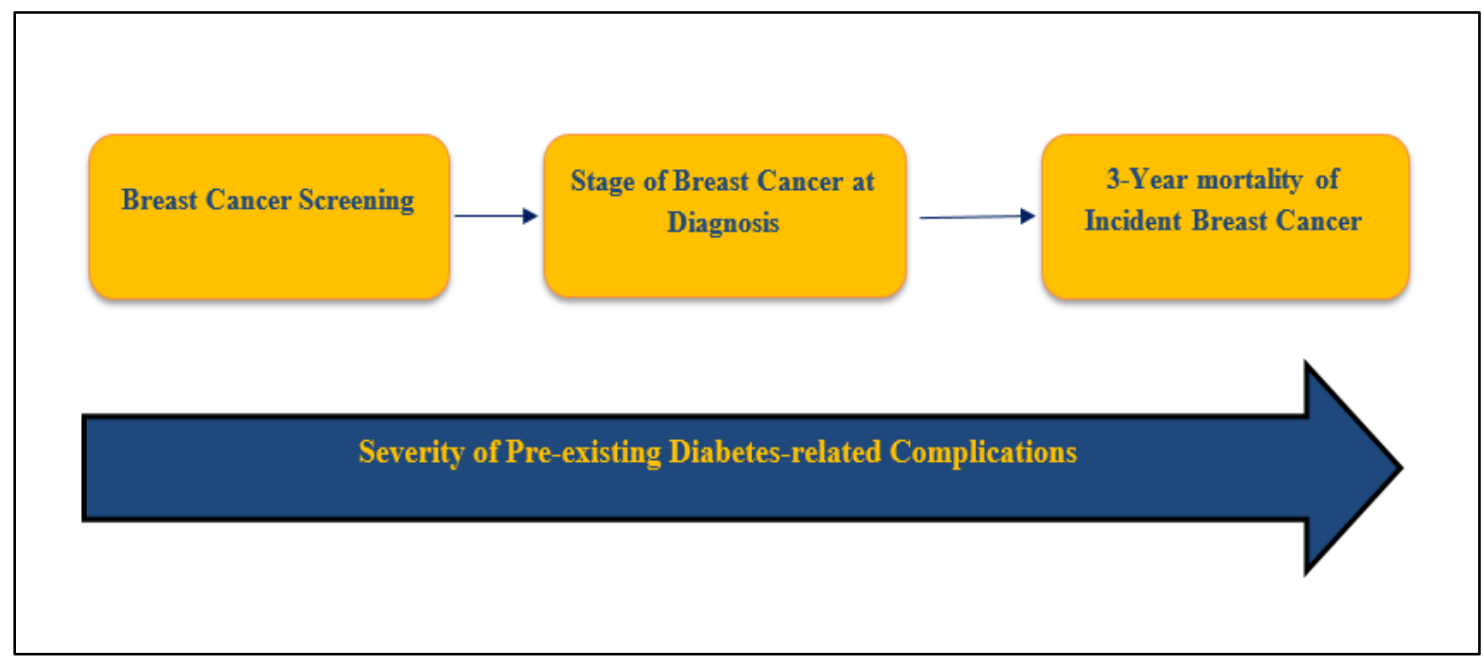

Figure 1: the impact of severity of pre-existing diabetes complications on breast cancer spectrum of care

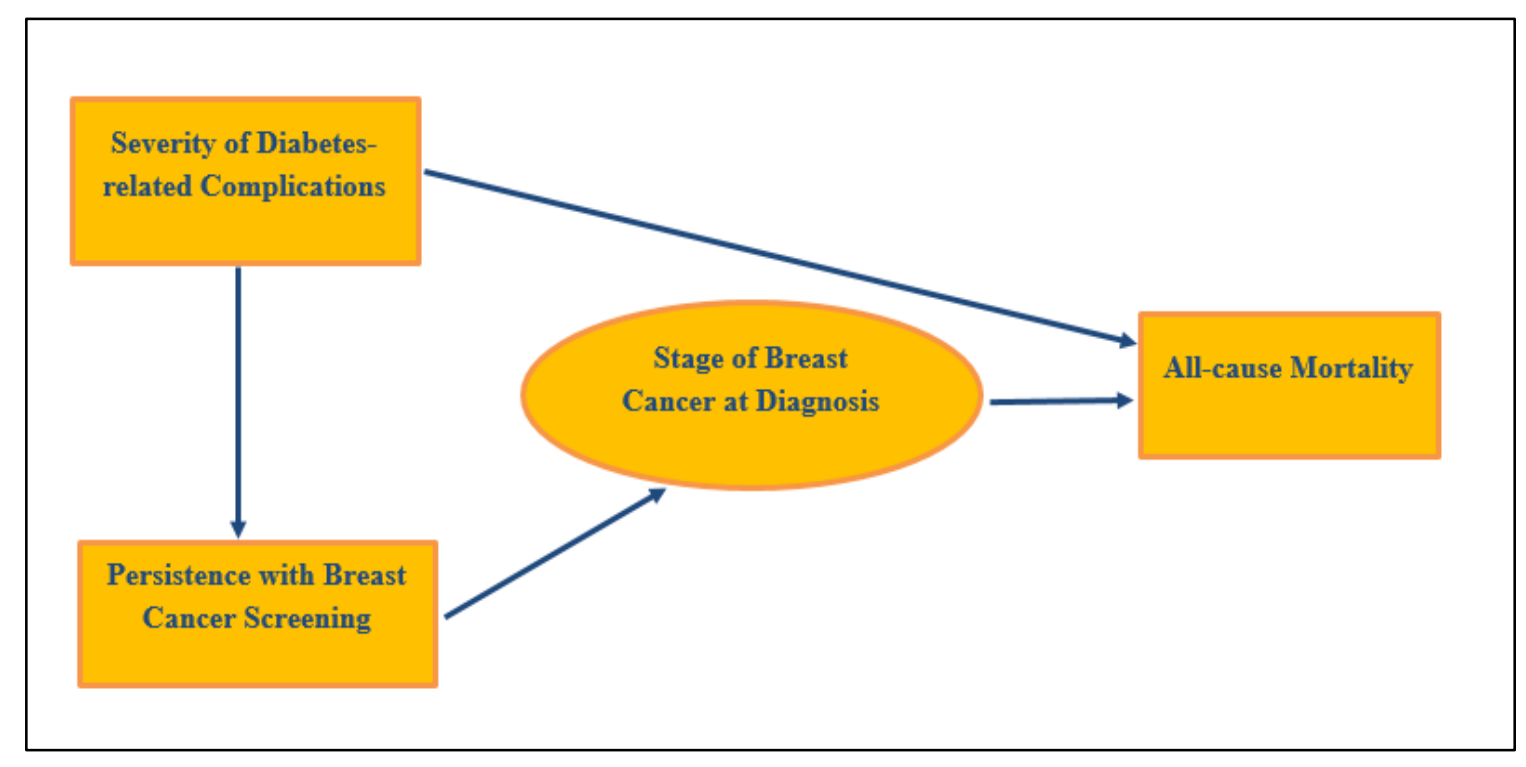

Figure 2: The main suggested associations from the study results 